NBSIR $80-2141$

\title{
Estimated Accuracy of Calibration of Some Membrane-Type LNG Transport Tanks
}

'N. C. Haight, R. J. Hocken, B. R. Borchardt, C. L. Carroll,

R. G. Hartscck, C. P. Reeve, F. E. Scire and R C. Vea!e

Automated Froduction? Technology Division

National Engineering Laboratory

U.S. Department of Commerce

Miationa! Bureau of Standards

Washington, $\mathrm{CC} \quad 2 \mathrm{C} 234$

\section{Febriary 1980}

issued January 1981
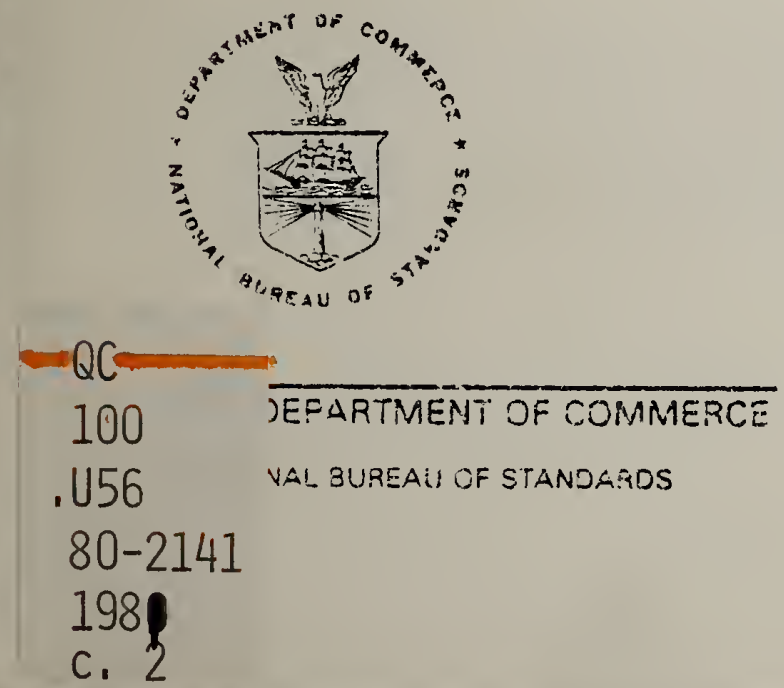

NBSIR $80-2141$

..'

ESTIMATED ACCURACY OF CALIBRATION OF SOME MEMBRANE-TYPE LNG TRANSPORT TANKS

W. C. Haight, R. J. Hocken, B. R. Borchardt, C. L. Carroll,

R. G. Hartsock, C. P. Reeve, F. E. Scire and R. C. Veale

Automated Production Technology Division

National Engineering Laboratory

U.S. Department of Commerce

National Bureau of Standards

Washington, DC 20234

November 1980

Issued January 1981

U.S. DEPARTMENT OF COMMERCE, Philip M. Klutznick, Secretary Jordan J. Baruch, Assistant Secretary for Productivity, Technology, and Innovation NATIONAL BUREAU OF STANDARDS, Ernest Ambler, Director 

Estimated Accuracy of Calibration of

Some Membrane-Type LNG Transport Tanks

W. C. Haight, R. J. Hocken, B. R. Borchardt, C. L. Carroll,

R. G. Hartsock, C. P. Reeve, F. E. Scire and R. C. Veale

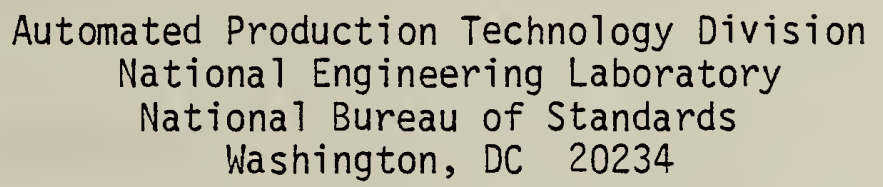

Automated Production Technology Division

National Engineering Laboratory

National Bureau of Standards

Washington, DC 20234

February 1980

These reports prepared for:

The LNG Custody Transfer Measurements Committee

and

The Maritime Administration of the Department of Commerce 



\section{Table of Contents}

Section

Title

Page

I.

Introduction

1

II.

The Tanks

1

II .

Tank Calibration Methods

1

IV.

Results

References

Appendices: Tank Calibration Reports

A. Calibration Reports for the Six Tanks of the EI Paso Southern

B. Calibration Reports for the Six Tanks of the El Paso Arzew

C. Calibration Reports for the Six Tanks

C-1 of the El Paso Howard Boyd 



\section{Estimated Accuracy of Calibration of \\ Some Membrane-Type LNG Transport Tanks}

W. C. Haight, R. J. Hocken, B. R. Borchardt, C. L. Carroll,

R. G. Hartsock, C. P. Reeve, F. E. Scire and R. C. Veale

\section{Introduction}

The National Bureau of Standards supported by the Department of Commerce Maritime Administration did some preliminary studies to establish an upper limit for the tank volume uncertainty of a spherical transport tank calibrated by photogrammetry [1]. Additional support from the Maritime Administration and the LNG Ship Custody Transfer Committee [2], has made possible a considerably expanded study of the calibration uncertainties of LNG transport tanks. The tank calibrations examined in this work are those of the three LNG Transports built by Newport News Shipbuilding and Drydock Company for El Paso Marine Company.

\section{The Tanks}

The cargo tanks on these $125000 \mathrm{~m}^{3}$ (approximate) capacity ships are membrane types of the Technigaz design described in reference [3]. The tanks are ten-sided prismatic solids and rectangular in horizontal cross section. The walls are all plane surfaces. The end walls are vertical as are the side walls. The side walls are connected to the horizontal floor and ceiling by sloping chine planes. All eight of the longitudinal planes are parallel to the longitudinal axis of the ship. The supporting walls of the tanks are the inner hull of the ship. Layers of insulation are attached to these walls and the internal surfaces of the insulation are covered with a liquidtight $1.2 \mathrm{~mm}$ stainless steel membrane. This membrane has corrugations stamped into it forming a waffle pattern.

\section{Tank Calibration Methods}

The measurements used to calculate the tank volume were generally made after the membrane installation was complete but before the removal of the construction scaffolding since it is needed to provide access to the tank surface. Briefly, the calibration method used by the calibration contractor consisted of measuring horizontal cross sectional areas of the tank at intervals from the bottom to the top of the tank. The products of these areas and the separation from the area immediately below summed to the level gives the volume to that level. This method is discussed in reference [4]. The cross sectional areas of these tanks were determined by measuring short distances to the wall from the sides of a horizontal rectangle of known dimensions defined by laser beams.

A calibration method developed at NBS and reported in reference [5] was used by NBS to assess the accuracy of the method used by the calibration contractor. The method used by NBS consists, in brief, of inscribing with laser planes a slightly smaller closed volume with the same shape as the tank. The dimensions of this laser-plane-defined volume are accurately measured. Perpendicular distances from the laser planes to the tank walls are measured at several hundred specified points distributed around the tank. The integration method used to determine volume as a function of height is also outlined in reference [5]. 


\section{Results}

The calibration reports for each of the six tanks of the three ships, the El Paso Southern, the El Paso Arzew and the El Paso Howard Boyd, appear in Appendix I, II, and III respectively. Each individual tank report supplies the following information:

a. A calibration report or a report of test describing the measurement technique, measurement conditions, and error estimate.

b. A summary main gaging table showing tank volume as a function of gage height.

c. Summary list and trim correction tables to supplement the main table under expected conditions of ship list and trim.

d. A plot comparing the NBS main gaging tables at selected intervals to the gage books for each tank provided by the calibration contractor.

The staging was removed in four of the tanks before the NBS measurements were made; hence the calibration check was done only to the height accessible from the bottom of the tank.

The calibration accuracy required by the ship owner is $+0.2 \%$ of total tank volume. The NBS results range in accuracy from $+0.05 \%$ to $+0.1 \%$ as indicated in the Reports of Calibration. In every case, the calibration contractor's results are well within $+0.2 \%$ of the NBS results. It therefore appears that the accuracy requirement has been achieved for the tanks at ambient temperature. The tank volume tables at ambient temperature are used by the transporter to determine LNG volume at operating temperature because the tank dimensions have been assumed independent of cargo temperature. This assumption is based on the fact that the shape of the tank is determined by the external tank wall which is the inner hull of the ship. The membrane wall is supported by this wall via the insulation. The corregated design of the membrane allows the membrane to shrink on cooling without altering the internal volume.

In actual operation, the external tank wall might be as cold as $0^{\circ} \mathrm{C}$ depending on weather conditions. The temperature of the interior of the tanks was as high as $30^{\circ} \mathrm{C}$ during calibration of the tanks. Provided the external tank wall reached temperatures that high, the difference between the calibration and operating temperature could be as large as $30^{\circ} \mathrm{C}$.

The thermal expansion coefficient of iron as well as iron containing smal1 quantities of nickel [6] is approximately $11.6 \times 10^{-6} \mathrm{~m} / \mathrm{m}^{\circ} \mathrm{C}$. This contraction only affects the length and width of the tank with regard to calibration since the liquid height is determined by the level gage rather than the tank height. Thus the tank volume change between the calibration and operating temperature could be as much as

$$
\begin{gathered}
\Delta V / V=-(2 \times 30 \times 11.6) / 100 \\
=-0.07 \%
\end{gathered}
$$


The shrinkage of the balsa wood insulation upon cooling (since the balsa is not a rigid body) as well as any bulging of the tank sides counteract the reduction in volume due to cooling the walls. The balsa shrinkage contributes a negligible change in tank volume. If this is also true with respect to tank wa 71 bulging due to hydrostatic head, then the maximum systematic error introduced into the tank calibrations due to cooling is estimated to be no more than $-0.07 \%$.

\section{References}

[1] Jackson, R.H.F. et a1. 1979. Custody Transfer Systems for LNG Ships: Tank Survey Techniques and Sounding Tables. NBSIR 79-1751.

[2] The members of the committee are: Ivan W. Schmitt, Chairman, El Paso Marine Company; Bland Osborn, Columbia LNG Corporation; Howard S. Joiner, Consolidated Systems LNG Company; and Ed Crenshaw, Southern Energy Company.

[3] Jackson, R. G. and Kotcharian M., 1968, Testing and Technology of Models of Integrated Tanks for LNG carriers, Paper No. 35, Session 6, First International Conference on LNG, Chicago, Apri1.

[4] Jelffs, P.A., 1972. "Calibration of Containers and Gages" J. Inst. Pet. Vol. 58, p. 117 .

[5] Hocken, R. J. and Haight, W. C., 1978. "MuTtiple Redundancy in the Measurement of Large Structures" Annals of the International Institution of Production Engineering Research (CIRP), Volume 27, p. 1.

[6] LNG Materials and Fluids User's Manual, 1977. D. B. Mann, Editor, National Bureau of Standards, Boulder, CO. 



\section{Appendix A}

Calibration Reports for the Six Tanks of the El Paso Southern 


\section{U.S. DEPARTMENT OF COMMERCE

\section{REPORT OF CALIBRATION}

For: Tank 非 1 on the LNG Tanker

El Paso Southern

Requested by: E1 Paso Marine Company

2919 Allen Parkway

P. 0. Box 1592

Houston, TX 77001

The following tables have been calculated from dimensional measurements on tank number 1 of the liquefied natural gas tanker El Paso Southern while berthed at Newport News Shipbuilding and Drydock Company, Newport News, VA. These tables represent the volume of a liquid enclosed in the tank as a function of the height of the liquid surface, measured along a straight line, fixed with respect to the tank. This line is defined as being located at the longitudinal center line of the tank's capacitance gage. Secondary tables are also presented which allow correction of the main tables for specific angles of ship orientation with respect to gravity, as referred to the six sets of draft marks on the ship's hull. Both the measurement method and the computational algorithms are outlined in the paper "Multiple Redundancy in the Measurement of Large Structures," Annals of the International Institution of Production Engineering Research (CIRP), Volume 27/1, 1978.

The tank was measured empty while at an average temperature of $9.0^{\circ} \mathrm{C}$. The tabulated volumes and the error estimates apply to the tank under these conditions. The volumes have also been corrected for the volume occupied by the corregations (deadwood) which was measured in the laboratory using a hydrostatic displacement technique.

The measurement method used includes geometrically redundant cross checks which allow assessment of the random error in the measurement process; For this tank, the total volume, excluding the vapor domes, was $12566.0 \mathrm{~m}^{3}$ with an uncertainty of $1.3 \mathrm{~m}^{3}(0.01 \%$ of total volume) at the three standard deviation limit of random error. Including an analysis of probable systematics by adding the absolute magnitude of the error sources, we estimate that the total uncertainty, at the $99 \%$ confidence level, is $\pm 0.05 \%$ of the total volume. No estimates of the errors in the individual table entries are included, since without an estimate of the height error introduced by the liquid level gage such estimates would of necessity be incomplete.

For the Director,

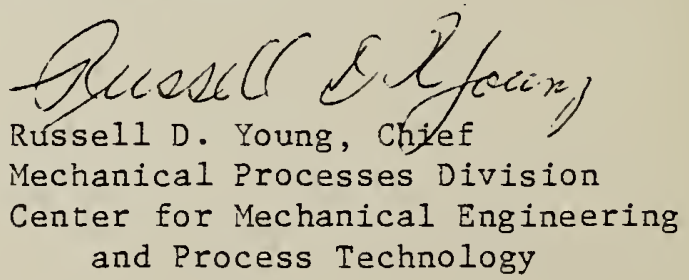

Date: August 17, 1979 
EL PASO SOUTHERN

MAIN VOLUME VS. HEIGHT TABLE

TANK NO. 1

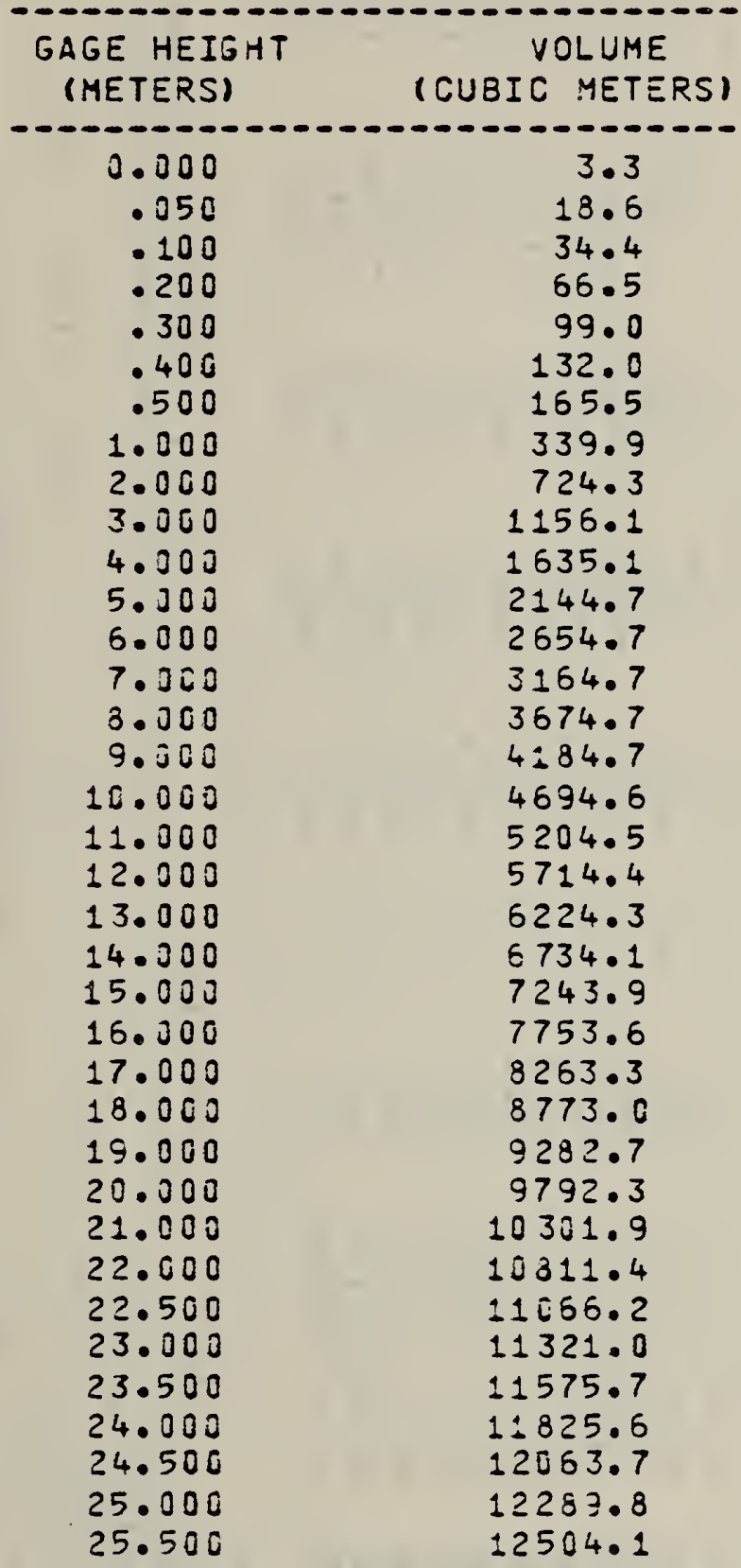




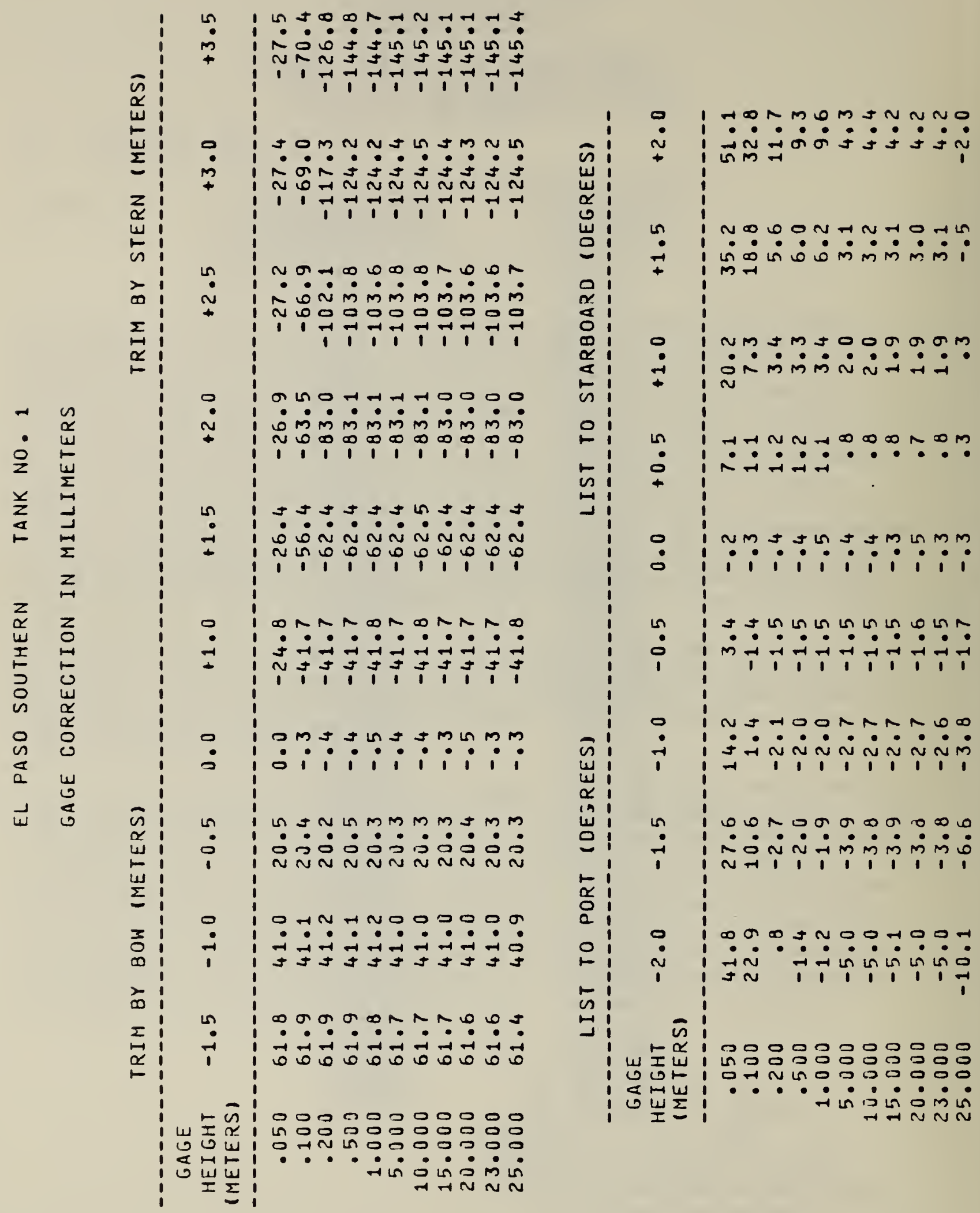




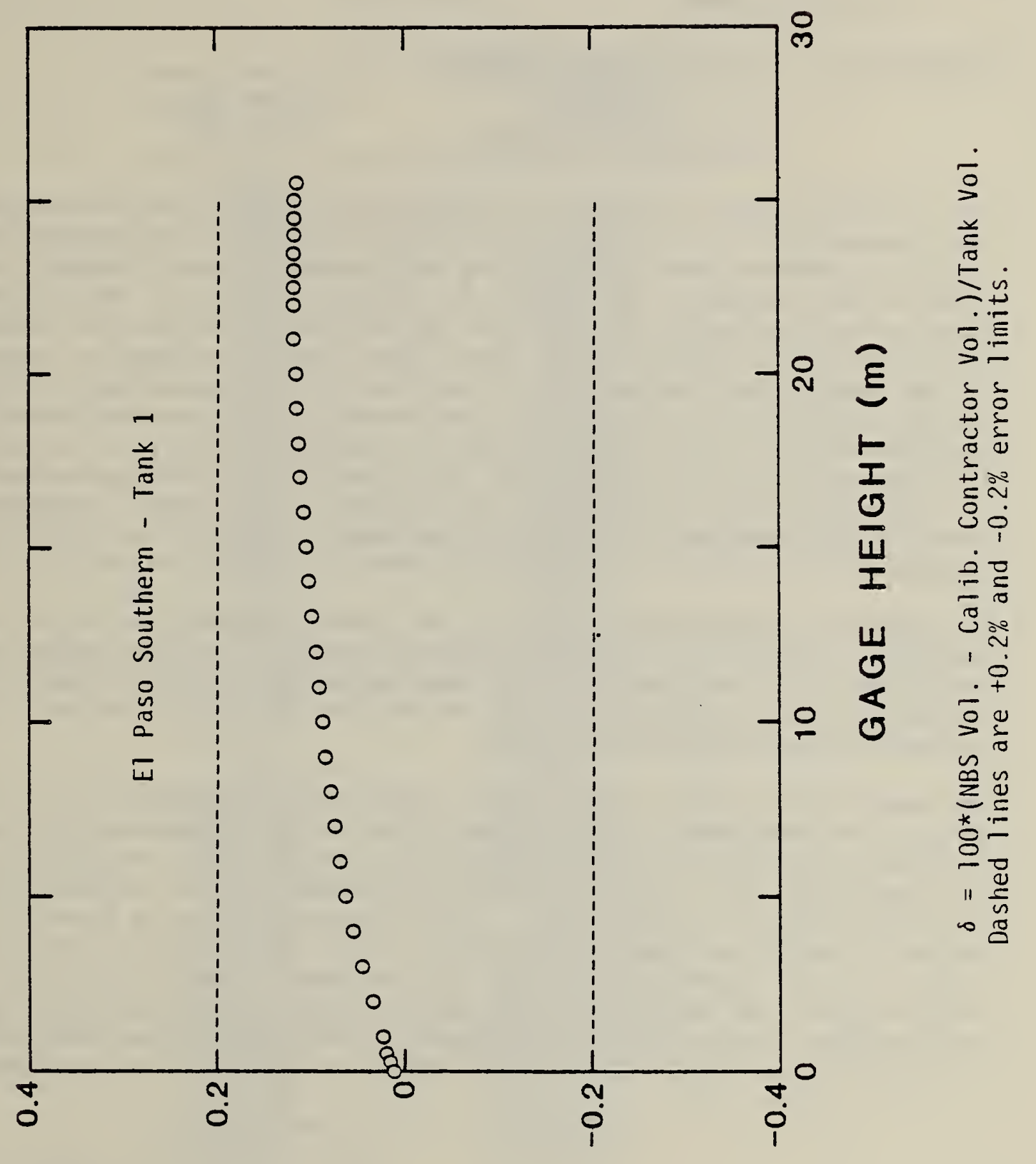

(\%) S $N O I \perp \forall I \wedge \exists O$ 


\section{REPORT OF CALIBRATION}

For: Tank 非 2 on the LNG Tanker

El Paso Southern

Requested by: E1 Paso Marine Company

2919 Allen Parkway

P. 0. Box 1592

Houston, TX 77001

The following tables have been calculated from dimensional measurements on tank number 2 of the liquefied natural gas tanker El Paso Southern while berthed at Newport News Shipbuilding and Drydock Company, Newport News, VA. These tables represent the volume of a liquid enclosed in the tank as a function of the height of the liquid surface, measured along a straight line, fixed with respect to the tank. This line is defined as being located at the longitudinal center line of the tank's capacitance gage. Secondary tables are also presented which allow correction of the main tables for specific angles of ship orientation with respect to gravity, as referred to the six sets of draft marks on the ship's hull. Both the measurement method and the computational algorithms are outlined in the paper "Multiple Redundancy in the Measurement of Large Structures," Annals of the International Institution of Production Engineering Research (CIRP), Volume 27/1, 1978.

The tank was measured empty while at an average temperature of $15.4^{\circ} \mathrm{C}$. The tabulated volumes and the error estimates apply to the tank under these conditions. The volumes have also been corrected for the volume occupied by the corregations (deadwood) which was measured in the laboratory using a hydrostatic displacement technique.

The measurement method used includes geometrically redundant cross checks which allow assessment of the random error in the measurement process, For this tank, the total volume, excluding the vapor domes, was $24858.8 \mathrm{~m}^{3}$ with an uncertainty of $2.5 \mathrm{~m}^{3}(0.01 \%$ of total volume) at the three standard deviation limit of random error. Including an analysis of probable systematics by adding the absolute magnitude of the error sources, we estimate that the total uncertainty, at the $99 \%$ confidence level, is $\pm 0.05 \%$ of the total volume. No estimates of the errors in the individual table entries are included, since without an estimate of the height error introduced by the liquid level gage such estimates would of necessity be incomplete.

For the Director,

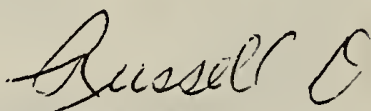

Russell D. Young, Chief

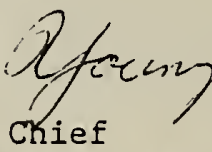

Mechanical Processes Division

Center for Mechanical Engineering and Process Technology 


\section{EL PASO SOUTHERN}

MAIN VOLUME VS. HEIGHT TABLE

TANK NO. 2

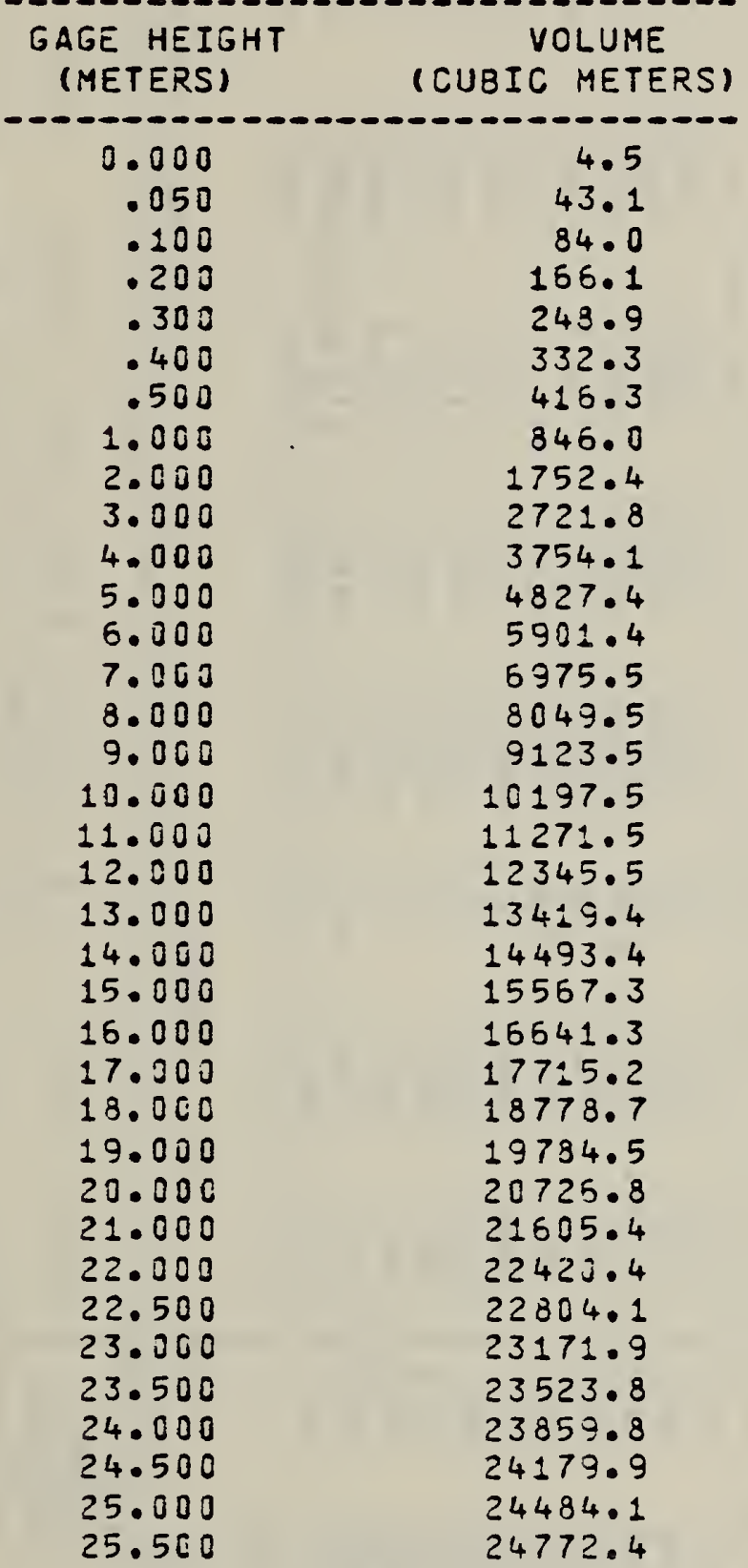




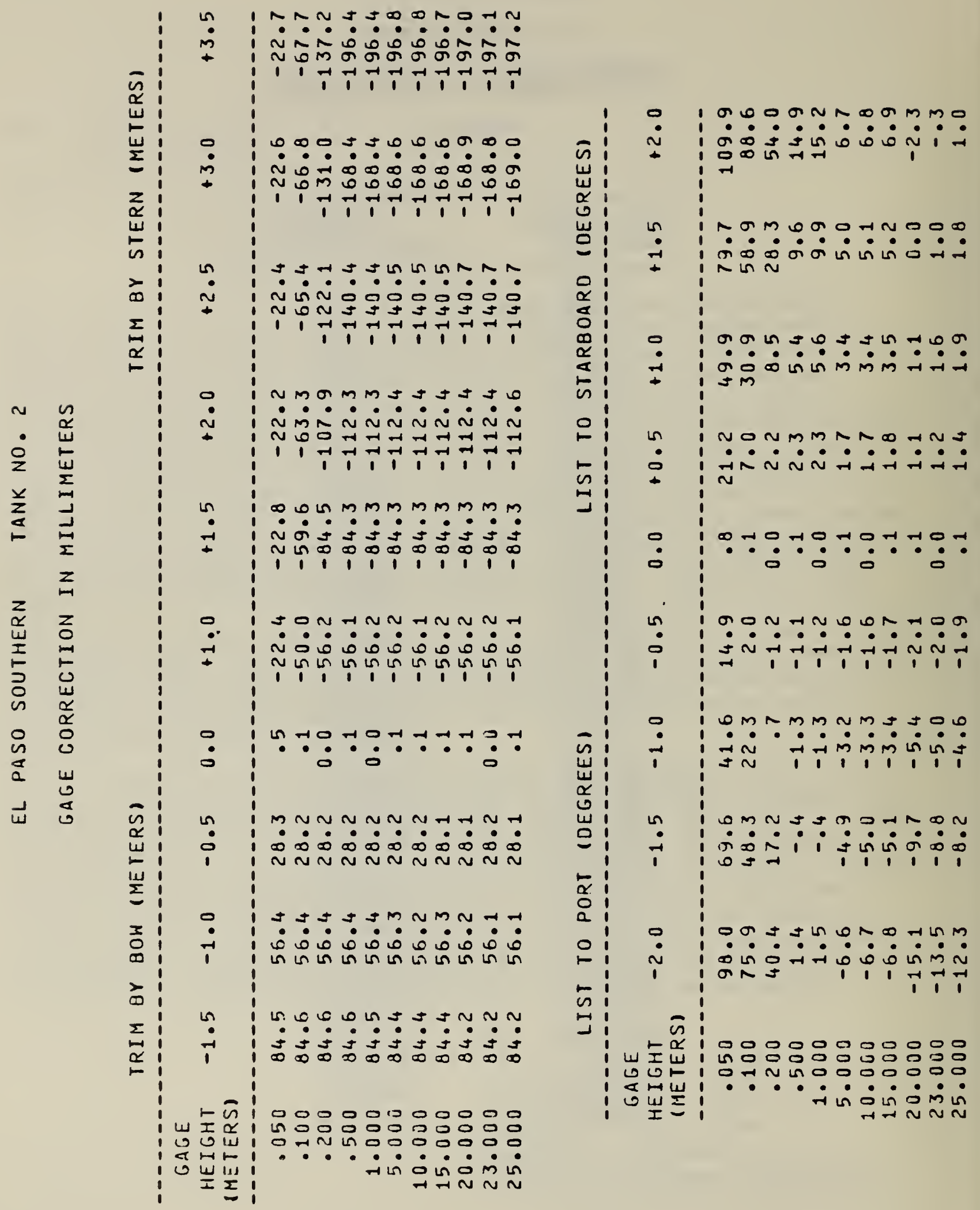




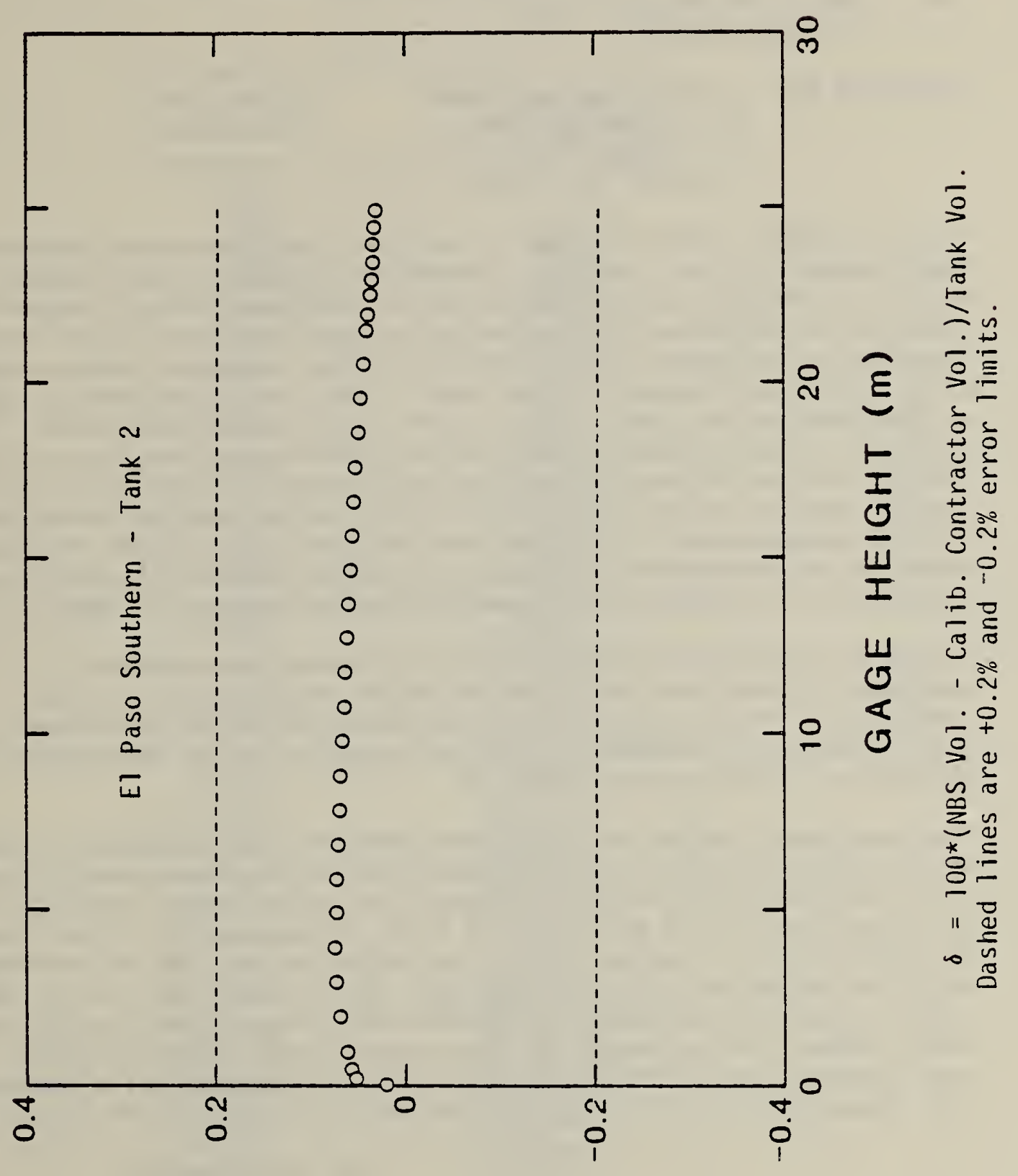

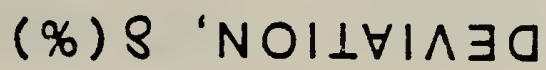




\section{REPORT OF CALIBRATION}

For: Tank \#3 on the LNG Tanker

El Paso Southern

Requested by: El Paso Marine Company

2919 Allen Parkway

P. O. Box 1592

Houston, TX 77001

The following tables have been calculated from dimensional measurements on tank number 3 of the liquefied natural gas tanker El Paso Southern while berthed at Newport News Shipbuilding and Drydock Company, Newport News, VA. These tables represent the volume of a liquid enclosed in the tank as a function of the height of the liquid surface, measured along a straight line, fixed with respect to the tank. This line is defined as being located at the longitudinal center line of the tank's capacitance gage. Secondary tables are also presented which allow correction of the main tables for specific angles of ship orientation with respect to gravity, as referred to the six sets of draft marks on the ship's hull. Both the measurement method and the computational algorithms are outlined in the paper. "Multiple Redundancy in the Measurement of Large Structures," Annals of the International Institution of Production Engineering Research (CIRP), Volume 27/1, 1978.

The tank was measured empty while at an average temperature of $16.4^{\circ} \mathrm{C}$. The tabulated volumes and the error estimates apply to the tank under these conditions. The volumes have also been corrected for the volume occupied by the corregations (deadwood) which was measured in the laboratory using a hydrostatic displacement technique.

The measurement method used includes geometrically redundant cross checks which allow assessment of the random error in the measurement process, For this tank, the total volume, excluding the vapor domes, was $27655.0 \mathrm{~m}^{3}$ with an uncertainty of $5.5 \mathrm{~m}^{3}(0.01 \%$ of total volume) at the three standard deviation limit of random error. Including an analysis of probable systematics by adding the absolute magnitude of the error sources, we estimate that the total uncertainty, at the $99 \%$ confidence level, is $+0.10 \%$ of the total volume. No estimates of the errors in the individual table entries are included, since without an estimate of the height error introduced by the liquid level gage such estimates would of necessity be incomplete.

For the Director,

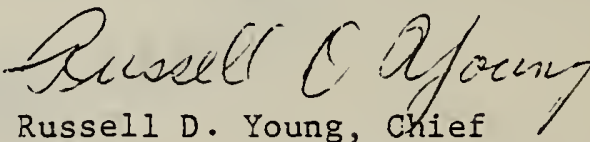

Mechanical Processes Division

Center for Mechanical Engineering and Process Technology 
EL PASO SOUTHERN

maIN VOLUME VS. heIght table

TANK NO. 3

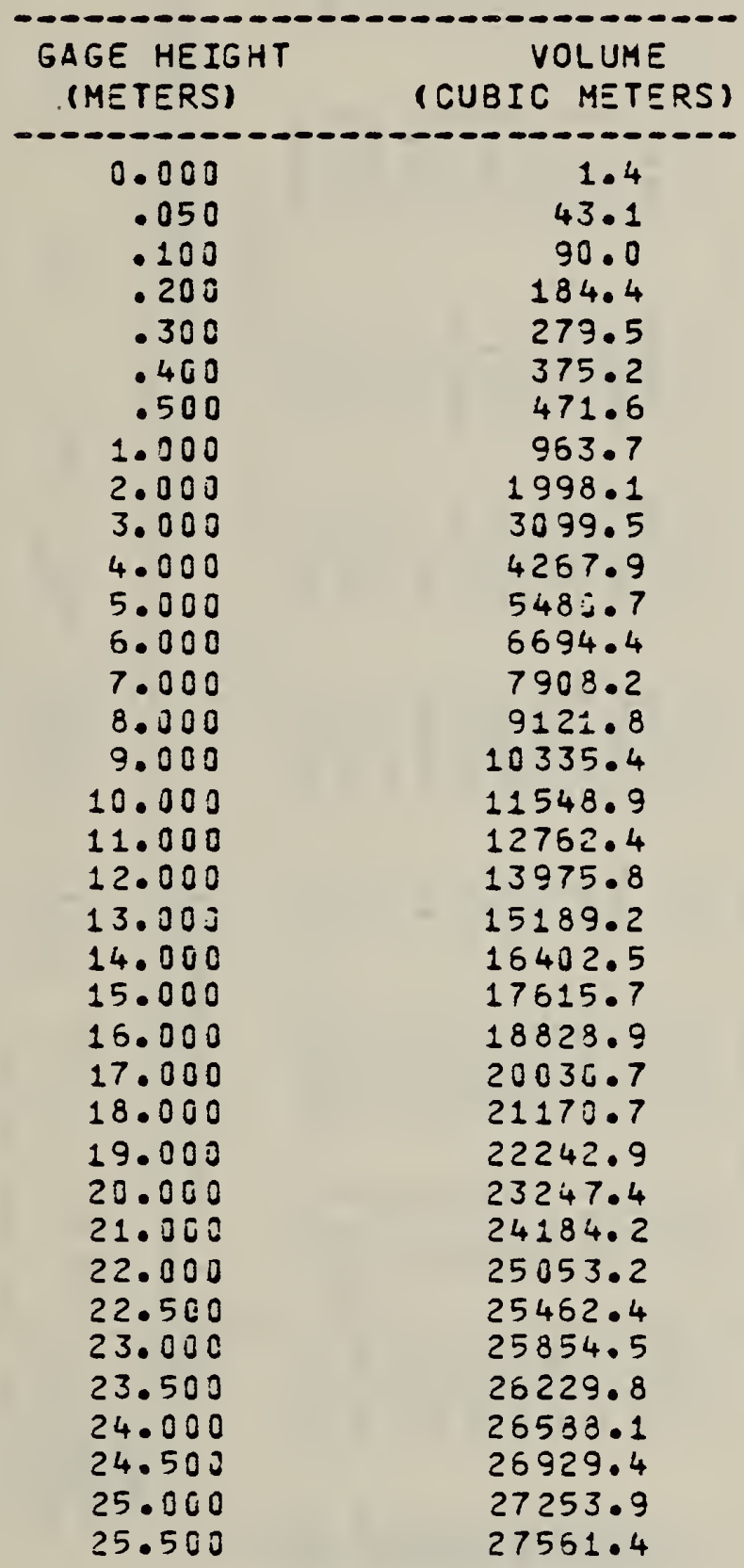




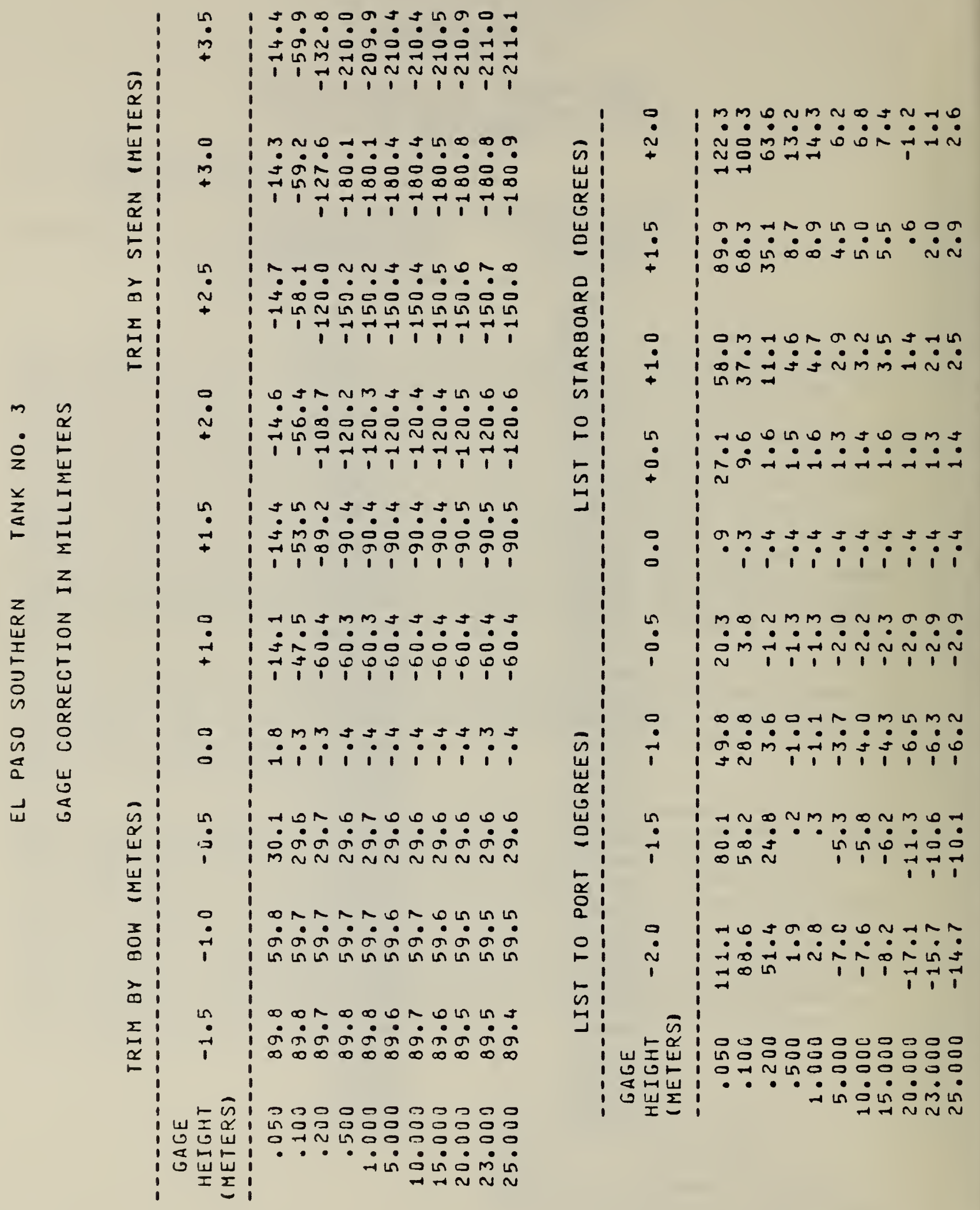




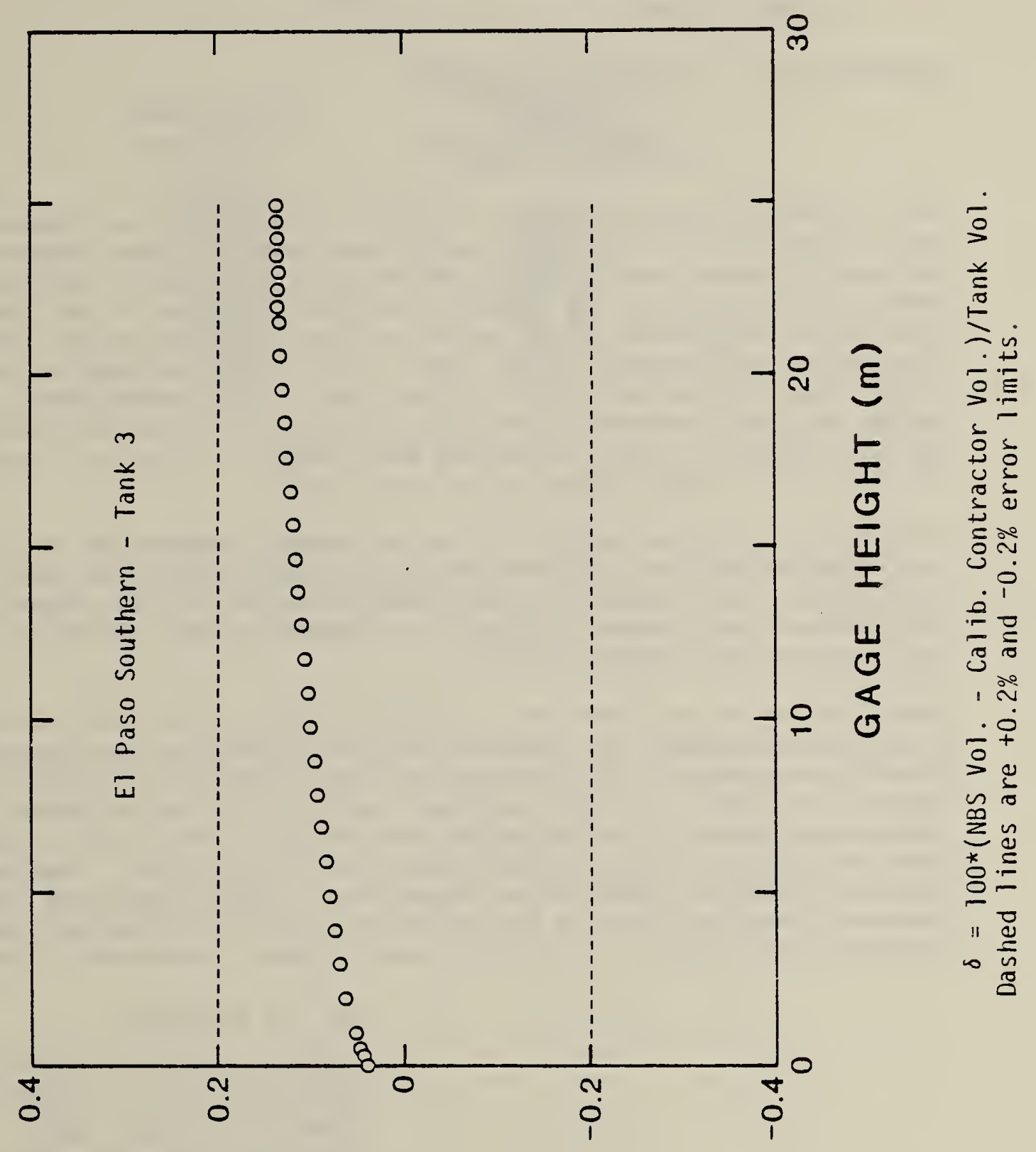

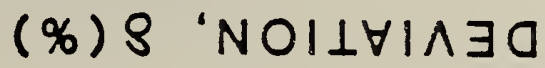




\section{U.S. DEPARTMENT OF COMMERCE \\ NATIONAL BUREAU OF STANDARDS \\ WASHINGTON, D.C. 20234}

\section{REPORT OF TEST}

For: Tank $\# 4$ on the LNG Tanker

E1 Paso Southern

Requested by: El Paso Marine Company

2919 Allen Parkway

P. 0. Box 1592

Houston, TX 77001

The following tables have been calculated from dimensional measurements on tank number 4 of the liquefied natural gas tanker EI Paso Southern while berthed at Newport News Shipbuilding and Drydock Company, Newport News, VA. These tables represent the volume of a liquid enclosed in the tank as a function of the height of the liquid surface, measured along a straight line, fixed with respect to the tank. This line is defined as being located at the longitudinal center line of the tank's capacitance gage. Secondary tables are also presented which allow correction of the main tables for specific angles of ship orientation with respect to gravity, as referred to the six sets of draft marks on the ship's hull.

The tank was measured empty while at an average temperature of $10.0^{\circ} \mathrm{C}$. The tabulated volumes and the error estimates apply to the tank under these conditions. The volumes have also been corrected for the volume occupied by the corregations (deadwood) which was measured in the laboratory using a hydrostatic displacement technique.

These tables are not based on a complete survey of the tank, since scaffolding necessary for complete interior access was not present at the time of measurement. As a consequence, geometrically redundant cross checks reported of tanks 1,2 and 3 were not made on this tank to assess random measurement errors. The estimated uncertainty of the tables is instead based on the comparison of measurements on tanks 1,2 and 3 against their respective nominal construction dimensions. These comparisons showed measured dimensions were in general within $0.2 \%$ of the nominals so an estimated uncertainty of $\pm 0.2 \%$ of total volume is assigned to the tables.

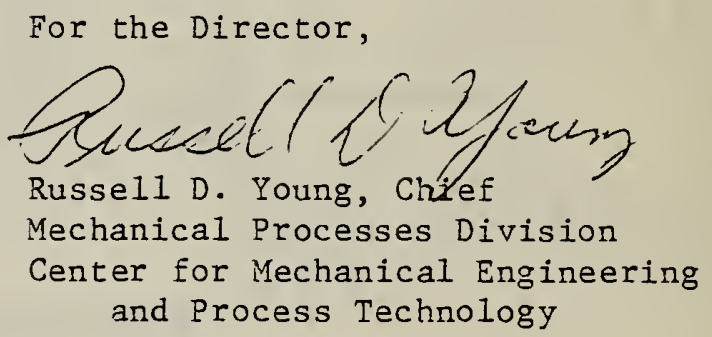

Date: August 17, 1979 
EL PASO SOUTHERN

MAIN VOLUME VS. HEIGHT TABLE

TANK NO. 4

\begin{tabular}{cc} 
GAGE HEIGHT & VOLUME \\
(METERS) & (CUBIC METERS) \\
\hline .000 & 0.0 \\
.050 & 11.2 \\
.100 & 23.4 \\
.200 & 48.0 \\
.300 & 72.5 \\
.400 & 97.0 \\
.500 & 121.6
\end{tabular}




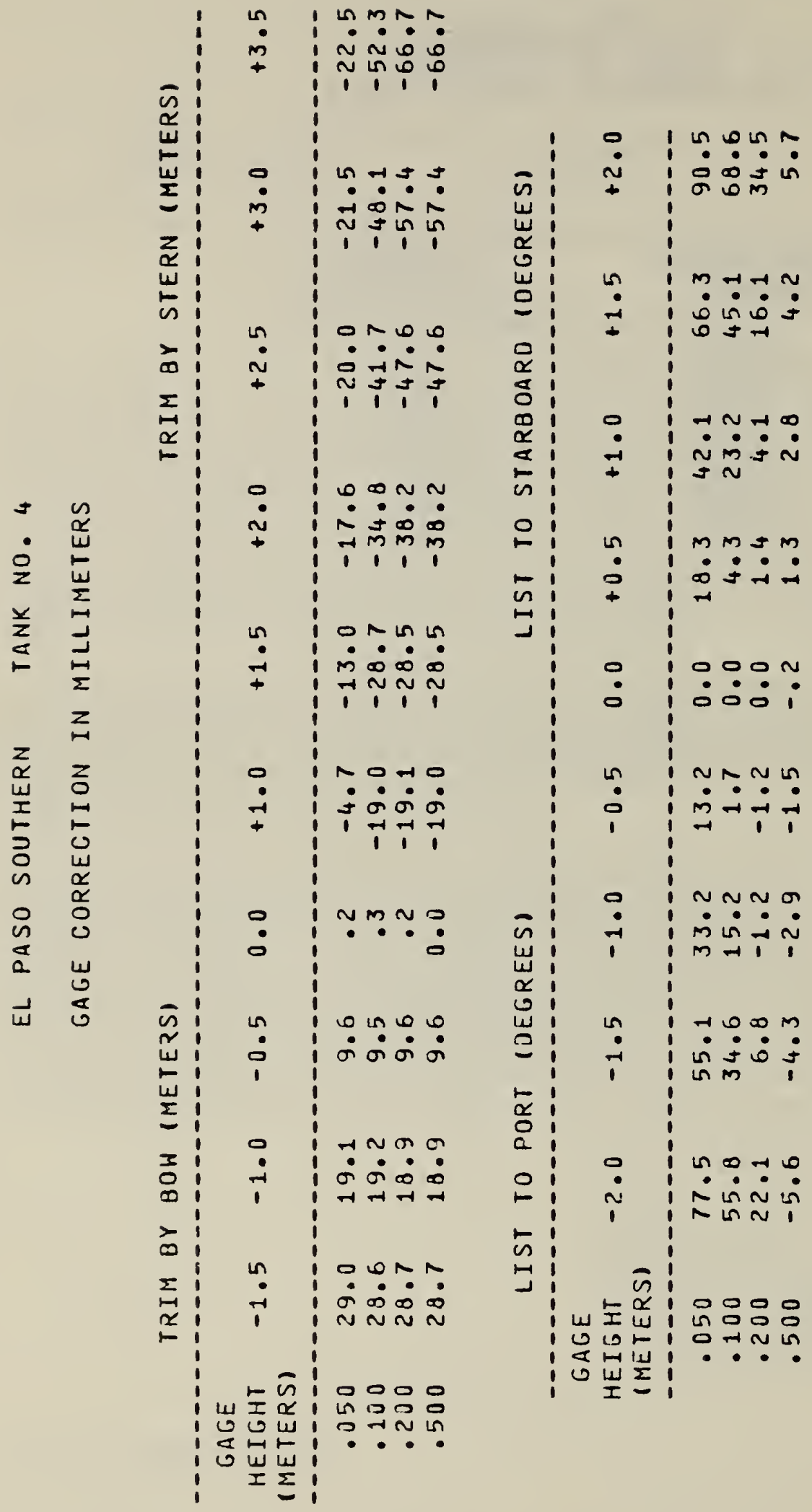




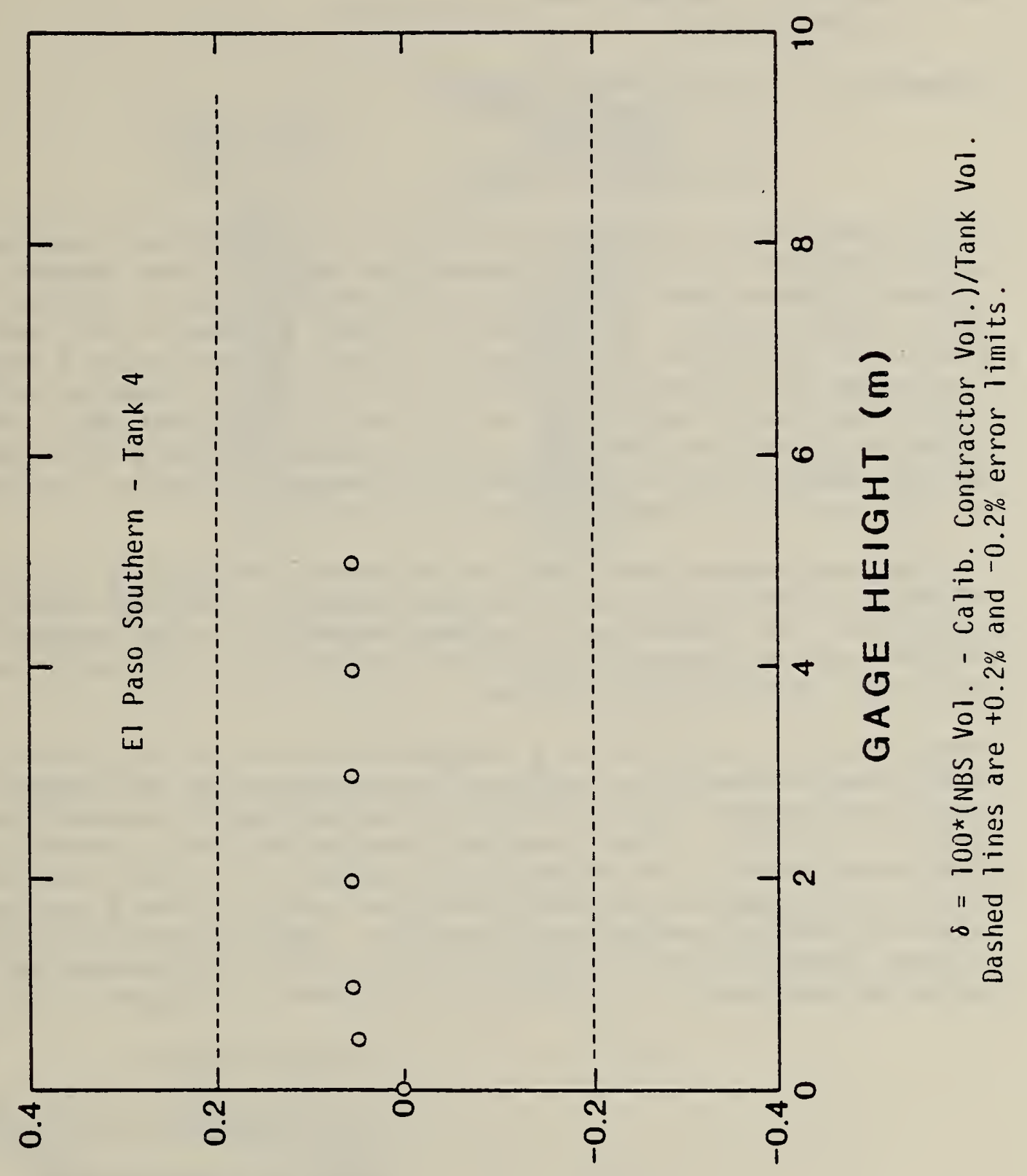

(\%) \& $N O I \perp \forall I \wedge \exists O$ 


\section{U.S. DEPARTMENT OF COMMERCE \\ NATIONAL BUREAU OF STANDARDS \\ WASHINGTON, D.C. 20234}

\section{REPORT OF TEST}

For: Tank 非 5 on the LNG Tanker

E1 Paso Southern

Requested by: El Paso Marine Company

2919 Allen Parkway

P. O. Box 1592

Houston, TX 77001

The following tables have been calculated from dimensional measurements on tank number 5 of the liquefied natural gas tanker El Paso Southern while berthed at Newport News Shipbuilding and Drydock Company, Newport News, VA. These tables represent the volume of a liquid enclosed in the tank as a function of the height of the liquid surface, measured along a straight line, fixed with respect to the tank. This line is defined as being located at the longitudinal center line of the tank's capacitance gage. Secondary tables are also presented which allow correction of the main tables for specific angles of ship orientation with respect to gravity, as referred to the six sets of draft marks on the ship's hull.

The tank was measured empty while at an average temperature of $6.4^{\circ} \mathrm{C}$. The tabulated volumes and the error estimates apply to the tank under these conditions. The volumes have also been corrected for the volume occupied by the corregations (deadwood) which was measured in the laboratory using a hydrostatic displacement technique.

These tables are not based on a complete survey of the tank, since scaffolding necessary for complete interior access was not present at the time of measurement. As a consequence, geometrically redundant cross checks reported of tanks 1,2 and 3 were not made on this tank to assess random measurement errors. The estimated uncertainty of the tables is instead based on the comparison of measurements on tanks 1, 2 and 3 against their respective nominal construction dimensions. These comparisons showed measured dimensions were in general within $0.2 \%$ of the nominals so an estimated uncertainty of $\pm 0.2 \%$ of total volume is assigned to the tables.

For the Director,

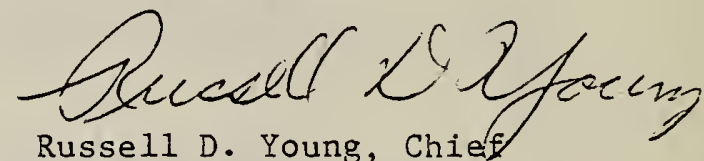

Russel1 D. Young, Chief

Mechanical Processes Division

Center for Mechanical Engineering and Process Technology

Date: August 17, 1979 


\section{EL PASO SOUTHERN}

MAIN VOLUME VS. HEIGHT TABLE

TANK NO. 5

$\begin{array}{cc}\text { GAGE HEIGHT } & \text { VOLUME } \\ \text { (METERS) } & \text { (CUBIC METERS) } \\ 0.000 & 8.5 \\ .050 & 37.8 \\ .100 & 83.9 \\ .200 & 178.6 \\ .300 & 274.0 \\ .400 & 370.1 \\ .500 & 465.9 \\ 1.000 & 960.6 \\ 2.000 & 1998.2 \\ 3.000 & 3102.5 \\ 4.000 & 4273.5\end{array}$




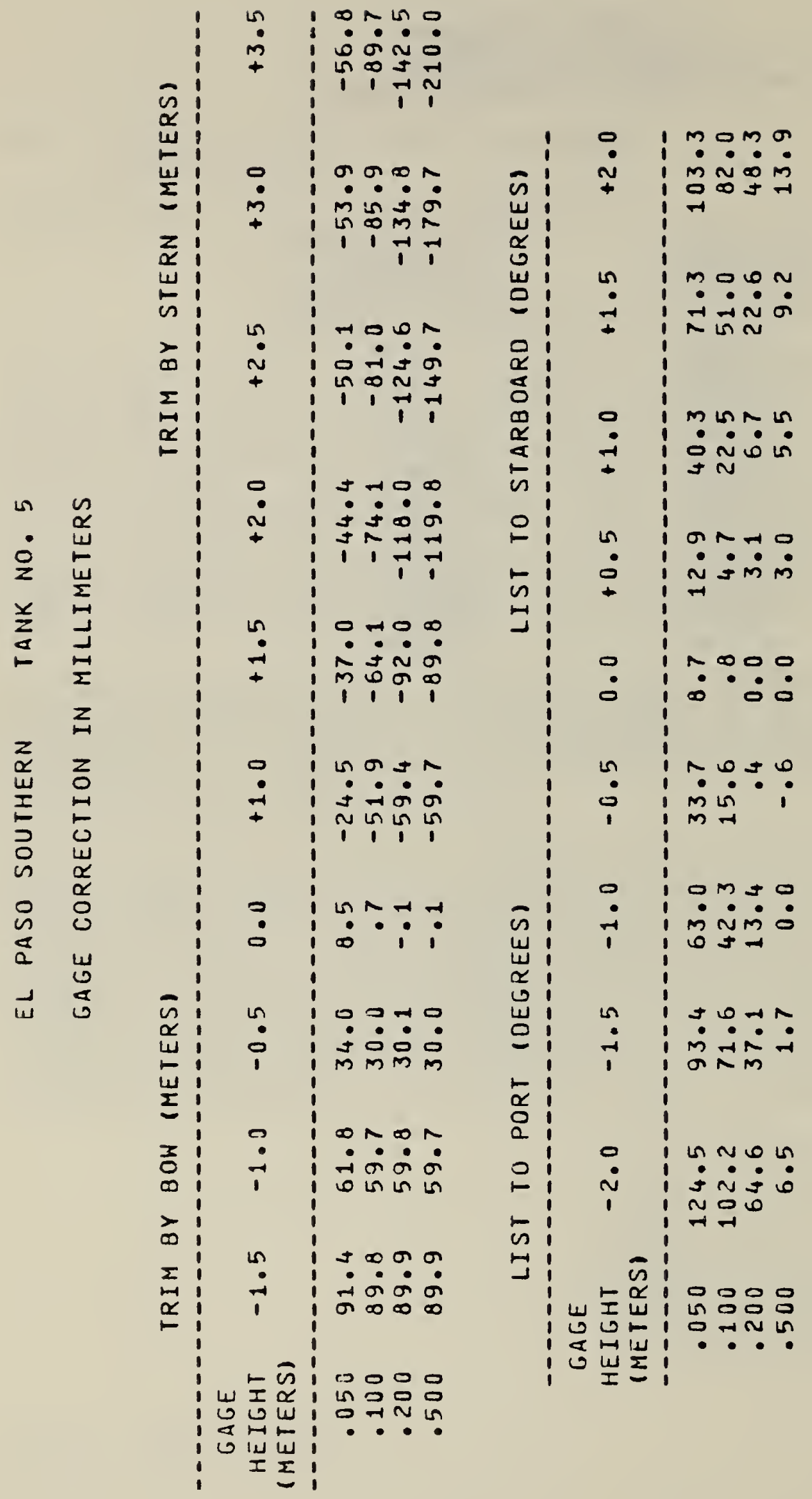




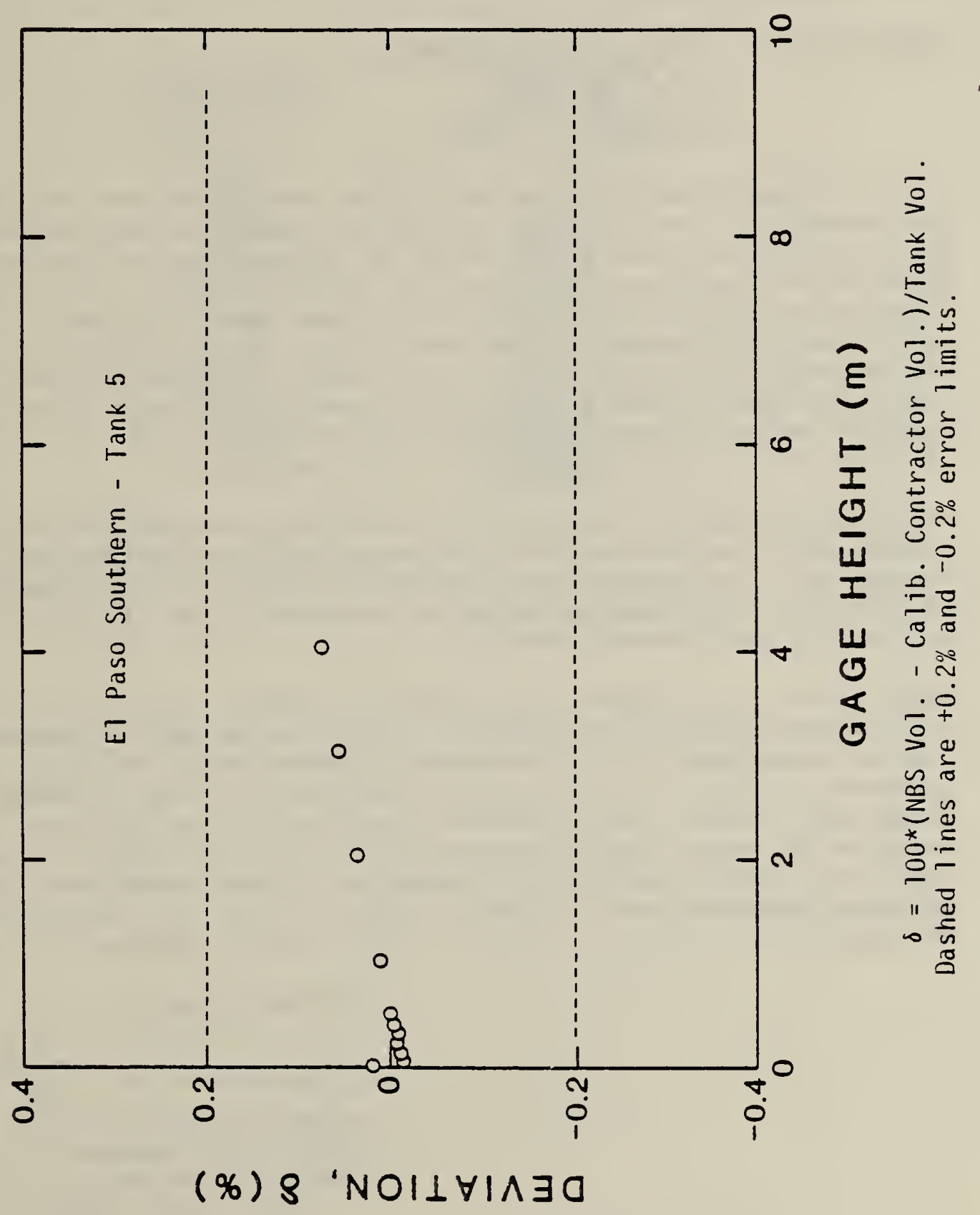




\section{U.S. DEPARTMENT OF COMMERCE NATIONAL BUREAU OF STANDARDS \\ WASHINGTON, D.C. 20234}

\section{REPORT OF TEST}

For: Tank \# 6 on the LNG Tanker

El Paso Southern

Requested by: El Paso Marine Company

2919 Allen Parkway

P. 0. Box 1592

Houston, TX 77001

The following tables have been calculated from dimensional measurements on tank number 6 of the liquefied natural gas tanker E1 Paso Southern while berthed at Newport News Shipbuilding and Drydock Company, Newport News, VA. These tables represent the volume of a liquid enclosed in the tank as a function of the height of the liquid surface, measured along a straight line, fixed with respect to the tank. This line is defined as being located at the longitudinal center line of the tank's capacitance gage. Secondary tables are also presented which allow correction of the main tables for specific angles of ship orientation with respect to gravity, as referred to the six sets of draft marks on the ship's hull.

The tank was measured empty while at an average temperature of $3.8^{\circ} \mathrm{C}$. The tabulated volumes and the error estimates apply to the tank under these conditions. The volumes have also been corrected for the volume occupied by the corregations (deadwood) which was measured in the laboratory using a hydrostatic displacement technique.

These tables are not based on a complete survey of the tank, since scaffolding necessary for complete interior access was not present at the time of measurement. As a consequence, geometrically redundant cross checks reported of tanks 1,2 and 3 were not made on this tank to assess random measurement errors. The estimated uncertainty of the tables is instead based on the comparison of measurements on tanks 1,2 and 3 against their respective nominal construction dimensions. These comparisons showed measured dimensions were in general within $0.2 \%$ of the nominals so an estimated uncertainty of $\pm 0.2 \%$ of total volume is assigned to the tables.

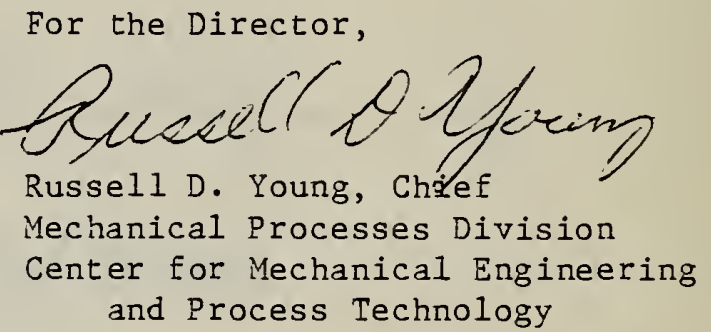

Date: August 17, 1979 


\section{EL PASO SOUTHERN}

MAIN VOLUME VS. hEIGHT TABLE

TANK NO. 6

$\begin{array}{cc}\text { GAGE HEIJHT } & \text { VOLUME } \\ \text { (METERS) } & \text { (CUBIC METERS) } \\ 0.000 & .6 \\ .050 & 34.3 \\ .100 & 81.1 \\ .200 & 175.1 \\ .300 & 269.9 \\ .400 & 365.3 \\ .500 & 461.4 \\ 1.000 & 951.9 \\ 2.000 & 1983.5 \\ 3.000 & 3082.5 \\ 4.003 & 4248.9\end{array}$




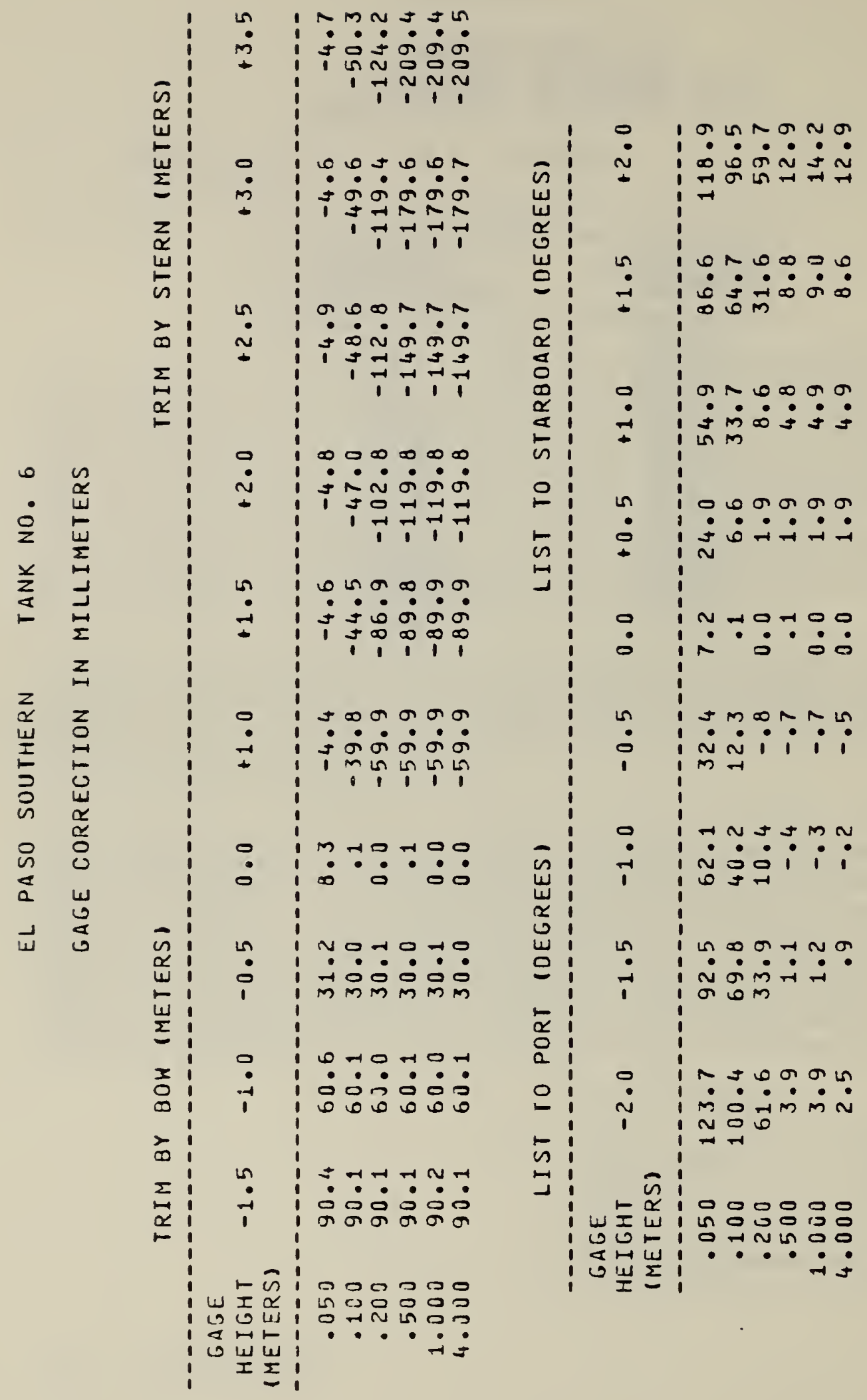




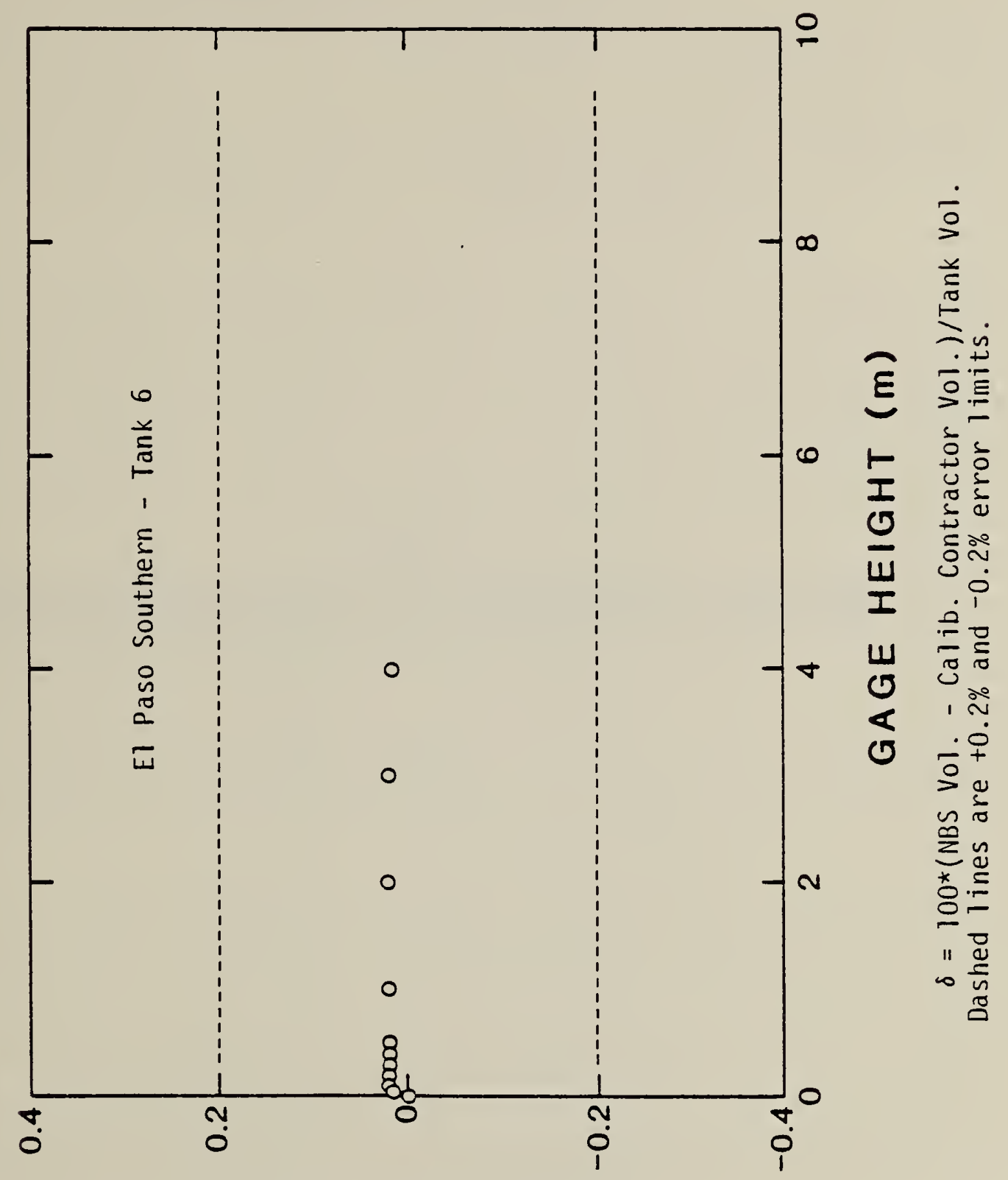

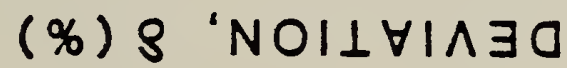





\section{Appendix B}

Calibration Reports for the Six Tanks of the El Paso Arzew 


\section{REPORT OF CALIBRATION}

For: Tank 1 on the LNG Tanker El Paso Arzew

Requested by: El Paso Marine Company 2919 Allen Parkway

P. O. Box 1592

Houston, TX 77001

The following tables have been calculated from dimensional measurements on tank number 1 of the liquefied natural gas tanker El Paso Arzew while berthed at Newport News Shipbuilding and Drydock Company, Newport News, VA. These tables represent the volume of a liquid enclosed in the tank as a function of the height of the liquid surface, measured along a straight line, fixed with respect to the tank. This line is defined as being located at the longitudinal center line of the tank's capacitance gage. Secondary tables are also presented which allow correction of the main tables for specific angles of ship orientation with respect to gravity, as referred to the six sets of draft marks on the ship's hull. Both the measurement method and the computational algorithms are outlined in the paper "Multiple Redundancy in the Measurement of Large Structures," Annals of the International Institution of Production Engineering Research (CIRP), Volume 27/1, 1978 .

The tank was measured empty while at an average temperature of $23.0^{\circ} \mathrm{C}$. The tabulated volumes and the error estimates apply to the tank under these conditions. The volumes have also been corrected for the volume occupied by the corregations (deadwood) which was measured in the laboratory using a hydrostatic displacement technique.

The measurement method used includes geometrically redundant cross checks which allow assessment of the random error in the measurement process; For this tank, the total volume, excluding the vapor domes, was $12571.8 \mathrm{~m}^{3}$ with an uncertainty of $6.3 \mathrm{~m}^{3}(0.05 \%$ of total volume) at the three standard deviation limit of random error. Including an analysis of probable systematics by adding the absolute magnitude of the error sources, we estimate that the total uncertainty, at the $99 \%$ confidence level, is $+0.10 \%$ of the total volume. No estimates of the errors in the individual table entries are included, since without an estimate of the height error introduced by the liquid level gage such estimates would of necessity be incomplete.

For the Director,

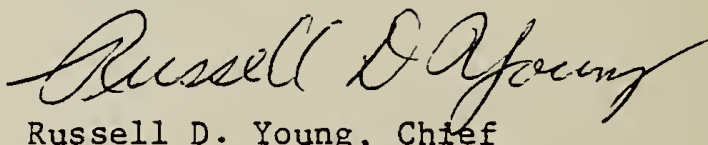

Russell D. Young, Chitef Mechanical Processes Division Center for Mechanical Engineering and Process Technology 


\section{EL PASO ARZEH \\ MAIN VOLUME VS. HEIGHT TABLE \\ TANK NO. 1}

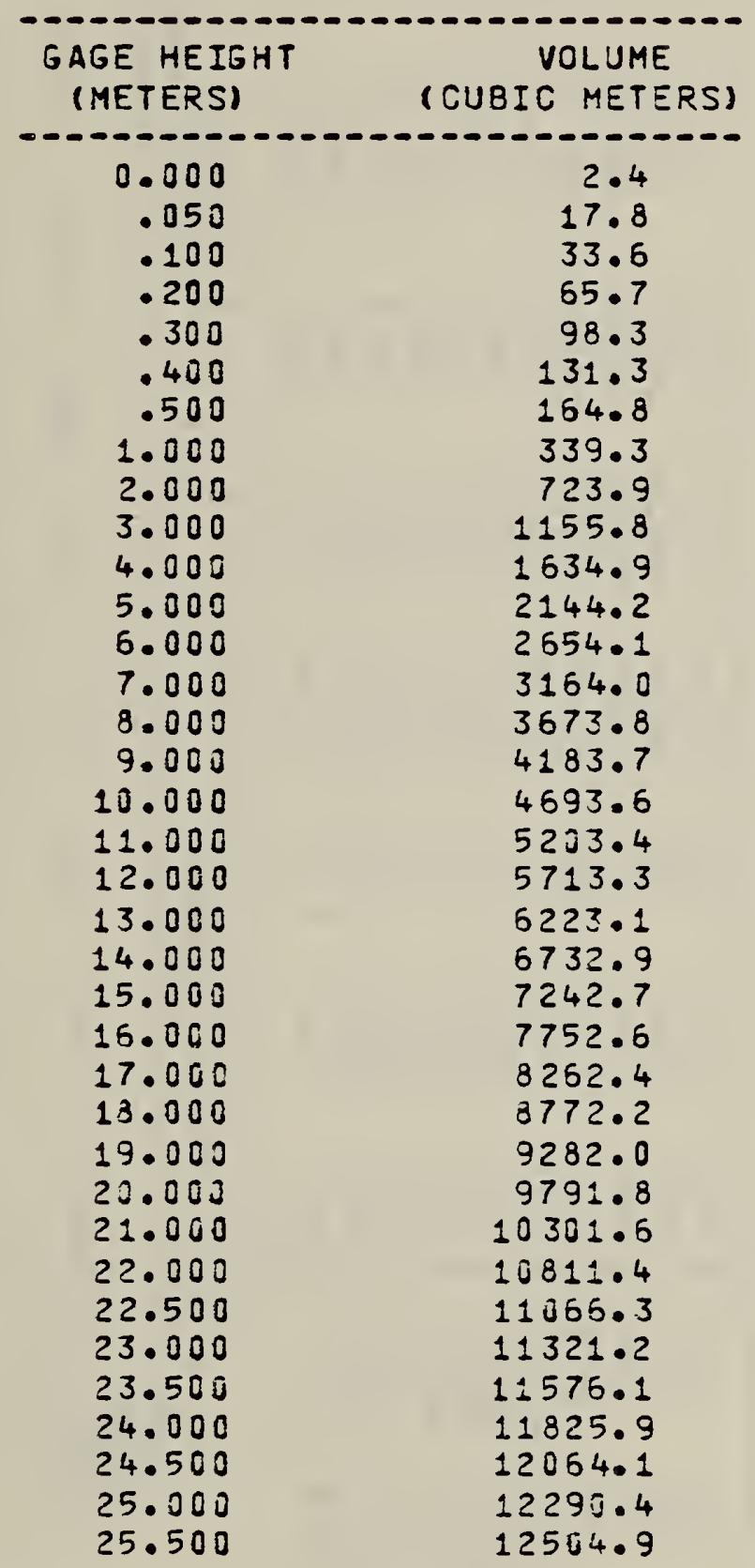




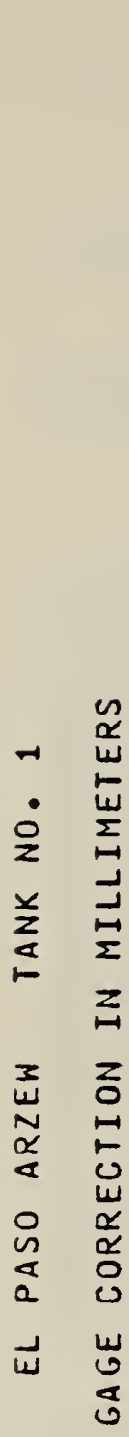

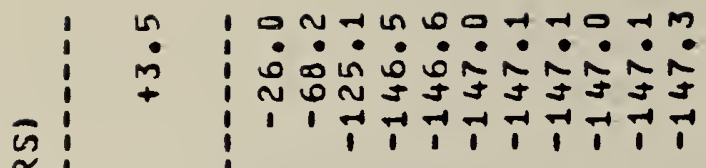

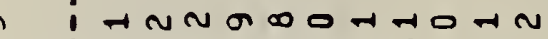

$\cdot \cdot \cdot \cdot \cdot \cdot \cdot \cdot \cdot \cdot \cdot$

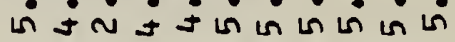

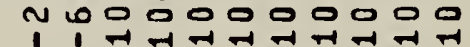

$\Sigma$

।

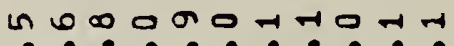

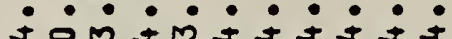

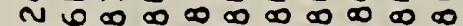
11111111111

o un a - • $\bullet \cdot \bullet \cdot \bullet \cdot \bullet \cdot$ $m=N N M M M M M M M$ n 10 ט

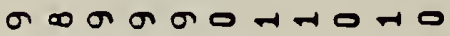

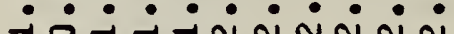

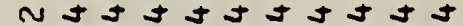

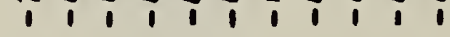

$004044-4 \rightarrow 0-10$

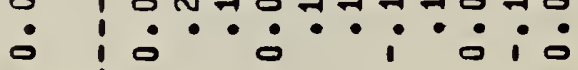

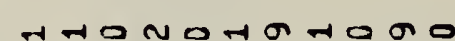

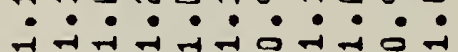

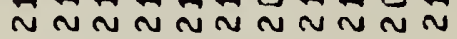

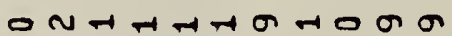

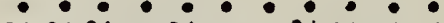

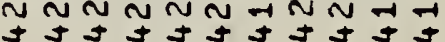

-n! wI $\alpha$, in 0 ग 000000000

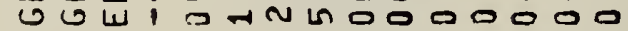

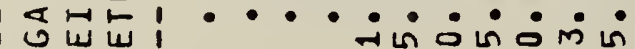
$I \sum 1$

$m \leqslant \rightarrow n n+4+40-40$ $M M M M M M M M M M M$ م 0 ف م

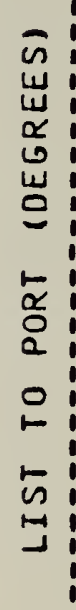
$\begin{array}{ll} & \\ & \end{array}$

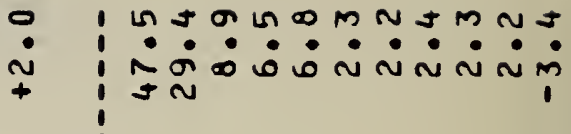

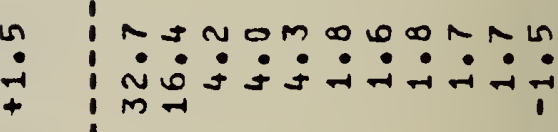
$+$

NNNAmNANNHm

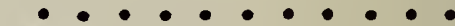

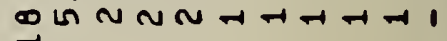
-

in 1 Ta

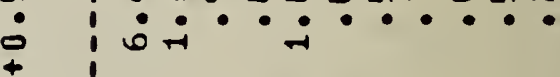

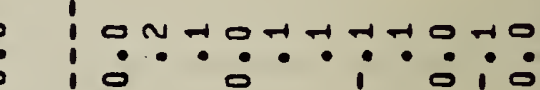
: 0 i 0 i 0 i

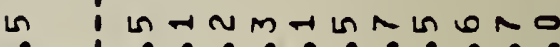
: i i i i i i i i: 1

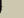

$N \infty \int_{0} \pi N+4+N N$ $\bullet \cdot \bullet \cdot \bullet \cdot \cdot \cdot \cdot \cdot$ Im0 1

$\sim \pi+\infty+\infty \infty \omega \sim \infty 0$ विं $\dot{0} \dot{4} \dot{4} \dot{4} \dot{4}$ im 11111 , w王

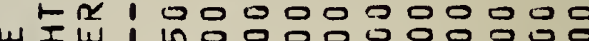

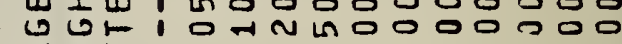
1 <मس ! • • • • • • • • • , U世上! 


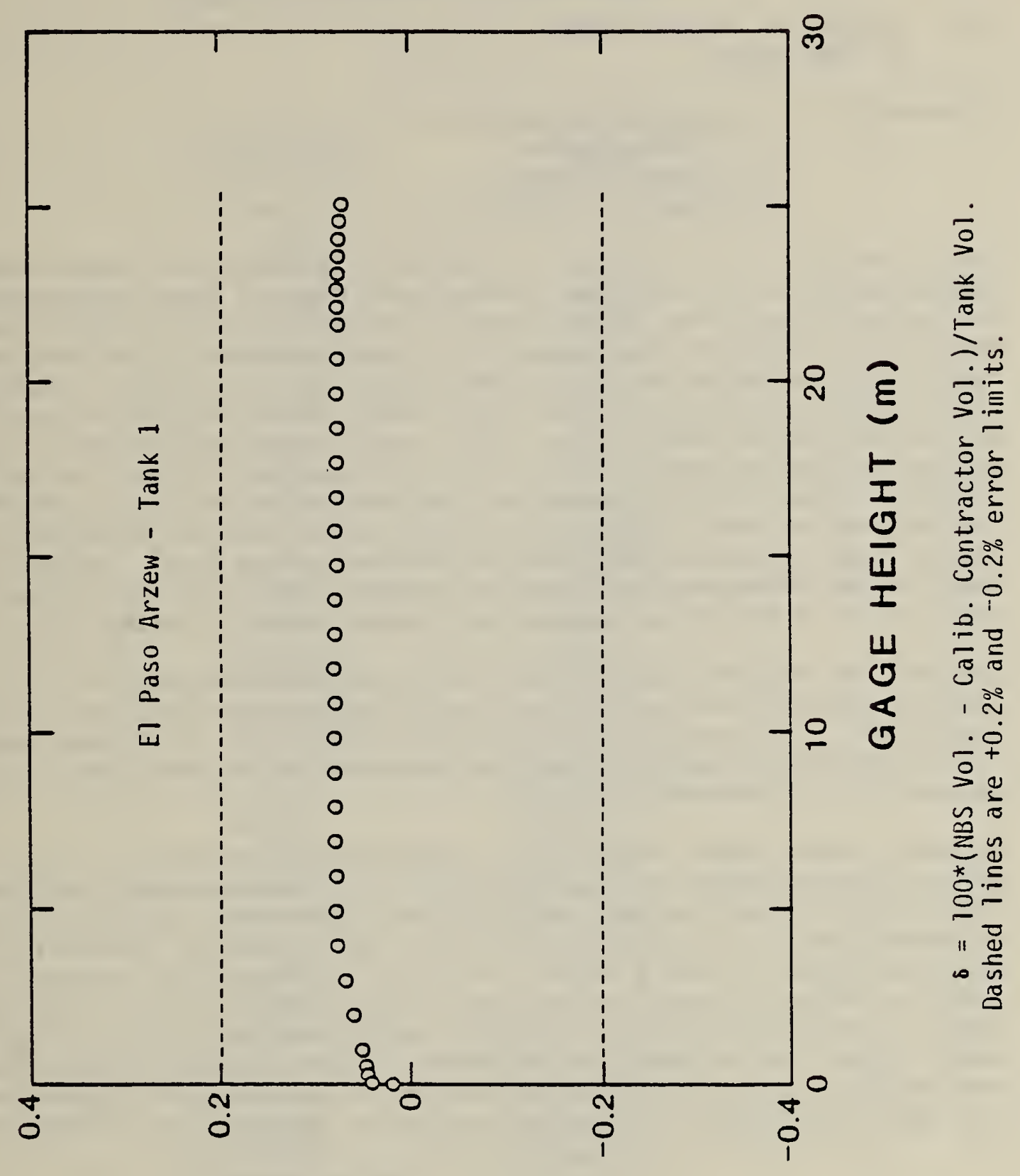

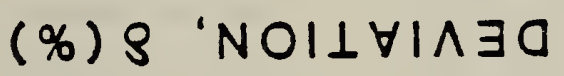




\section{REPORT OF CALIBRATION}

For: Tank 2 on the LNG Tanker

El Paso Arzew

Requested by: E1 Paso Marine Company

2919 Allen Parkway

P. O. Box 1592

Houston, TX 77001

The following tables have been calculated from dimensional measurements on tank number 2 of the liquefied natural gas tanker EI Paso Arzew while berthed at Newport News Shipbuilding and Drydock Company, Newport News, VA. These tables represent the volume of a liquid enclosed in the tank as a function of the height of the liquid surface, measured along a straight line, fixed with respect to the tank. This line is defined as being located at the longitudinal center line of the tank's capacitance gage. Secondary tables are also presented which allow correction of the main tables for specific angles of ship orientation with respect to gravity, as referred to the six sets of draft marks on the ship's hull. Both the measurement method and the computational algorithms are outlined in the paper "Multiple Redundancy in the Measurement of Large Structures," Annals of the International Institution of Production Engineering Research (CIRP), Volume 27/1, 1978.

The tank was measured empty while at an average temperature of $23.5^{\circ} \mathrm{C}$. The tabulated volumes and the error estimates apply to the tank under these conditions. The volumes have also been corrected for the volume occupied by the corregations (deadwood) which was measured in the laboratory using a hydrostatic displacement technique.

The measurement method used includes geometrically redundant cross checks which allow assessment of the random error in the measurement process; For this tank, the total volume, excluding the vapor domes, was $24885.3 \mathrm{~m}^{3}$ with an uncertainty of $12.4 \mathrm{~m}^{3}(0.05 \%$ of total volume) at the three standard deviation limit of random error. Including an analysis of probable systematics by adding the absolute magnitude of the error sources, we estimate that the total uncertainty, at the $99 \%$ confidence 1 evel, is $\pm 0.10 \%$ of the total volume. No estimates of the errors in the individual table entries are included, since without an estimate of the height error introduced by the liquid level gage such estimates would of necessity be incomplete.

For the Director,

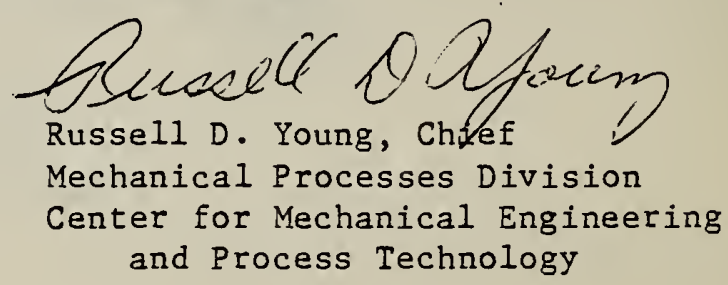

Date: August 16, 1979 
EL PASO ARZEW

MAIN VOLUME VS. HEIGHT TABLE

TANK NO. 2

\begin{tabular}{|c|c|}
\hline $\begin{array}{l}\text { GAGE HEIGHT } \\
\text { (METERS) }\end{array}$ & $\begin{array}{l}\text { VOLUME } \\
\text { (CUBIC METERS) }\end{array}$ \\
\hline 0,000 & $--0-----2-0$ \\
\hline $\begin{array}{r}0.000 \\
.050\end{array}$ & $\begin{array}{r}5.3 \\
45.3\end{array}$ \\
\hline .100 & $86 \cdot 1$ \\
\hline $\begin{array}{l}.200 \\
.300\end{array}$ & $\begin{array}{l}158 \cdot 1 \\
250.8\end{array}$ \\
\hline .400 & $334 \cdot 2$ \\
\hline $\begin{array}{r}.500 \\
1.000\end{array}$ & $\begin{array}{l}418.1 \\
847.5\end{array}$ \\
\hline $\begin{array}{l}1.000 \\
2.000 \\
3.000\end{array}$ & $\begin{array}{l}1754 \cdot 1 \\
2724 \cdot 3\end{array}$ \\
\hline 4.000 & 3758.1 \\
\hline $\begin{array}{l}5.000 \\
6.000\end{array}$ & $\begin{array}{l}4832.5 \\
5907.5\end{array}$ \\
\hline 7.000 & 6982.6 \\
\hline $\begin{array}{l}3.000 \\
9.000\end{array}$ & $\begin{array}{l}8057.8 \\
9132.9\end{array}$ \\
\hline 10.000 & 10200.1 \\
\hline $\begin{array}{l}11.000 \\
12.000\end{array}$ & $\begin{array}{l}11283 \cdot 3 \\
12358.5\end{array}$ \\
\hline 13.000 & 13433.8 \\
\hline $\begin{array}{l}14.000 \\
15.000\end{array}$ & $\begin{array}{l}14509.1 \\
15584.4\end{array}$ \\
\hline 16.000 & 16659.8 \\
\hline $\begin{array}{l}17.000 \\
18.000\end{array}$ & $\begin{array}{l}17735.1 \\
18799.6\end{array}$ \\
\hline 19.000 & 19805.9 \\
\hline 20.050 & 20748.6 \\
\hline 21.000 & $21627 \cdot 9$ \\
\hline 22.000 & 22443.6 \\
\hline 22.500 & 22827.6 \\
\hline 23.000 & 23195.7 \\
\hline 23.500 & 23548.0 \\
\hline 24.000 & $23884 \cdot 4$ \\
\hline 24.500 & 24204.9 \\
\hline 25.000 & 24569.5 \\
\hline 25.500 & 24798.2 \\
\hline
\end{tabular}



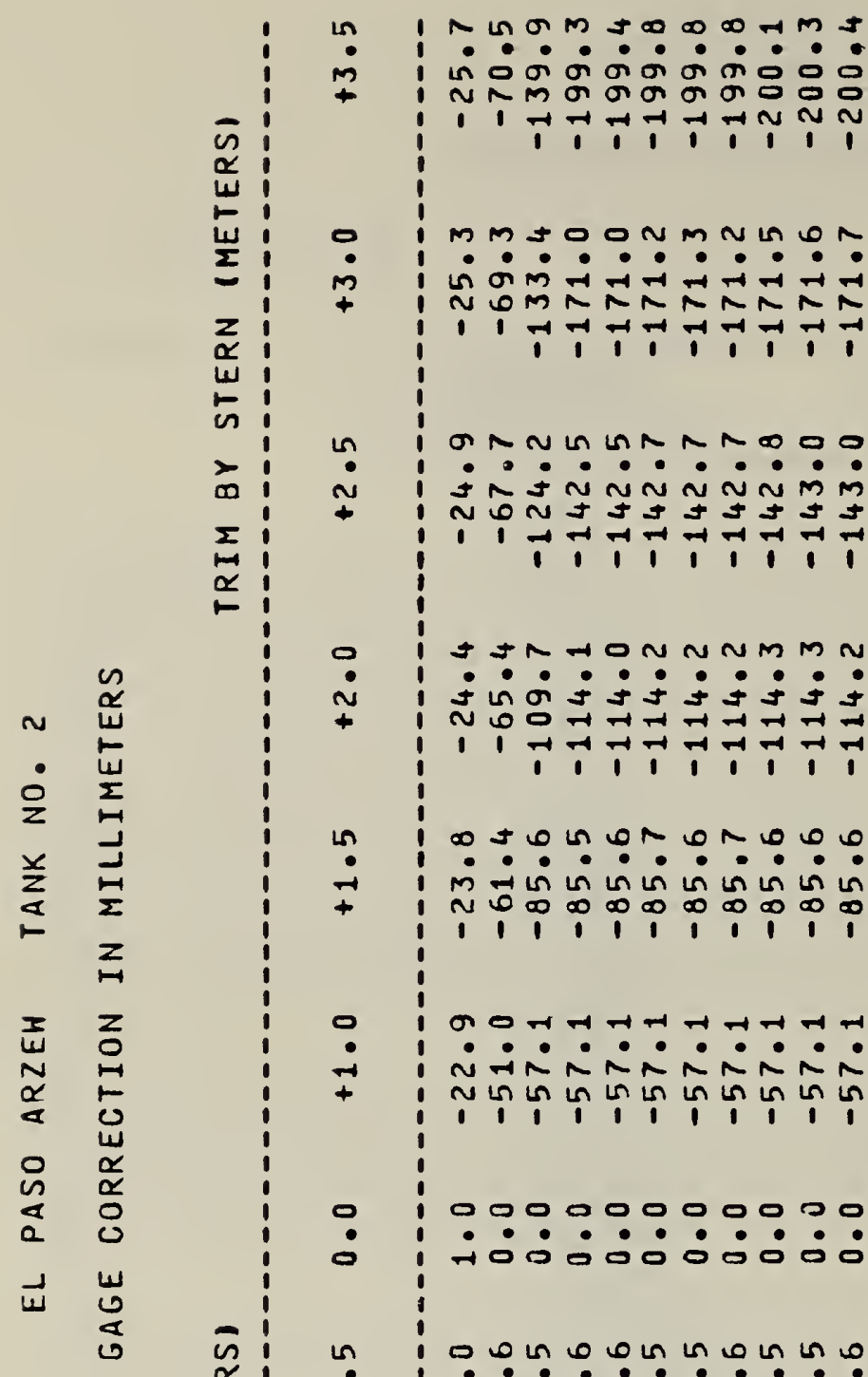

I

N $: \pm N N N N N N N m$ n

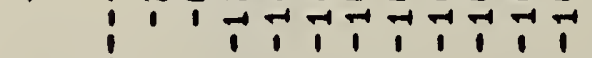

- $1: z n-10 n \pi N m m$

皮

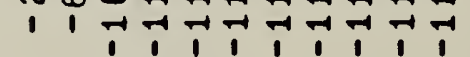

นก

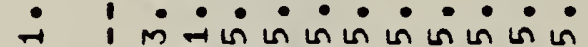

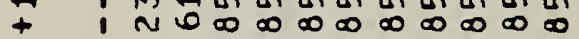

1111111,1111

$0 !$

- NANNNNNNNN

$+\quad$ i in un in in in in in in in

- 100000000000

- :

aิ

u

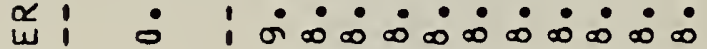

$-1, \quad 1 \quad N N N N N N N N N$

Iㄴ

3

?

- inNNanNNañN

un un un un un in in un un in in

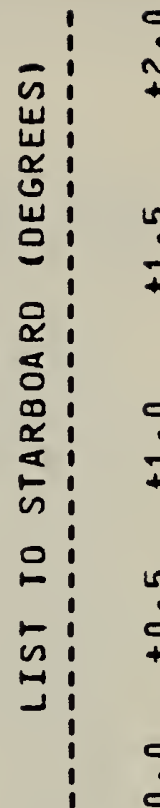

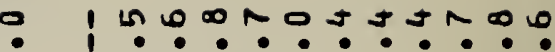
$\bullet \cdot \bullet \cdot \bullet \cdot \bullet \cdot \bullet \cdot \bullet$

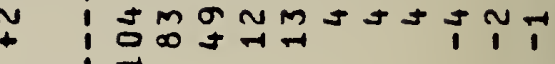
1

ก : $: 0=0+m M m a \infty n$

$\rightarrow \quad$ in $\dot{1} \dot{0} \dot{0} \dot{m} \dot{m} \dot{m} \dot{-1}:$

in $N$

1

0
+
+
0
+
0
0

0 O OMmN NNNm

$\bullet \bullet \bullet \bullet \bullet \bullet \cdot \bullet \cdot$

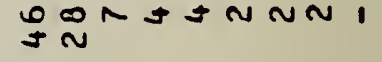

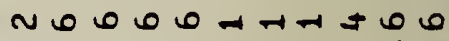
बin $\dot{4} \dot{4} \dot{4} \dot{4} \dot{4} \cdot \bullet$ $\rightarrow$

00000000000 - $\dot{10} \dot{0} \dot{0} \dot{0} \dot{0} \dot{0} \dot{0} \dot{0}$

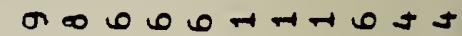

$\bullet \quad \bullet \cdot \bullet \cdot \bullet \cdot 1 \cdot \bullet$

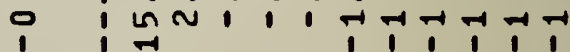

0

OHNMNNNNMNS

- $\bullet \cdot \bullet \cdot \bullet \cdot \bullet \cdot$ InNi $n N \cdots$

is: i

岁! 的

n 1 I $\infty N+M M M M O \sigma N$

- $\quad \dot{0} \dot{0} \dot{i} \dot{A} \dot{M} \dot{m} \dot{0} \dot{0}$

$\check{\alpha}$

$\frac{\alpha}{0}$

$\infty \pm \infty$

1.11: 1

$\begin{array}{l:l}\infty & \\ \Sigma & 0 \\ \simeq & 1\end{array}$

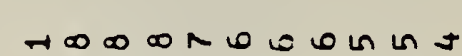

$\cdot \bullet \cdot \cdot \cdot \cdot \cdot \cdot \cdot \cdot \cdot \cdot$

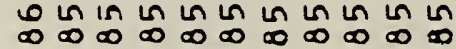

五

i

เ幺.

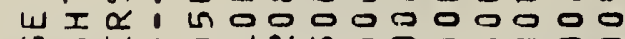

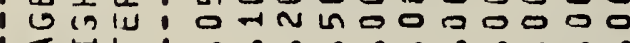
$1<n+1 \cdot \bullet \cdot \bullet \cdot \bullet \cdot \bullet \cdot \bullet$

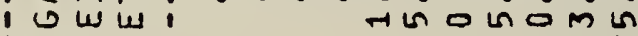
$I \sum$ :

$\rightarrow$ HN N 


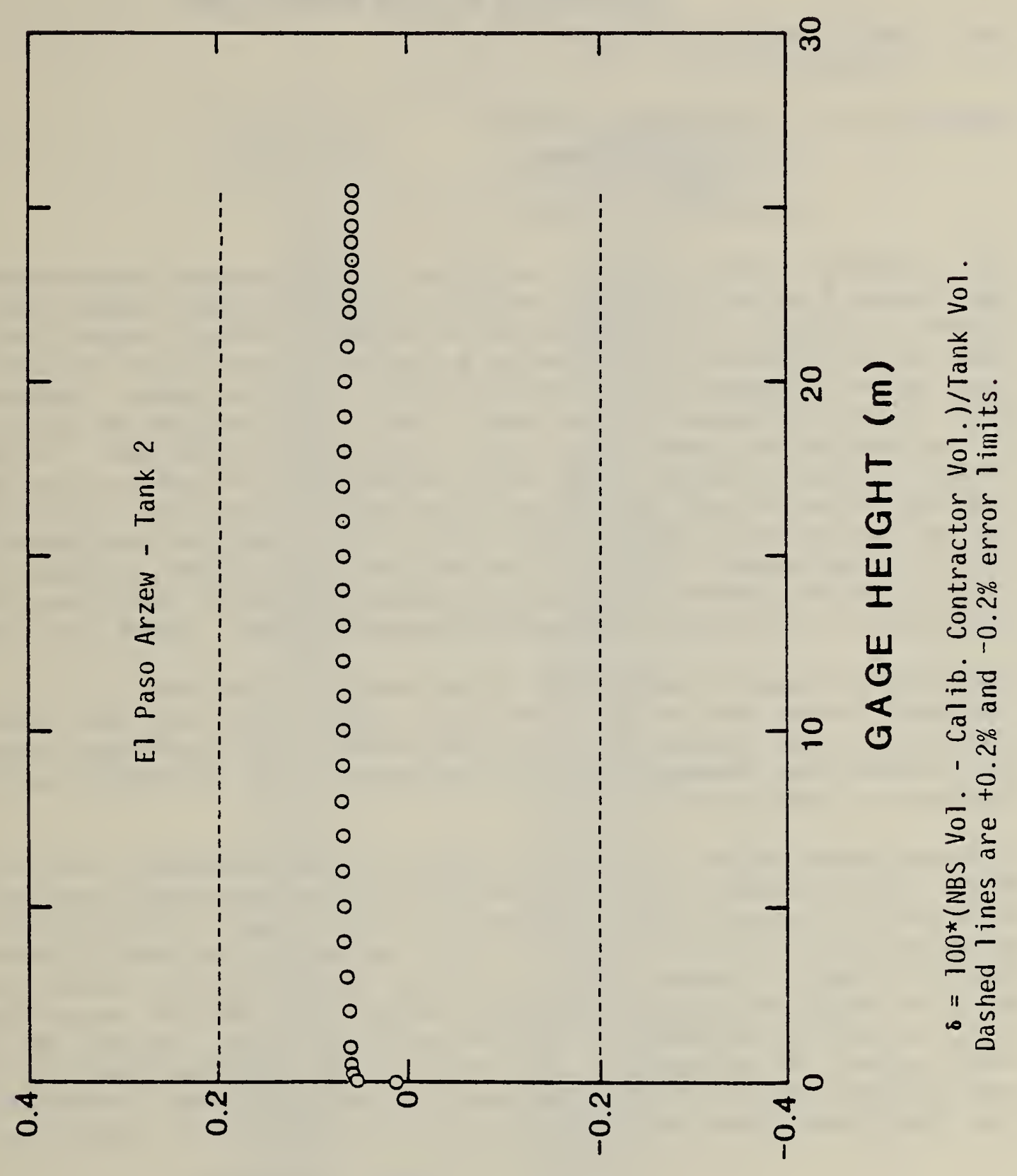

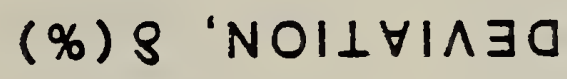




\section{REPORT OF CALIBRATION}

For: Tank $\equiv_{3} 3$ on the LNG Tanker

E1 Paso Arzew

Requested by: El Paso Marine Company

2919 Allen Parkway

P. 0. Box 1592

Houston, TX 77001

The following tables have been calculated from dimensional measurements on tank number 3 of the liquefied natural gas tanker El Paso Arzew while berthed at Newport News Shipbuilding and Drydock Company, Newport News, VA. These tables represent the volume of a liquid enclosed in the tank as a function of the height of the liquid surface, measured along a straight line, fixed with respect to the tank. This line is defined as being located at the longitudinal center line of the tank's capacitance gage. Secondary tables are also presented which allow correction of the main tables for specific angles of ship orientation with respect to gravity, as referred to the six sets of draft marks on the ship's hull. Both the measurement method and the computational algorithms are outlined in the paper "Multiple Redundancy in the Measurement of Large Structures," Annals of the International Institution of Production Engineering Research (CIRP), Volume 27/1, 1978 .

The tank was measured empty while at an average temperature of $23.5^{\circ} \mathrm{C}$. The tabulated volumes and the error estimates apply to the tank under these conditions. The volumes have also been corrected for the volume occupied by the corregations (deadwood) which was measured in the laboratory using a hydrostatic displacement technique.

The measurement method used includes geometrically redundant cross checks which allow assessment of the random error in the measurement process. For this tank, the total volume, excluding the vapor domes, was $27646.0 \mathrm{~m}^{3}$ with an uncertainty of $13.8 \mathrm{~m}^{3}(0.05 \%$ of total volume) at the three standard deviation limit of random error. Including an analysis of probable systematics by adding the absolute magnitude of the error sources, we estimate that the total uncertainty, at the $99 \%$ confidence level, is $+0.10 \%$ of the total volume. No estimates of the errors in the individual table entries are included, since without an estimate of the height error introduced by the liquid level gage such estimates would of necessity be incomplete.

For the Director,

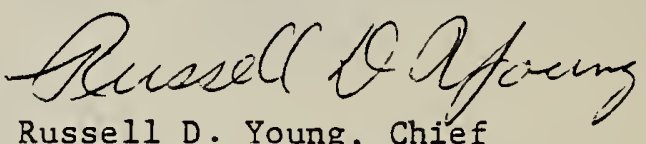

Russell D. Young, Chief Mechanical Processes Division Center for Mechanical Engineering and Process Technology 


\section{EL PASO ARZEW}

MAIN VOLUME VS. HEIGHT TABLE

TANK NO. 3

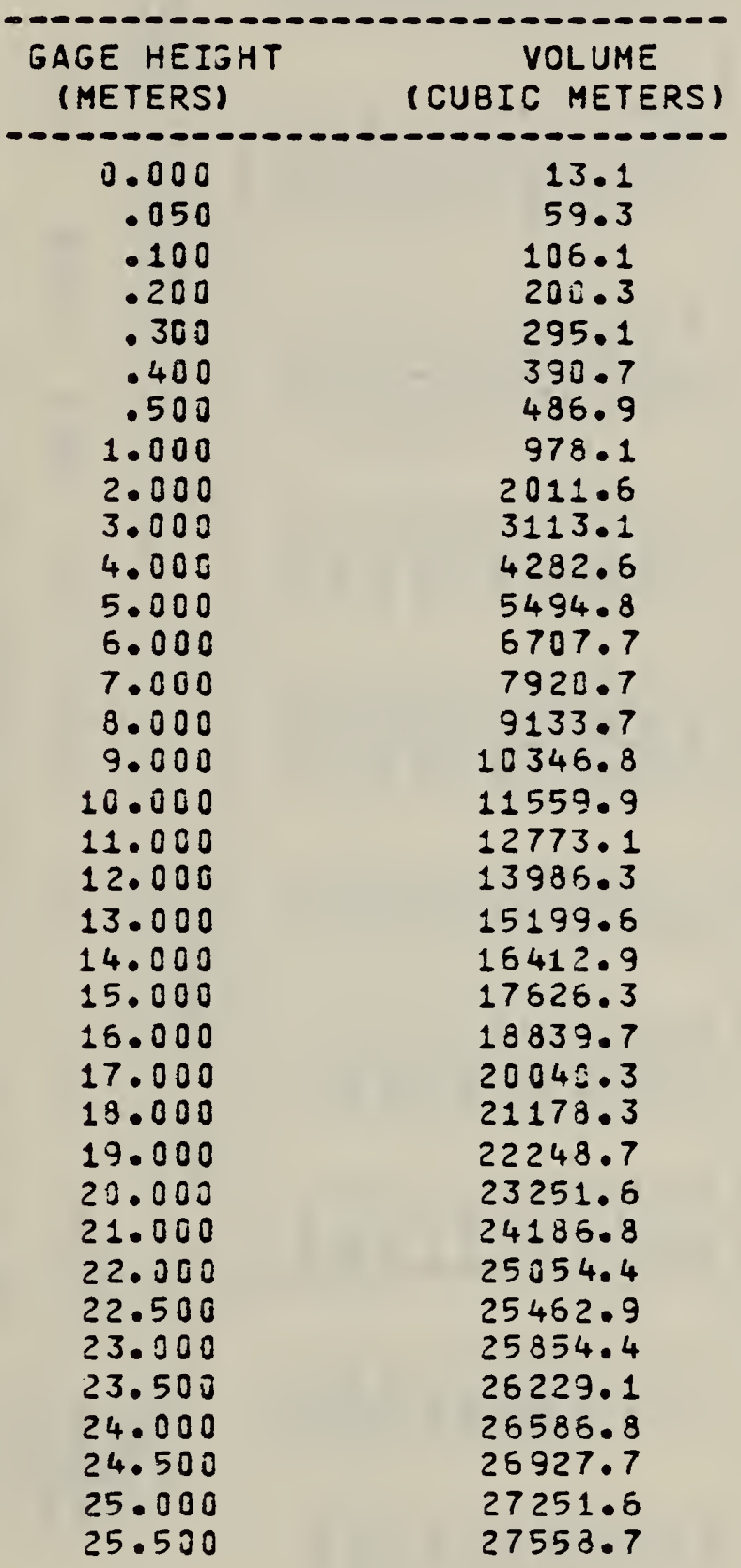


- imnNan anman i : $\dot{0} \dot{0} \dot{m} \dot{m} \dot{m} \dot{m} \dot{m} \dot{m} \dot{\sim}$

1 00000000000 00000000000

in :

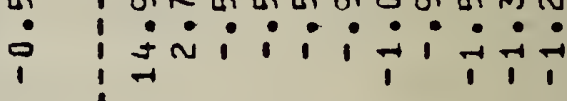

- iasnonomáasn

$i \quad j a m b$ in

In $: 0-\infty \wedge \sigma \infty \infty \infty \infty=\infty$ $\rightarrow \quad: \quad \dot{n} \dot{i} \dot{i} \dot{\sim} \dot{\sim} \dot{\sim} \dot{0}$ N inn $N$

$\stackrel{1}{0}$

0
0
5
$\sim$

$\stackrel{0}{i}$

$\infty \sim 0 \ln \infty \pi \infty m=n$

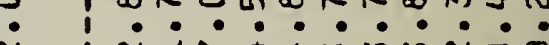
$\because \quad N-N N=J M M M O \sigma$ 0
0,0 is

เ幺: wIW, in 0000000000 , 0 G \& : vILI: - A 


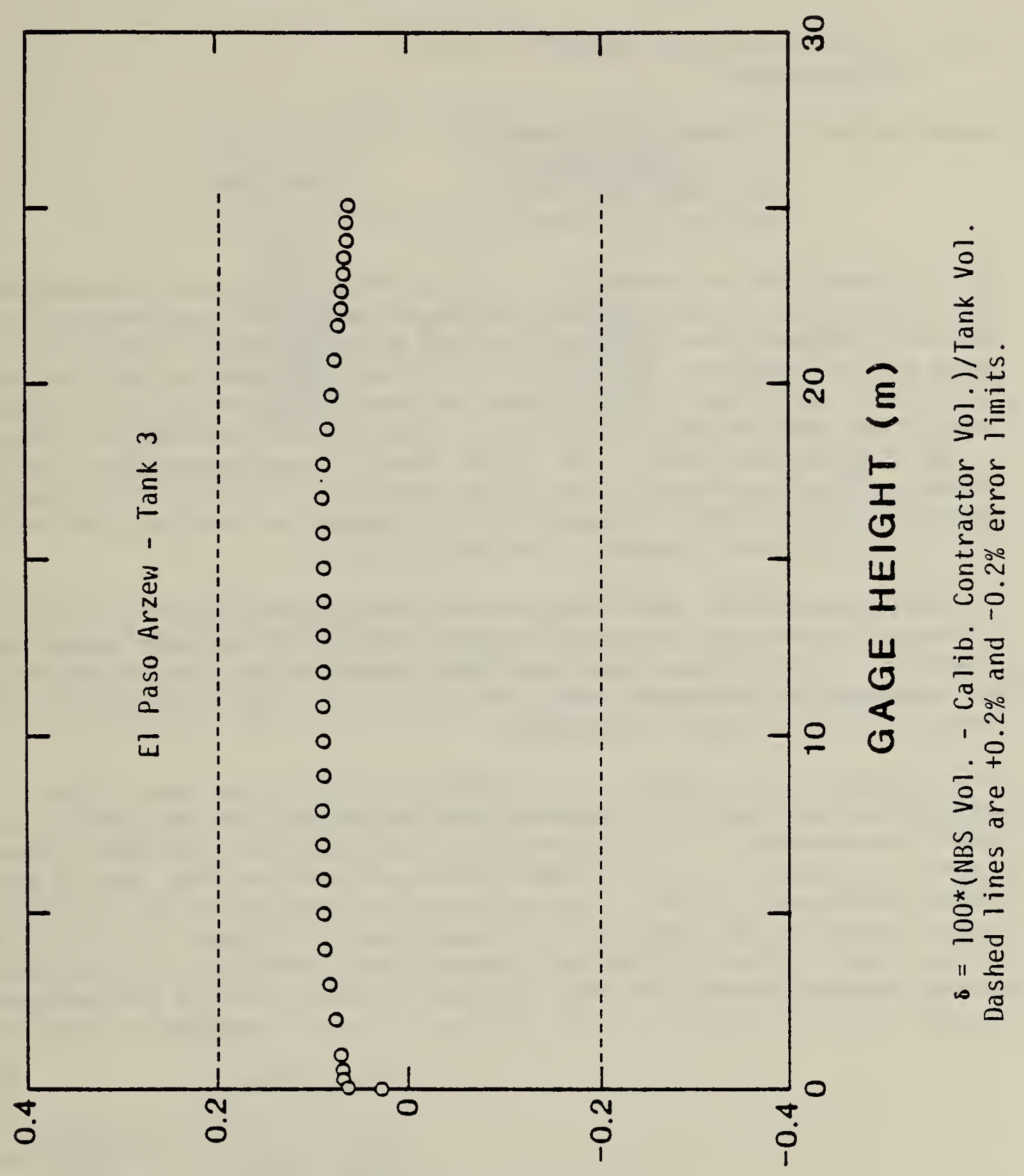

(\%) S 'NOIL $\forall I \wedge \exists O$ 


\section{U.S. DEPARTMENT OF COMMERCE \\ NATIONAL BUREAU OF STANDARDS \\ WASHINGTON, D.C. 20234}

\section{REPORT OF TEST}

For: Tank $\equiv 4$ on the LNG Tanker

El Paso Arzew

Requested by: El Paso Marine Company

2919 Allen Parkway

P. 0. Box 1592

Houston, TX 77001

The following tables have been calculated from dimensional measurements on tank number 4 of the liquefied natural gas tanker EI Paso Arzew while berthed at Newport News Shipbuilding and Drydock Company, Newport News, VA. These tables represent the volume of a liquid enclosed in the tank as a function of the height of the liquid surface, measured along a straight line, fixed with respect to the tank. This line is defined as being located at the longitudinal center line of the tank's capacitance gage. Secondary tables are also presented which allow correction of the main tables for specific angles of ship orientation with respect to gravity, as referred to the six sets of draft marks on the ship's hull.

The tank was measured empty while at an average temperature of $27.3^{\circ} \mathrm{C}$. The tabulated volumes and the error estimates apply to the tank under these conditions. The volumes have also been corrected for the volume occupied by the corregations (deadwood) which was measured in the laboratory using a hydrostatic displacement technique.

These tables are not based on a complete survey of the tank, since scaffolding necessary for complete interior access was not present at the time of measurement. As a consequence, geometrically redundant cross checks reported of tanks $1,2,3,5$, and 6 were not made on this tank to assess random measurement errors. The estimated uncertainty of the tables is instead based on the comparison of measurements on tanks $1,2,3,5$, and 6 against their respective nominal construction dimensions. These comparisons showed measured dimensions were in general within $0.2 \%$ of the nominals so an estimated uncertainty of $\pm 0.2 \%$ of total volume is assigned to the tables.

For the Director,

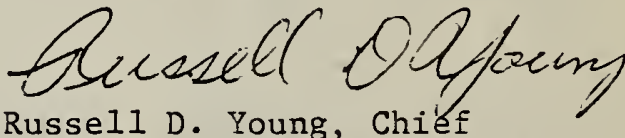

Russell D. Young, Chief

Mechanical Processes Division

Center for Mechanical Engineering and Process Technology

Date: August 16, 1979 


\section{EL PASO ARZEW}

MAIN VOLUME VS. HEIGHT TABLE

TANK NO. 4

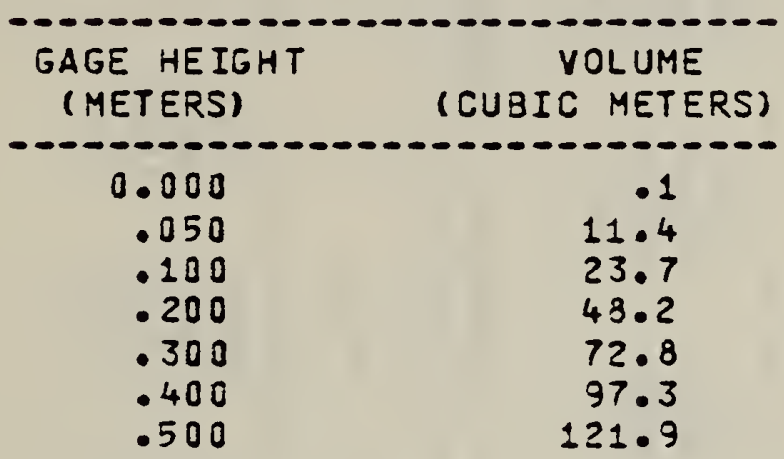




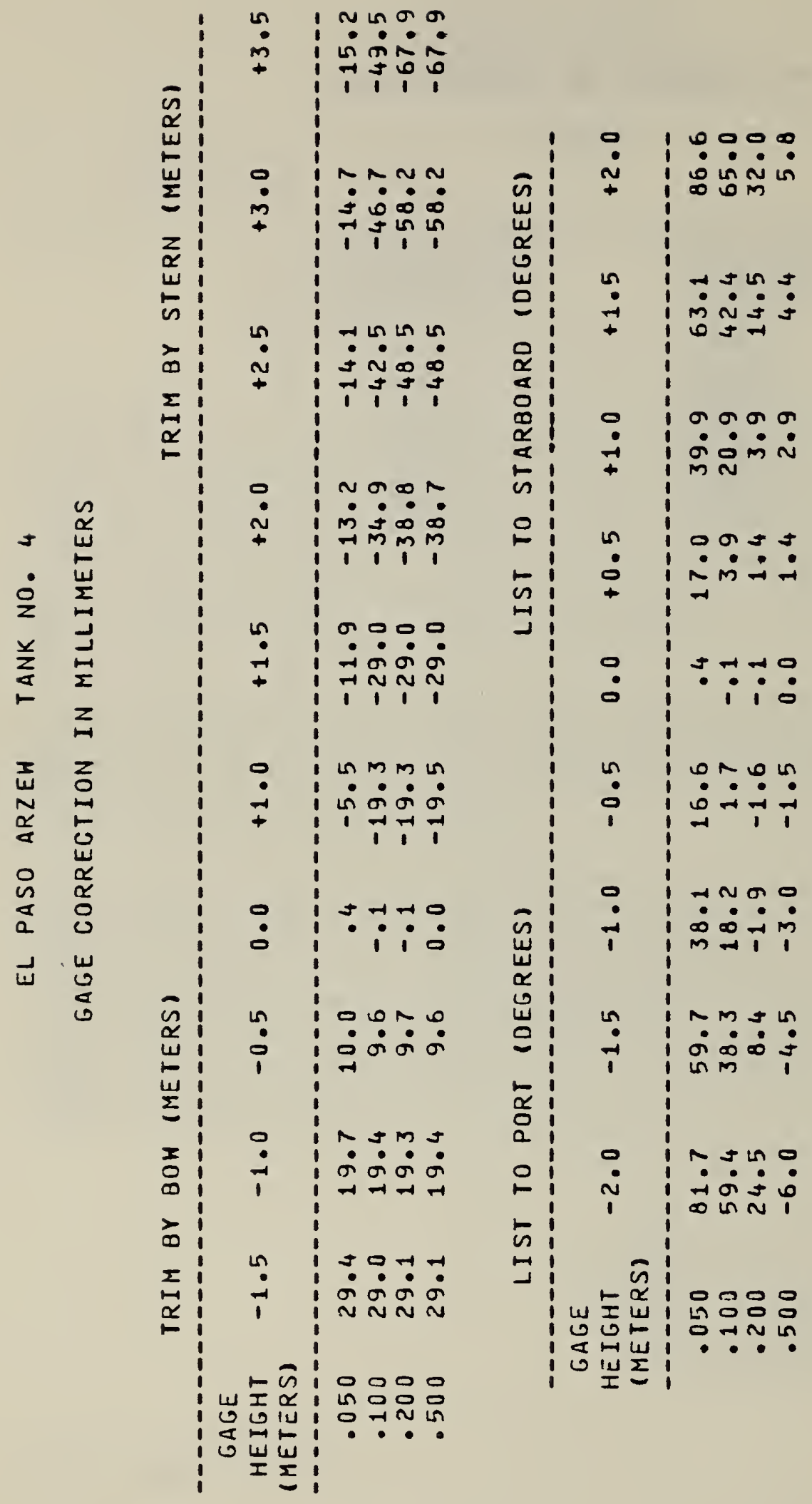




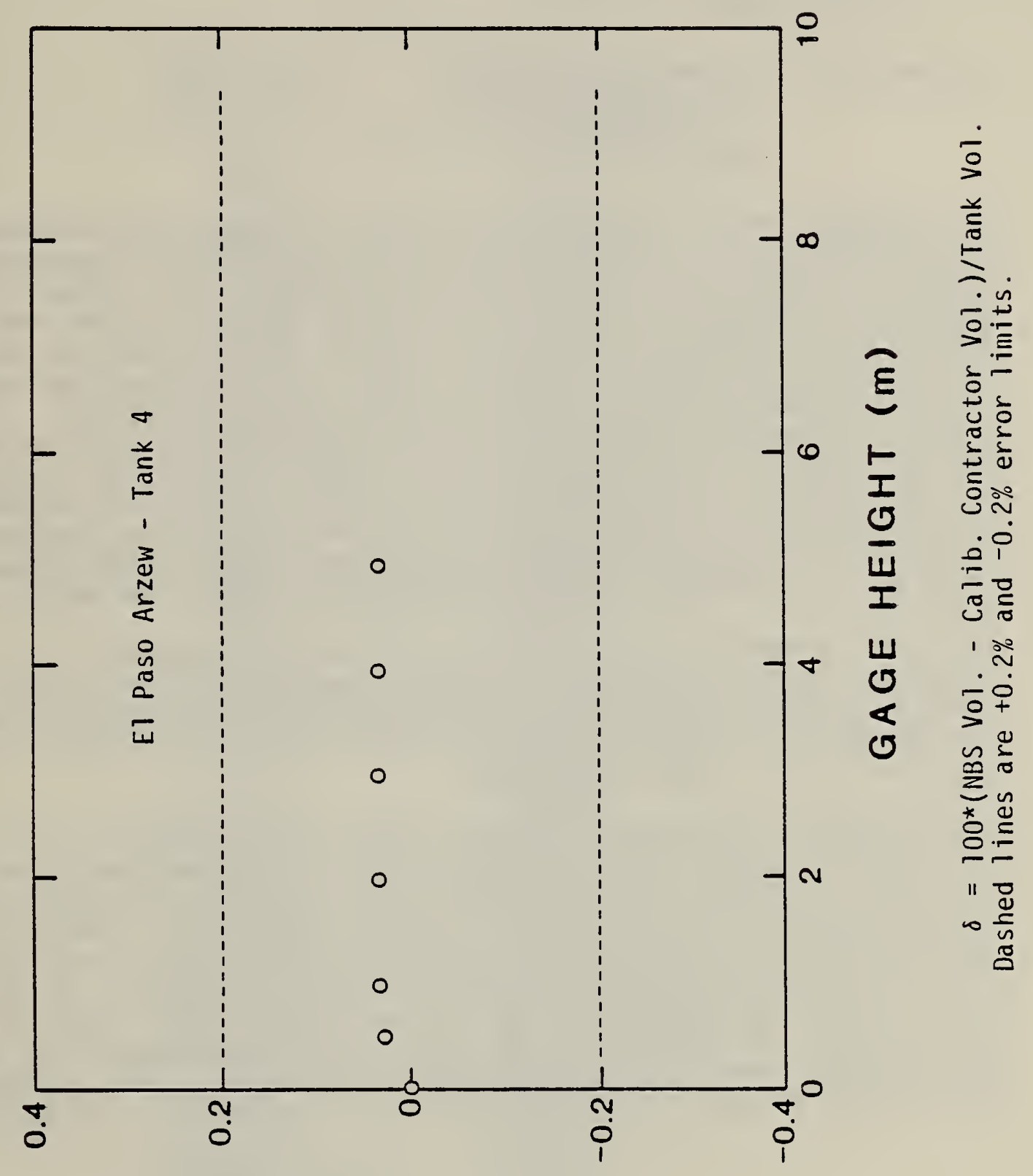

(\%) \& $N O I \perp \forall I \wedge \exists O$ 


\section{U.S. DEPARTMENT OF COMMERCE \\ NATIONAL BUREAU OF STANDARDS \\ WASHINGTON, D.C. 20234}

\section{REPORT OF CALIBRATION}

For: Tank $\$ 5$ on the LNG Tanker

El Paso Arzew

Requested by: E1 Paso Marine Company

2919 Allen Parkway

P. O. Box 1592

Houston, TX 77001

The following tables have been calculated from dimensional measurements on tank number 5 of the liquefied natural gas tanker EI Paso Arzew while berthed at Newport News Shipbuilding and Drydock Company, Newport News, VA. These tables represent the volume of a liquid enclosed in the tank as a function of the height of the liquid surface, measured along a straight line, fixed with respect to the tank. This line is defined as being located at the longitudinal center line of the tank's capacitance gage. Secondary tables are also presented which allow correction of the main tables for specific angles of ship orientation with respect to gravity, as referred to the six sets of draft marks on the ship's hull. Both the measurement method and the computational algorithms are outlined in the paper "Multiple Redundancy in the Measurement of Large Structures," Annals of the International Institution of Production Engineering Research (CIRP), Volume 27/1, 1978 .

The tank was measured empty while at an average temperature of $27.1^{\circ} \mathrm{C}$. The tabulated volumes and the error estimates apply to the tank under these conditions. The volumes have also been corrected for the volume occupied by the corregations (deadwood) which was measured in the laboratory using a hydrostatic displacement technique.

The measurement method used includes geometrically redundant cross checks which allow assessment of the random error in the measurement process, For this tank, the total volume, excluding the vapor domes, was $27622.9 \mathrm{~m}^{3}$ with an uncertainty of $13.8 \mathrm{~m}^{3}(0.05 \%$ of total volume) at the three standard deviation limit of random error. Including an analysis of probable systematics by adding the absolute magnitude of the error sources, we estimate that the total uncertainty, at the $99 \%$ confidence level, is $+0.10 \%$ of the total volume. No estimates of the errors in the individual table entries are included, since without an estimate of the height error introduced by the liquid level gage such estimates would of necessity be incomplete.

For the Director,

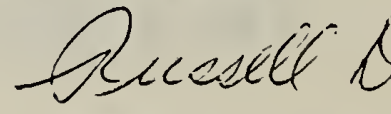

Russel1 D. Young, Chief

Mechanical Processes Division

Center for Mechanical Engineering and Process Technology 


\section{EL PASO ARZEW}

MAIN VOLUME VS. HEIGHT TABLE

TANK NO. 5

\begin{tabular}{|c|c|}
\hline $\begin{array}{l}\text { GAGE HEISHT } \\
\text { (METERS) }\end{array}$ & $\begin{array}{c}\text { VOLUME } \\
\text { (CUBIC METERS) }\end{array}$ \\
\hline----- & $+-\infty-\infty-\infty,-\infty$, \\
\hline $\begin{array}{r}0.000 \\
.050\end{array}$ & $\begin{array}{l}14.4 \\
59.7\end{array}$ \\
\hline $\begin{array}{l}.100 \\
.200\end{array}$ & $\begin{array}{l}106 \cdot 5 \\
200.8\end{array}$ \\
\hline $\begin{array}{l}.300 \\
.400 \\
.500\end{array}$ & $\begin{array}{l}295.7 \\
391.3 \\
487.5\end{array}$ \\
\hline $\begin{array}{l}1.000 \\
2.000 \\
3.000\end{array}$ & $\begin{array}{r}979.0 \\
2012.8 \\
3114.2\end{array}$ \\
\hline $\begin{array}{l}4.000 \\
5.000 \\
6.000\end{array}$ & $\begin{array}{l}4283.3 \\
5495.1 \\
6707.6\end{array}$ \\
\hline $\begin{array}{l}7.000 \\
8.000 \\
9.000\end{array}$ & $\begin{array}{r}7920.2 \\
9132.7 \\
10345.2\end{array}$ \\
\hline $\begin{array}{l}10.000 \\
11.000 \\
12.000\end{array}$ & $\begin{array}{l}11557.8 \\
12770.3 \\
13982.9\end{array}$ \\
\hline $\begin{array}{l}13.000 \\
14.000 \\
15.000\end{array}$ & $\begin{array}{l}15195.5 \\
16408.1 \\
17623.7\end{array}$ \\
\hline $\begin{array}{l}16.000 \\
17.000 \\
18.000\end{array}$ & $\begin{array}{l}18833.4 \\
20033.0 \\
21173.0\end{array}$ \\
\hline $\begin{array}{l}19.000 \\
20.000 \\
21.000\end{array}$ & $\begin{array}{l}22239.2 \\
23243.9 \\
24174.9\end{array}$ \\
\hline $\begin{array}{l}22.000 \\
22.500 \\
23.000\end{array}$ & $\begin{array}{l}25041.3 \\
25449.1 \\
25840.0\end{array}$ \\
\hline $\begin{array}{l}23.500 \\
24.000 \\
24.500\end{array}$ & $\begin{array}{l}26214 \cdot 0 \\
26571 \cdot 1 \\
26911 \cdot 3\end{array}$ \\
\hline $\begin{array}{l}25.000 \\
25.500\end{array}$ & $\begin{array}{l}27234.5 \\
27540.9\end{array}$ \\
\hline
\end{tabular}



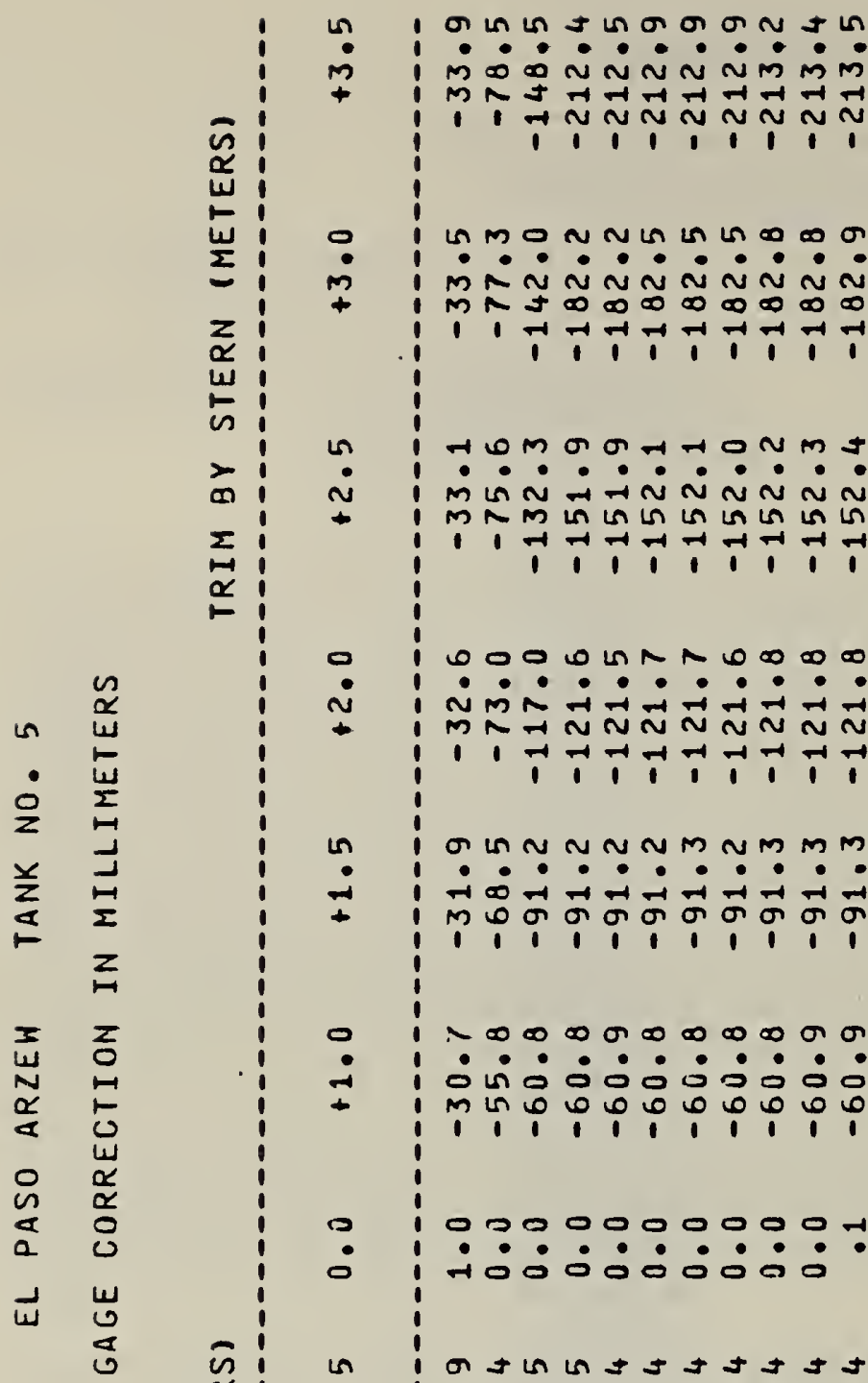

-

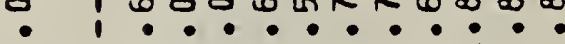

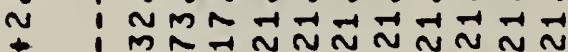

1 - त्रतन त्रतन त्रत्र

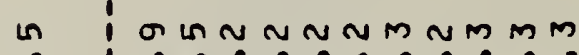

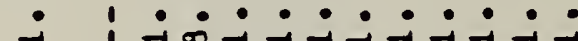

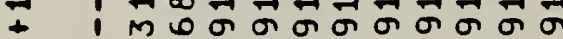

$1,1,1,1,1,1$

- $\quad-\infty \infty \infty \sigma \infty \infty \infty \pi \sigma a$

- í: $\dot{0} \dot{0} \dot{0} \dot{0} \dot{0} \dot{0} \dot{0}$

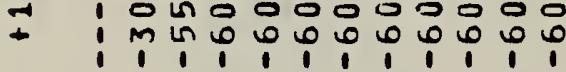

- : 100000000004

: 1 i

$\tilde{\sim}$

$\underset{\alpha}{\omega}$

w

L i i.

- $\quad$ i $M M M M M M M M M M$

$\Sigma$

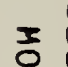

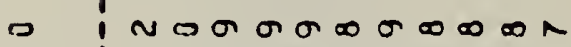

$\cdot 1 \cdot \bullet \cdot \bullet \cdot \bullet \cdot \bullet \cdot$

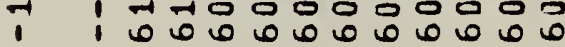

$>$ ! !

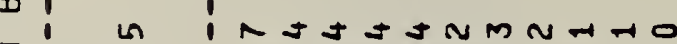

ᄂ)

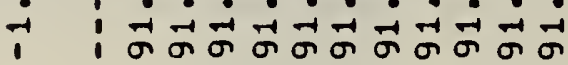

$\stackrel{1}{\leftarrow}$

เ

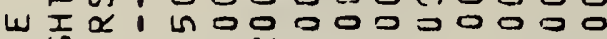

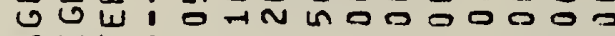
\&

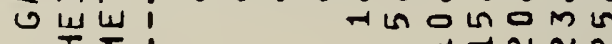
$\rightarrow \neg n \sim N$ 


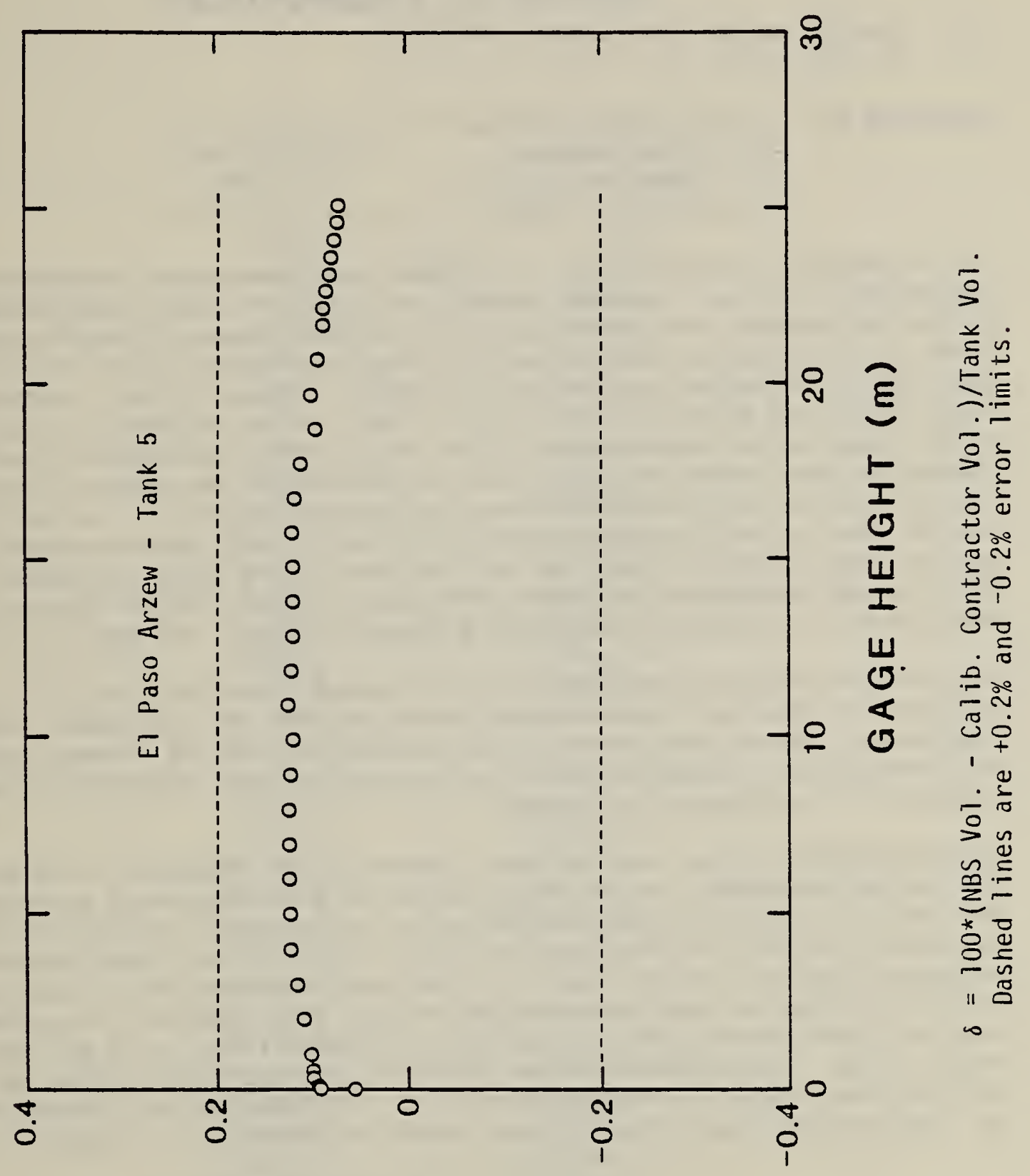

(\%) S 'NOIL $\forall I \wedge \exists O$ 


\section{U.S. DEPARTMENT OF COMMERCE \\ NATIONAL BUREAU OF STANDARDS \\ WASHINGTON, D.C. 20234}

\section{REPORT OF CALIBRATION}

For: Tank 非 6 on the LNG Tanker

El Paso Arzew

Requested by: El Paso Marine Company

2919 Allen Parkway

P. 0. Box 1592

Houston, TX 77001

The following tables have been calculated from dimensional measurements on tank number 6 of the liquefied natural gas tanker E1 Paso Arzew while berthed at Newport News Shipbuilding and Drydock Company, Newport News, VA. These tables represent the volume of a liquid enclosed in the tank as a function of the height of the liquid surface, measured along a straight line, fixed with respect to the tank. This line is defined as being located at the longitudinal center line of the tank's capacitance gage. Secondary tables are also presented which allow correction of the main tables for specific angles of ship orientation with respect to gravity, as referred to the six sets of draft marks on the ship's hull. Both the measurement method and the computational algorithms are outlined in the paper "Multiple Redundancy in the Measurement of Large Structures," Annals of the International Institution of Production Engineering Research (CIRP), Volume 27/1, 1978 .

The tank was measured empty while at an average temperature of $29.0^{\circ} \mathrm{C}$. The tabulated volumes and the error estimates apply to the tank under these conditions. The volumes have also been corrected for the volume occupied by the corregations (deadwood) which was measured in the laboratory using a hydrostatic displacement technique.

The measurement method used includes geometrically redundant cross checks which allow assessment of the random error in the measurement process; For this tank, the total volume, excluding the vapor domes, was $27639.1 \mathrm{~m}^{3}$ with an uncertainty of $13.8 \mathrm{~m}^{3}$ ( $0.05 \%$ of total volume) at the three standard deviation limit of random error. Including an analysis of probable systematics by adding the absolute magnitude of the error sources, we estimate that the total uncertainty, at the $99 \%$ confidence level, is $\pm 0.10 \%$ of the total volume. No estimates of the errors in the individual table entries are included, since without an estimate of the height error introduced by the liquid level gage such estimates would of necessity be incomplete.

For the Director,

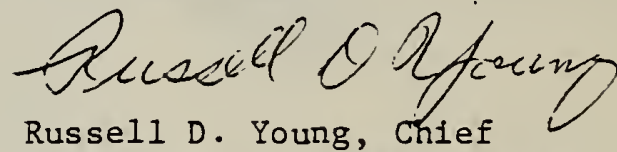

Mechanical Processes Division

Center for Mechanical Engineering and Process Technology

Date: August 16, 1979 
EL PASO ARZEH

MAIN VOLUME VS. HEIGHT TABLE

TANK NO. 6

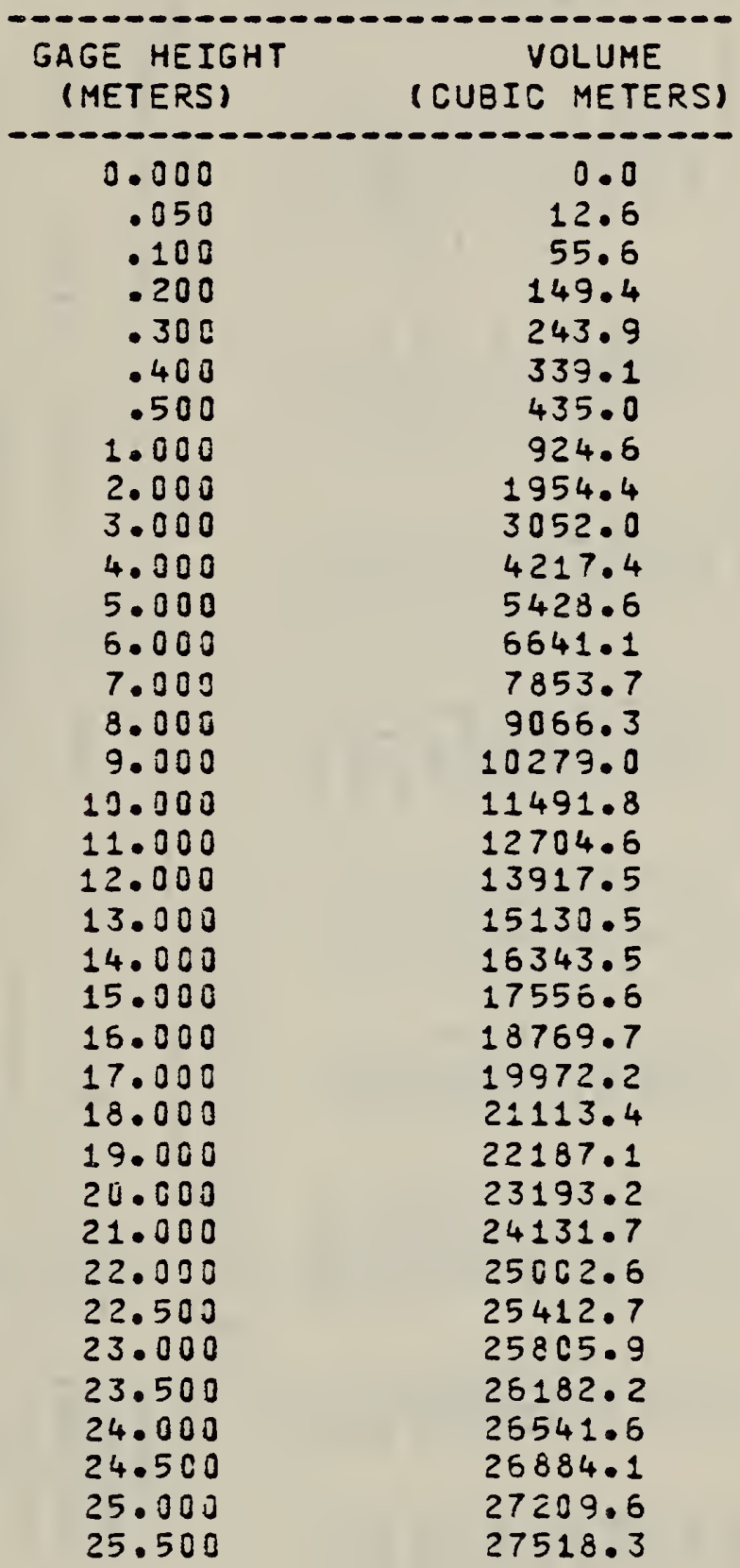




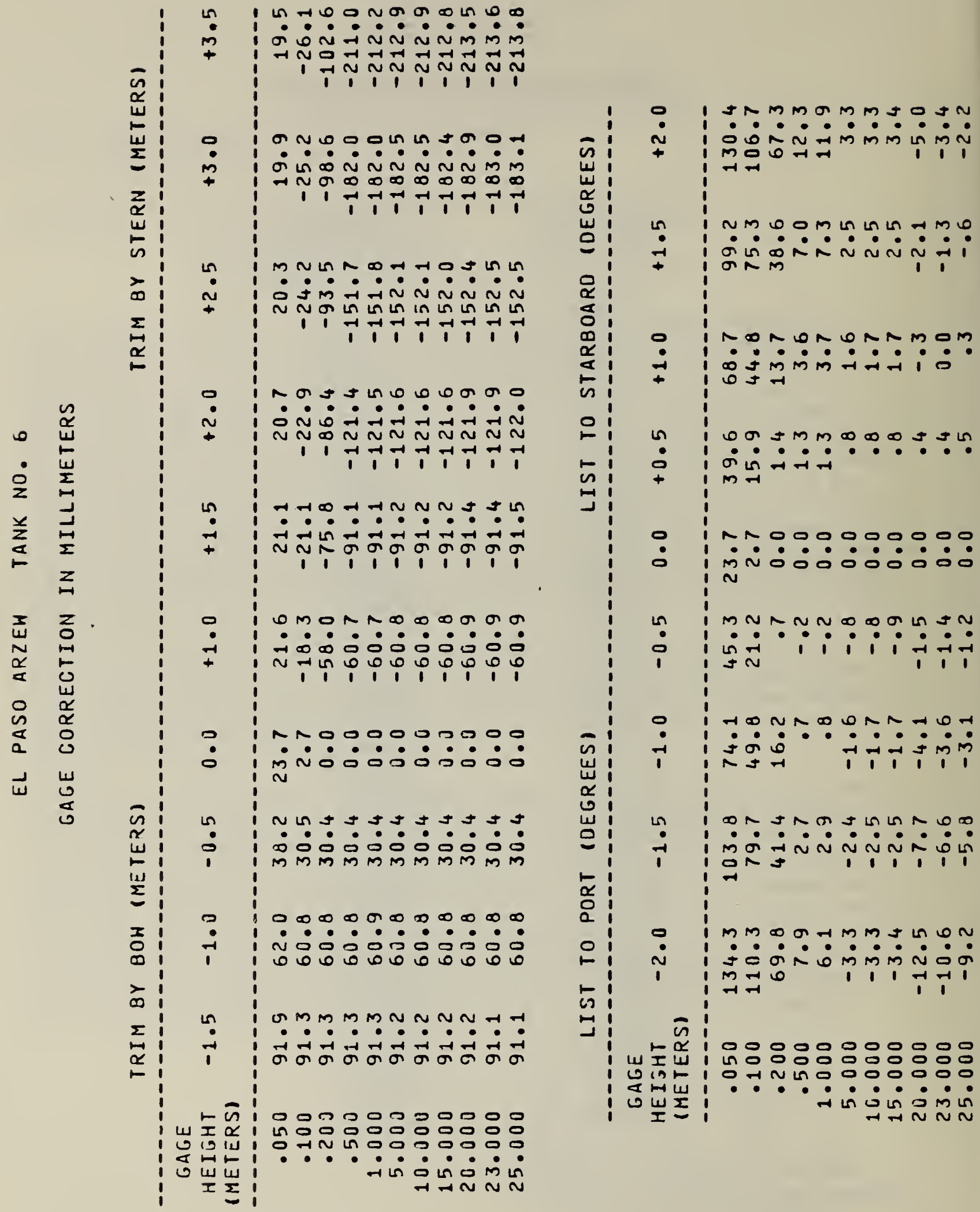




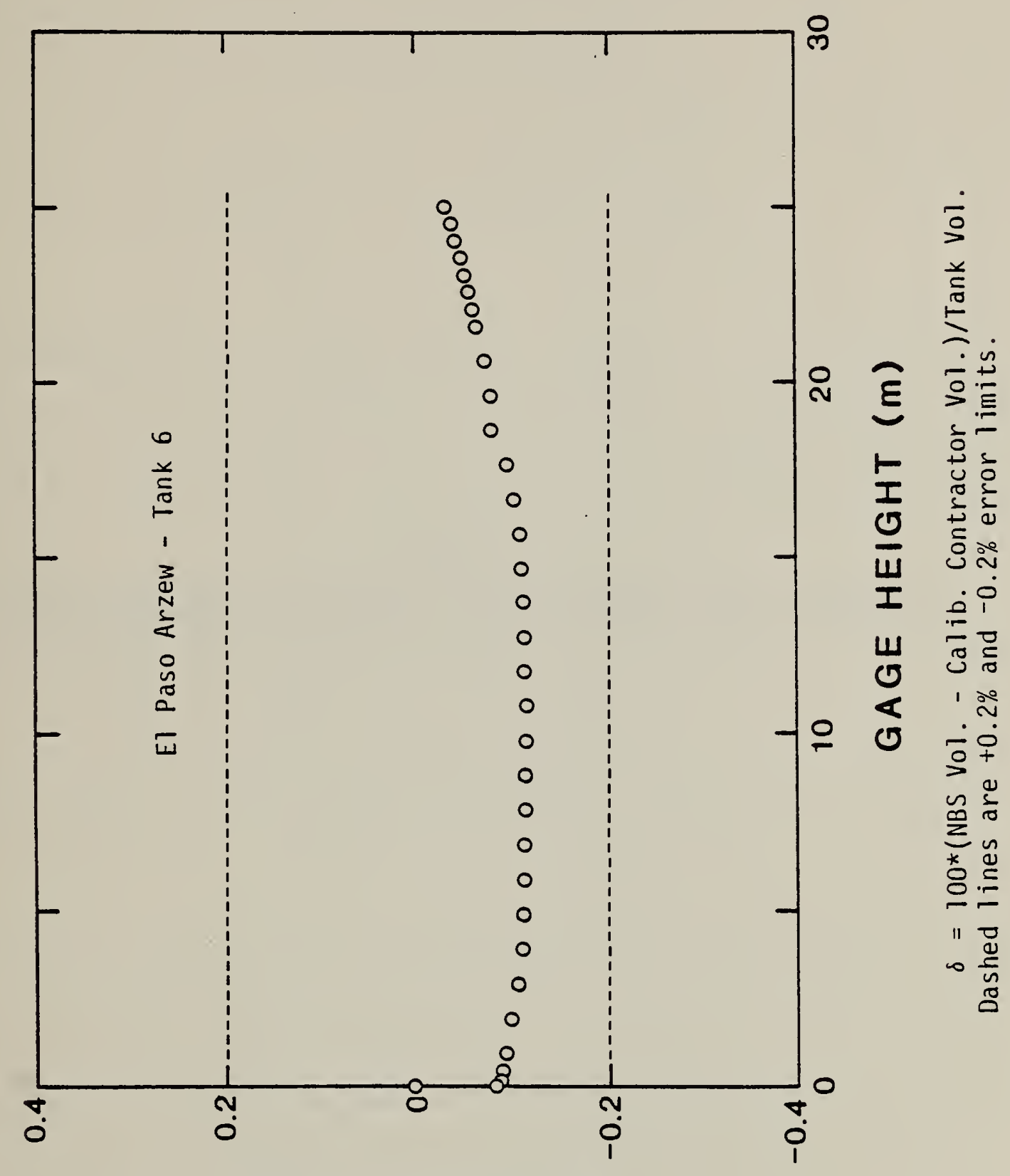

(\%) S ' $N O I \perp \forall I \wedge \exists O$ 



\section{Appendix C}

Calibration Reports for the Six Tanks of the El Paso Howard Boyd 


\section{REPORT OF CALIBRATION}

For: Tank \# I on the ING Tanker

EI Paso Howard Boyd

Requested by: El Paso Marine Company

2919 Allen Parkway

P. 0. Box 1592

Houston, TX 77001

The following tables have been calculated from dimensional measurements on tank number 1 of the liquefied natural gas tanker El Paso Howard Boyd while berthed at Newport News Shipbuilding and Drydock Company, Newport News, VA. These tables represent the volume of a liquid enclosed in the tank as a function of the height of the liquid surface, measured along a straight line, fixed with respect to the tank. This line is defined as being located at the longitudinal center line of the tank's capacitance gage. Secondary tables are also presented which allow correction of the main tables for specific angles of ship orientation with respect to gravity, as referred to the six sets of draft marks on the ship's hull. Both the measurement method and the computational algorithms are outlined in the paper "Multiple Redundancy in the Measurement of Large Structures," Annals of the International Institution of Production Engineering Research (CIRP), Volume 27/1, 1978 .

The tank was measured empty while at an average temperature of $22.6^{\circ} \mathrm{C}$. The tabulated volumes and the error estimates apply to the tank under these conditions. The volumes have also been corrected for the volume occupied by the corregations (deadwood) which was measured in the laboratory using a hydrostatic displacement technique.

The measurement method used includes geometrically redundant cross checks which allow assessment of the random error in the measurement process, For this tank, the total volume, excluding the vapor domes, was $12554.3 \mathrm{~m}^{3}$ with an uncertainty of $6.3 \mathrm{~m}^{3}(0.05 \%$ of total volume) at the three standard deviation limit of random error. Including an analysis of probable systematics by adding the absolute magnitude of the error sources, we estimate that the total uncertainty, at the $99 \%$ confidence level, is $\pm 0.10 \%$ of the total volume. No estimates of the errors in the individual table entries are included, since without an estimate of the height error introduced by the liquid level gage such estimates would of necessity be incomplete.

For the Director,

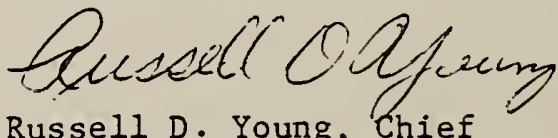

Russe11 D. Young, Chief Mechanical Processes Division Center for Mechanical Engineering and Process Technology 


\section{EL PASO HOWARD BOYD}

MAIN VOLUME VS. HEIGHT TABLE

TANK NO. 1

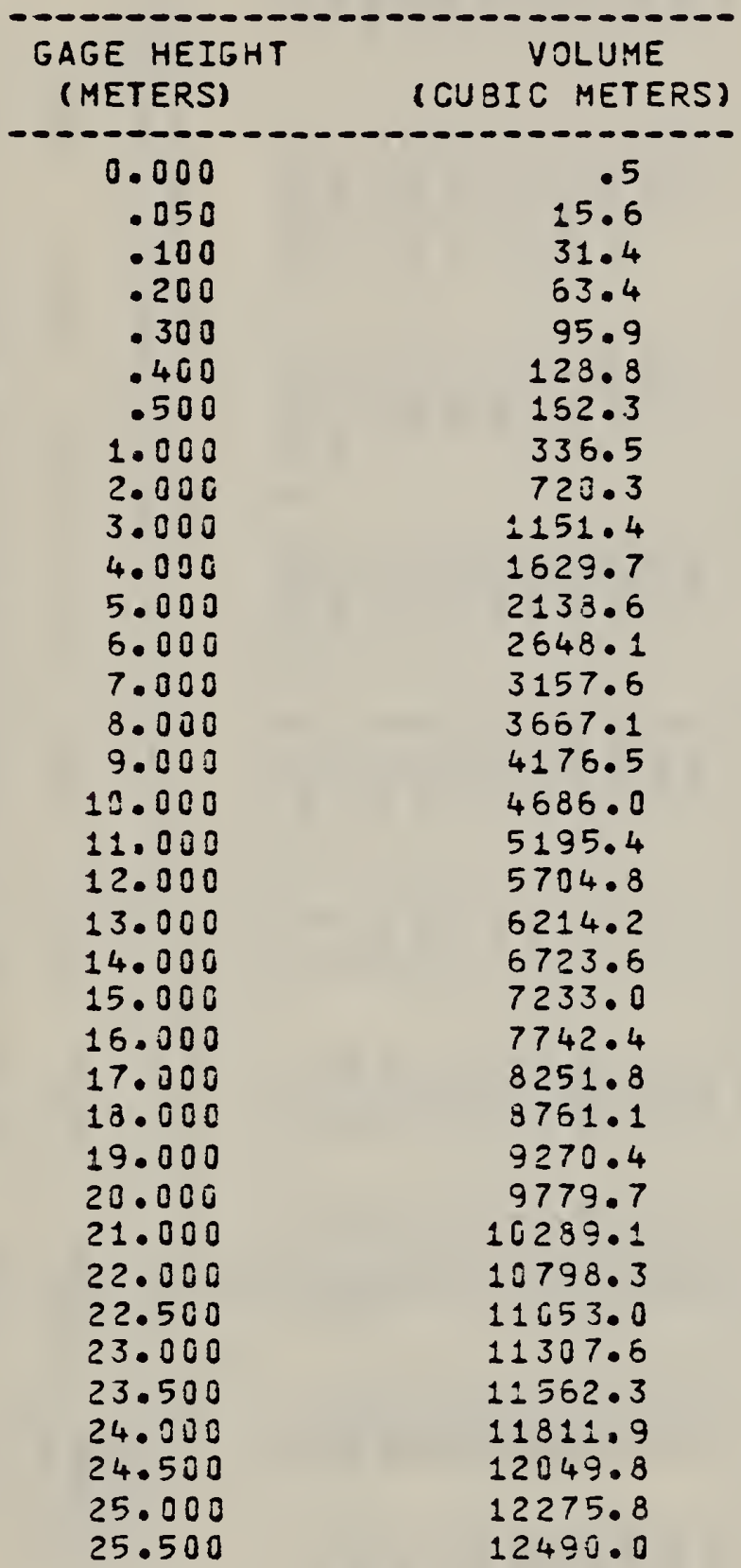




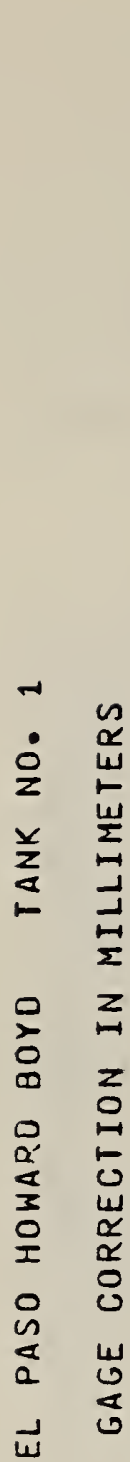

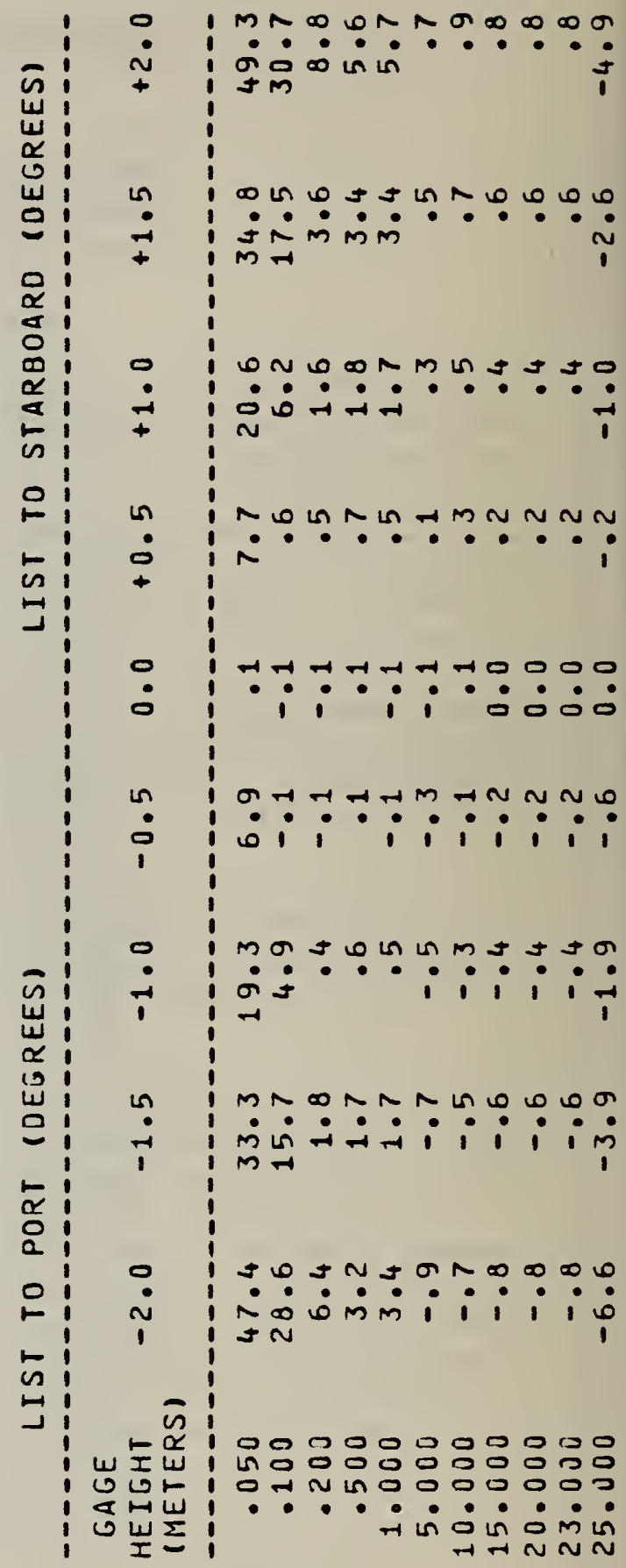




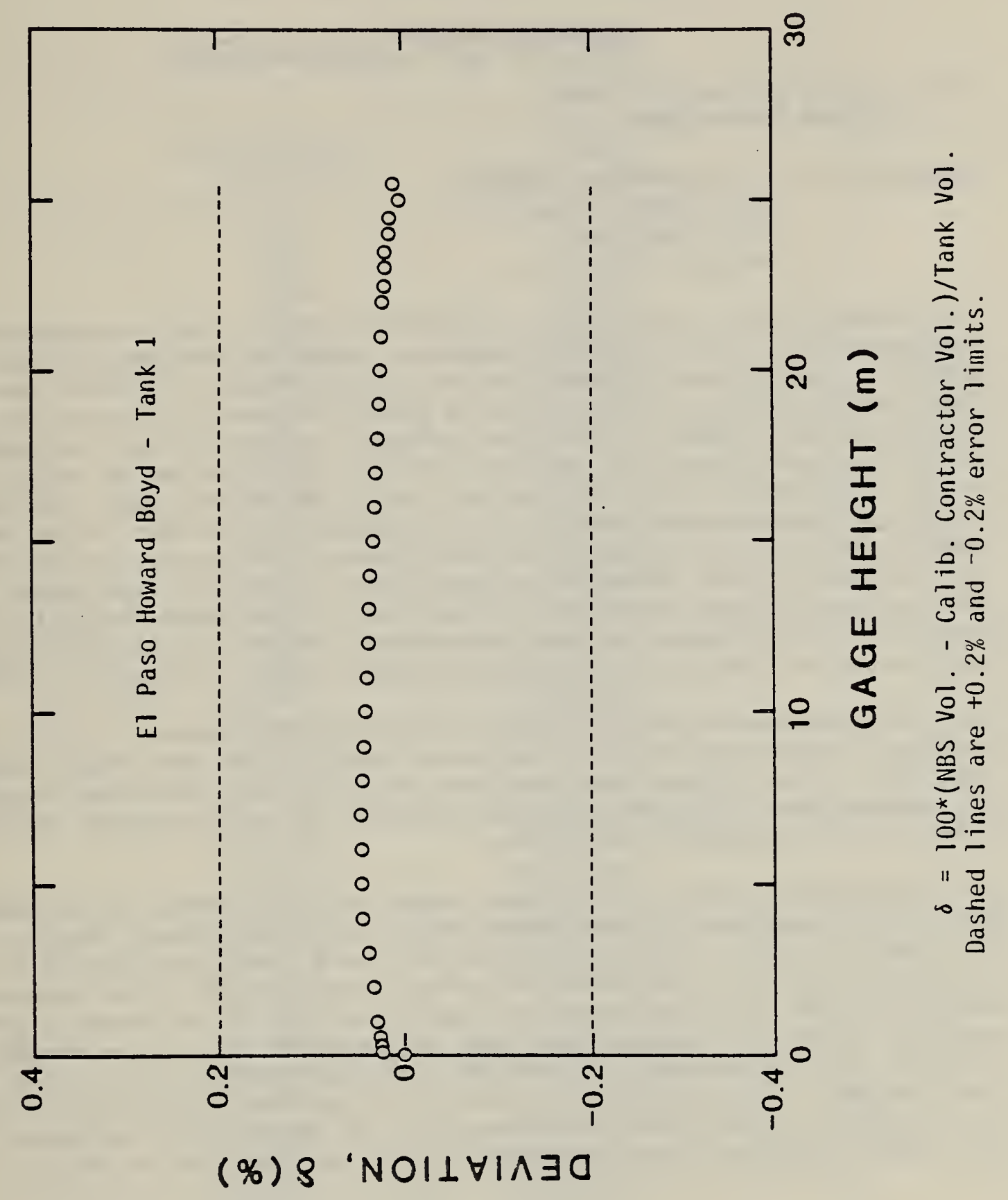




\section{REPORT OF CALIBRATION}

For: Tank 非 2 on the LNG Tanker El Paso Howard Boyd

Requested by: El Paso Marine Company

2919 Allen Parkway

P. 0. Box 1592

Houston, TX 77001

The following tables have been calculated from dimensional measurements on tank number 2 of the liquefied natural gas tanker El Paso Howard Boyd while berthed at Newport News Shipbuilding and Drydock Company, Newport News, VA. These tables represent the volume of a liquid enclosed in the tank as a function of the height of the liquid surface, measured along a straight line, fixed with respect to the tank. This line is defined as being located at the longitudinal center line of the tank's capacitance gage. Secondary tables are also presented which allow correction of the main tables for specific angles of ship orientation with respect to gravity, as referred to the six sets of draft marks on the ship's hull. Both the measurement method and the computational algorithms are outlined in the paper "Multiple Redundancy in the Measurement of Large Structures," Annals of the International Institution of Production Engineering Research (CIRP), Volume 27/1, 1978 .

The tank was measured empty while at an average temperature of $15.2^{\circ} \mathrm{C}$. The tabulated volumes and the error estimates apply to the tank under these conditions. The volumes have also been corrected for the volume occupied by the corregations (deadwood) which was measured in the laboratory using a hydrostatic displacement technique.

The measurement method used includes geometrically redundant cross checks which allow assessment of the random error in the measurement process 3 For this tank, the total volume, excluding the vapor domes, was $24844.4 \mathrm{~m}^{3}$ with an uncertainty of $12.4 \mathrm{~m}^{3}(0.05 \%$ of total volume) at the three standard deviation limit of random error. Including an analysis of probable systematics by adding the absolute magnitude of the error sources, we estimate that the total uncertainty, at the $99 \%$ confidence level, is $\pm 0.10 \%$ of the total volume. No estimates of the errors in the individual table entries are included, since without an estimate of the height error introduced by the liquid level gage such estimates would of necessity be incomplete.

For the Director,

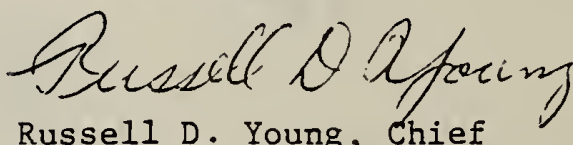

Russell D. Young, Chief Mechanical Processes Division Center for Mechanical Engineering and Process Technology 


\section{EL PASO HOWARO BOYO}

MAIN VOLUME VS. HEIGHT TABLE

TANK NO. 2

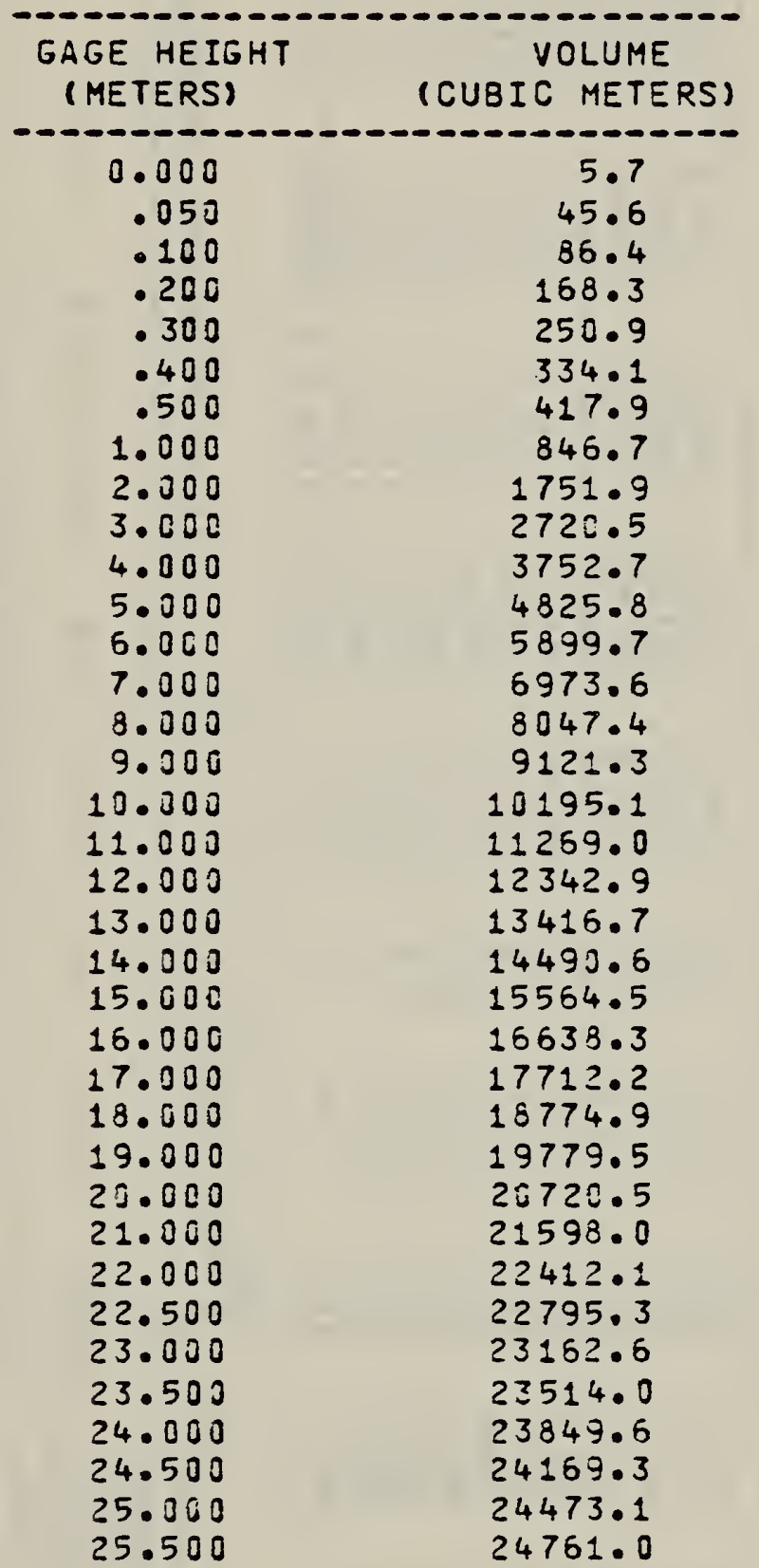




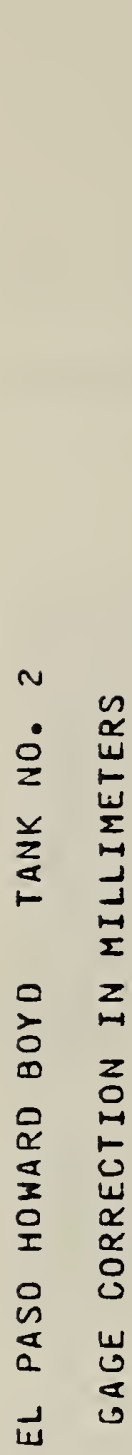

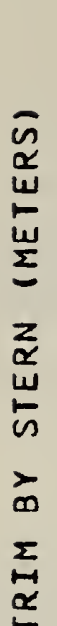

In 1 ก $\bullet \bullet \cdot \bullet \cdot \bullet \cdot \bullet \cdot \bullet$ त

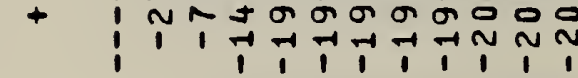

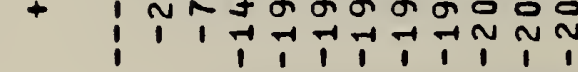

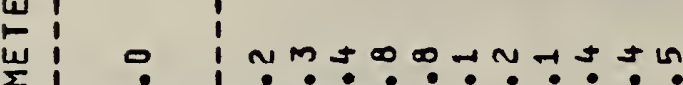

- i vo.

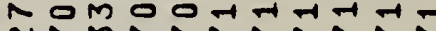
$N \wedge M \wedge \wedge \sim \wedge \wedge \sim \wedge \wedge$

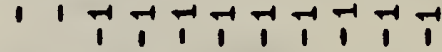

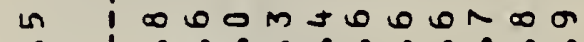

$\dot{\sim} \quad: \dot{0} \dot{0} \dot{\sim} \dot{\sim} \dot{\sim} \dot{\sim} \dot{\sim} \dot{\sim}$ n $11 \overrightarrow{1}+\overrightarrow{1}+\overrightarrow{1} \overrightarrow{1} \overrightarrow{1}$

- INOJ0a-1

$\bullet \bullet \cdot \bullet \cdot \bullet \cdot 1 \cdot$ ค

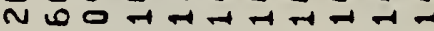

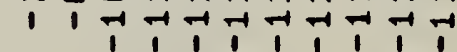

in $\quad$ in

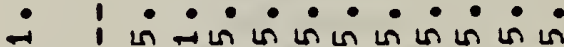
$N \infty \infty \infty_{\infty}^{\infty} \infty \infty_{\infty}^{\infty} \infty \infty_{\infty}^{\infty} \infty \infty_{\infty}^{\infty}$ 11111111111

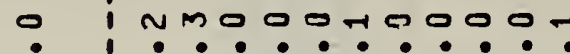

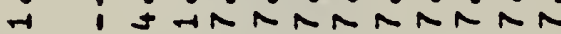
$N$ in in in in in in in un in in $1,1,1,1,1,1$

: : : 0 000000000

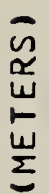

in 1 in in - $\quad \dot{\infty} \dot{\infty} \dot{\infty} \dot{\infty} \dot{\infty} \dot{\infty} \dot{\infty} \dot{\infty} \dot{\infty}$ $\sim \sim N \sim N N N N N$

$0 \quad 1-4-H+000$ or 0 -1 in 1 in in in in in in in in in in in

$>$

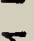

in : in

- 1.

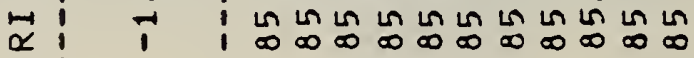
-

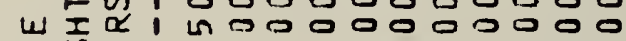
जUw: otn in 0000000 开

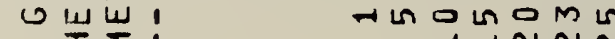
$\rightarrow \sim N N$ N 


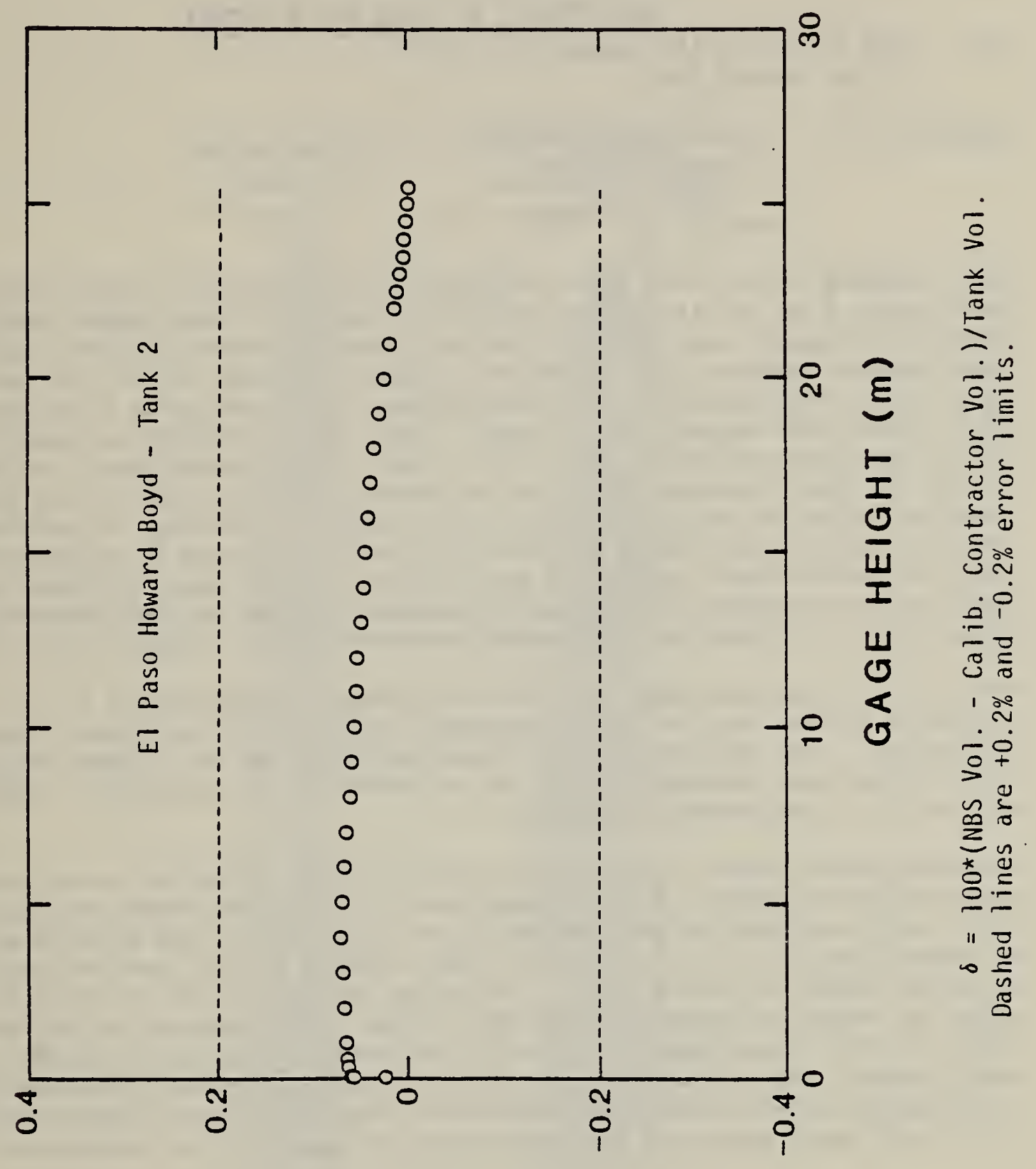

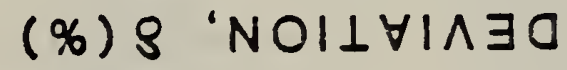




\section{U.S. DEPARTMENT OF COMMERCE \\ NATIONAL BUREAU OF STANDARDS \\ WASHINGTON, O.C. 20024}

For: Tank 非 3 on the LNG Tanker

El Paso Howard Boyd

Requested by: El Paso Marine Company

2919 Allen Parkway

P. 0. Box 1592

Houston, IX 77001

The following tables have been calculated from dimensional measurements on tank number 3 of the liquefied natural gas tanker El Paso Howard Boyd while berthed at Newport News Shipbuilding and Drydock Company, Newport News, VA. These tables represent the volume of a liquid enclosed in the tank as a function of the height of the liquid surface, measured along a straight line, fixed with respect to the tank. This line is defined as being located at the longitudinal center line of the tank's capacitance gage. Secondary tables are also presented which allow correction of the main tables for specific angles of ship orientation with respect to gravity, as referred to the six sets of draft marks on the ship's hull. Both the measurement method and the computational algorithms are outlined in the paper "Multiple Redundancy in the Measurement of Large Structures," Annals of the International Institution of Production Engineering Research (CIRP), Volume 27/1, 1978 .

The tank was measured empty while at an average temperature of $15.0^{\circ} \mathrm{C}$. The tabulated volumes and the error estimates apply to the tank under these conditions. The volumes have also been corrected for the volume occupied by the corregations (deadwood) which was measured in the laboratory using a hydrostatic displacement technique.

The measurement method used includes geometrically redundant cross checks which allow assessment of the random error in the measurement process 3 For this tank, the total volume, excluding the vapor domes, was $27615.6 \mathrm{~m}^{3}$ with an uncertainty of $13.8 \mathrm{~m}^{3}(0.05 \%$ of total volume) at the three standard deviation limit of random error. Including an analysis of probable systematics by adding the absolute magnitude of the error sources, we estimate that the total uncertainty, at the $99 \%$ confidence level, is $\pm 0.10 \%$ of the total volume. No estimates of the errors in the individual table entries are included, since without an estimate of the height error introduced by the liquid level gage such estimates would of necessity be incomplete.

For the Director,

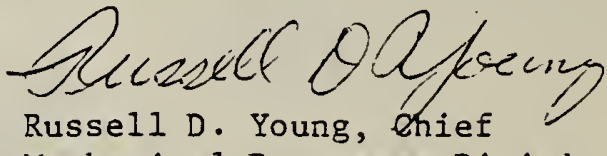

Mechanical Processes Division

Center for Mechanical Engineering and Process Technology 
EL PASO HOHARD BOYD

MAIN VOLUME VS. HEIGHT TABLE

TANK NO. 3

\begin{tabular}{|c|c|}
\hline $\begin{array}{l}\text { GAGE HEIGHT } \\
\text { (METERS) }\end{array}$ & $\begin{array}{c}\text { VOLUME } \\
\text { (CUBIC METERS) }\end{array}$ \\
\hline 0.000 & $\begin{array}{c}1 \\
.1\end{array}$ \\
\hline $\begin{array}{l}.050 \\
.100 \\
.200\end{array}$ & $\begin{array}{r}40.2 \\
87.0 \\
181.0\end{array}$ \\
\hline .300 & 275.8 \\
\hline $\begin{array}{l}.400 \\
.500\end{array}$ & $\begin{array}{l}371 \cdot 2 \\
467 \cdot 3\end{array}$ \\
\hline $\begin{array}{l}1.000 \\
2.000 \\
3.000\end{array}$ & $\begin{array}{r}957.9 \\
1989.7 \\
3089.2\end{array}$ \\
\hline $\begin{array}{l}4.000 \\
5.200 \\
5.000\end{array}$ & $\begin{array}{l}4256.2 \\
5467.6 \\
6680.1\end{array}$ \\
\hline 7.000 & 7892.5 \\
\hline $\begin{array}{l}8.000 \\
9.000\end{array}$ & $\begin{array}{r}9104.9 \\
10317.3\end{array}$ \\
\hline $\begin{array}{l}10.000 \\
11.000 \\
12.000\end{array}$ & $\begin{array}{l}11529.7 \\
12742.1 \\
13954.5\end{array}$ \\
\hline $\begin{array}{l}13.000 \\
14.000 \\
15.000\end{array}$ & $\begin{array}{l}15166.9 \\
16379.3 \\
17591.7\end{array}$ \\
\hline $\begin{array}{l}16.000 \\
17.000 \\
18.000\end{array}$ & $\begin{array}{l}18804.1 \\
20004.3 \\
21142.3\end{array}$ \\
\hline $\begin{array}{l}19.000 \\
20.000\end{array}$ & $\begin{array}{l}22212.6 \\
23215 \cdot 3\end{array}$ \\
\hline $\begin{array}{l}21.000 \\
22.000\end{array}$ & $\begin{array}{l}24150 \cdot 3 \\
25017 \cdot 7\end{array}$ \\
\hline $\begin{array}{l}22.500 \\
23.000\end{array}$ & $\begin{array}{l}25425 \cdot 0 \\
25817.4\end{array}$ \\
\hline 23.500 & 26191.9 \\
\hline $\begin{array}{l}24.000 \\
24.500\end{array}$ & $\begin{array}{l}26549 \cdot 5 \\
25893 \cdot 2\end{array}$ \\
\hline $\begin{array}{l}25.000 \\
25.500\end{array}$ & $\begin{array}{l}27213.9 \\
27520.8\end{array}$ \\
\hline
\end{tabular}




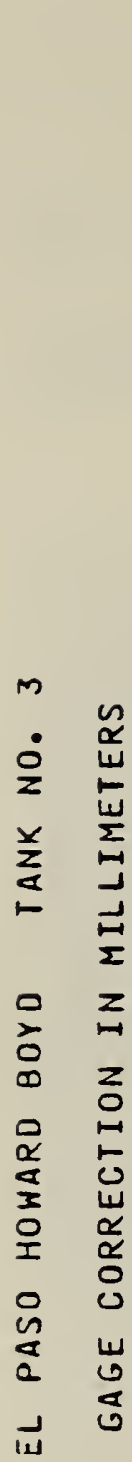

in $m a m \geq 500 \sigma=6 N$ $\dot{m} \dot{m} \dot{0} \dot{N} \dot{\sim} \dot{m} \dot{m} \dot{m} \dot{m} \dot{m}$ $m \quad m \infty n n m m m m$ 1 1 - $N$ N $N N N N N$

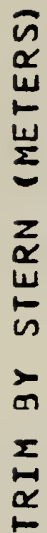

$\begin{array}{lll}1 & 0 \\ \sim & \vdots & +\end{array}$

$\stackrel{4}{i}$

in

$000+N \omega$ un un 0 a $\bullet \cdot \bullet \cdot \bullet \cdot \bullet \cdot \bullet \cdot$ $M \infty N N N N N N N N M$ $\pi$ in N $\infty \infty_{-1}^{\infty} \infty \infty_{-1}^{\infty} \infty \infty_{-1}^{\infty} \infty$

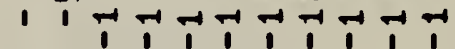

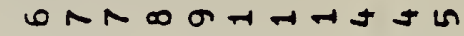
$\dot{0} \dot{0} \dot{0} \dot{\sim} \dot{\sim} \dot{\sim} \dot{\sim} \dot{\sim}$ th in $\rightarrow$ in in in in in in in in

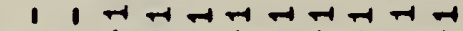

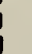

No 0 in $\ln N \wedge N \infty \sigma$ i $\cdot 0 \cdot 0 \cdot 0 \cdot 0 \cdot 1$

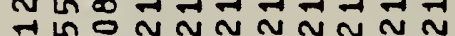
11 मा

$\infty N H A M M M M M M$

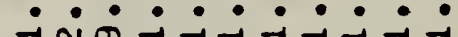
- in $\infty$ ar ar ar a a $1,1,11,1111$

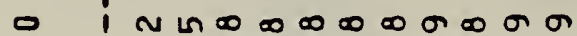

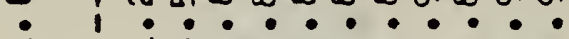

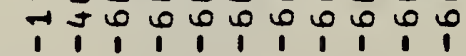

- ino000000000

- $\quad$ i $\$$

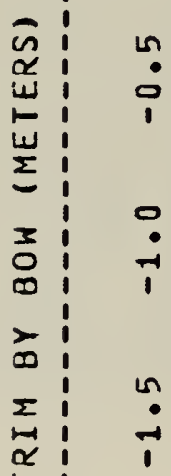

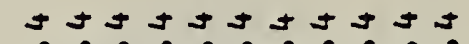

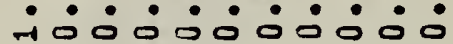
$M M M M M M M M M M M$

un $\sigma a \sigma \infty \sigma \infty \infty \infty$ $\bullet \bullet \bullet \bullet \bullet \bullet \bullet \bullet \bullet$ - 10000050000

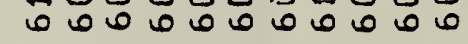

$D J M M=M M M+40$

o.?

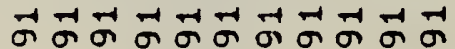

上U I I I $\alpha$ i เ 0000000000

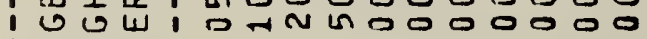
I !

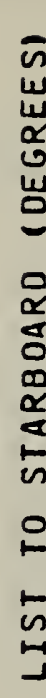

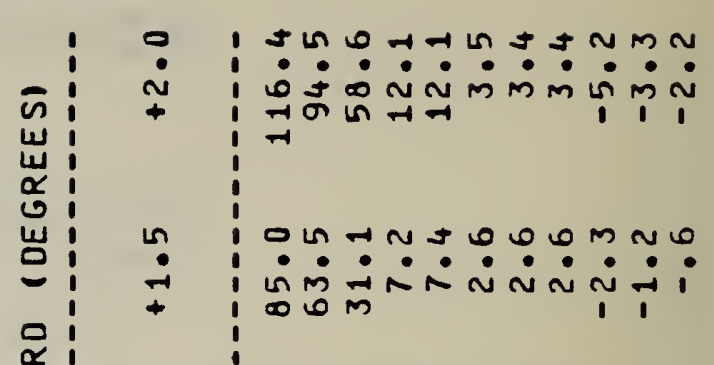

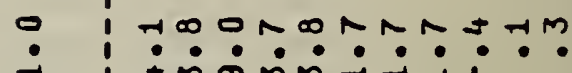

$\rightarrow \quad j m a m m-4-1$

in $m$

n $\quad$ t

b :

$-:$

(

- I ln

- $\quad: \dot{0} \dot{0} \dot{0} \dot{0} \dot{0} \dot{0} \dot{0} \dot{0}$

I $m 0 m N m \sigma \sigma \infty=m N$

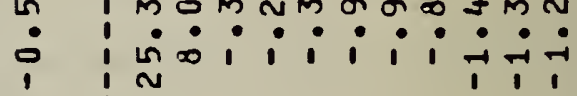

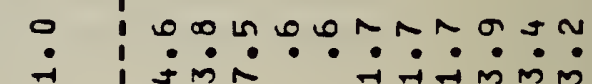

$1,1,1$

wi i

in $m$

$\propto$ i

แ艹

0

in $:$ a

- $\quad: \dot{0} \dot{0} \dot{0} \dot{0} \dot{0} \dot{0}$

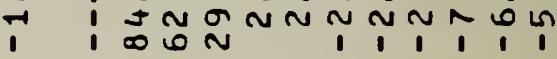

$\frac{\alpha}{0}$

$0: \quad i$

o imanamin manja

i $1 \cdot \dot{0} \cdot \dot{0} \cdot \dot{0} \cdot \dot{0}$

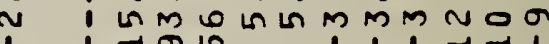

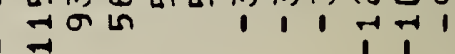

品:

H

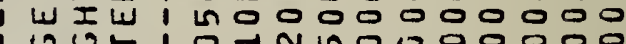
1 טUR

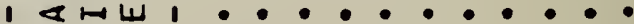

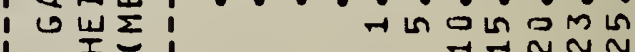




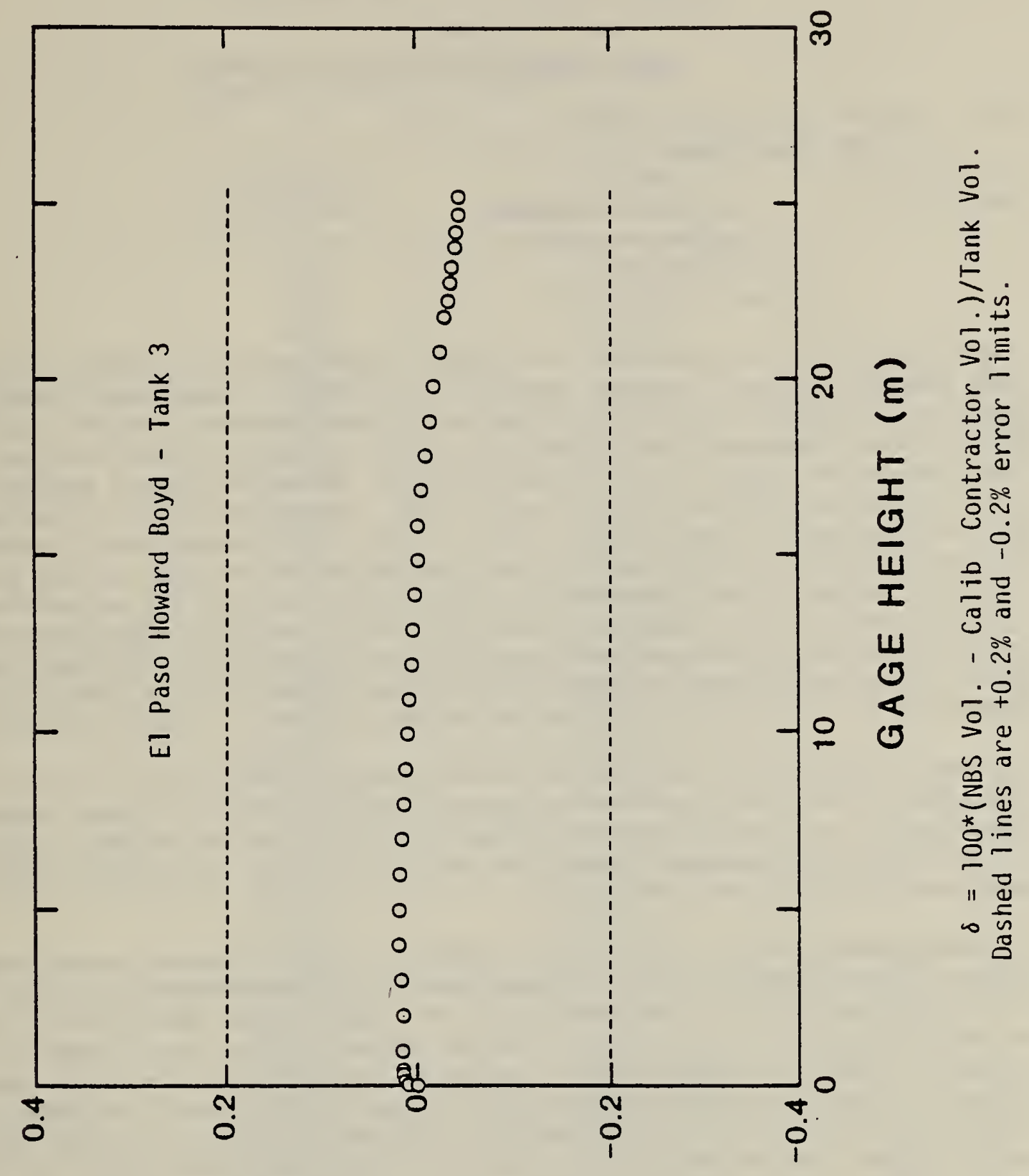

(\%) \& 'NOIL $\forall I \wedge \exists O$ 


\section{U.S. DEPARTMENT OF COMMERCE \\ NATIONAL GUREAU OF STANDARDS \\ WASHINGTON, D.C. 20234}

\section{REPORT OF CALIBRATION}

For: Tank $\#^{4} 4$ on the LNG Tanker

E1 Paso Howard Boyd

Requested by: E1 Paso Marine Company

2919 Allen Parkway

P. O. Box 1592

Houston, IX 77001

The following tables have been calculated from dimensional measurements on tank number 4 of the liquefied natural gas tanker EI Paso Howard Boyd while berthed at Newport News Shipbuilding and Drydock Company, Newport News, VA. These tables represent the volume of a liquid enclosed in the tank as a function of the height of the liquid surface, measured along a straight line, fixed with respect to the tank. This line is defined as being located at the longitudinal center line of the tank's capacitance gage. Secondary tables are also presented which allow correction of the main tables for specific angles of ship orientation with respect to gravity, as referred to the six sets of draft marks on the ship's hull. Both the measurement method and the computational algorithms are outlined in the paper "Multiple Redundancy in the Measurement of Large Structures," Annals of the International Institution of Production Engineering Research (CIRP), Volume 27/1, 1978 .

The tank was measured empty while at an average temperature of $25.8^{\circ} \mathrm{C}$. The tabulated volumes and the error estimates apply to the tank under these conditions. The volumes have also been corrected for the volume occupied by the corregations (deadwood) which was measured in the laboratory using a hydrostatic displacement technique.

The measurement method used includes geometrically redundant cross checks which allow assessment of the random error in the measurement process. For this tank, the total volume, excluding the vapor domes, was $6249.3 \mathrm{~m}^{3}$ with an uncertainty of $3.1 \mathrm{~m}^{3}(0.05 \%$ of total volume) at the three standard deviation limit of random error. Including an analysis of probable systematics by adding the absolute magnitude of the error sources, we estimate that the total uncertainty, at the $99 \%$ confidence level, is $\pm 0.10 \%$ of the total volume. No estimates of the errors in the individual table entries are included, since without an estimate of the height error introduced by the liquid level gage such estimates would of necessity be incomplete.

For the Director,

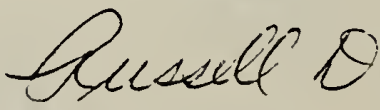

Russell D. Young, Chref

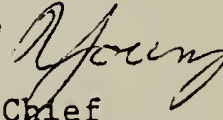

Mechanical Processes Division

Center for Mechanical Engineering and Process Technology 
EL PASO HOWARD BOYD

MAIN VOLUME VS. HEIGHT TABLE

TANK NO. 4

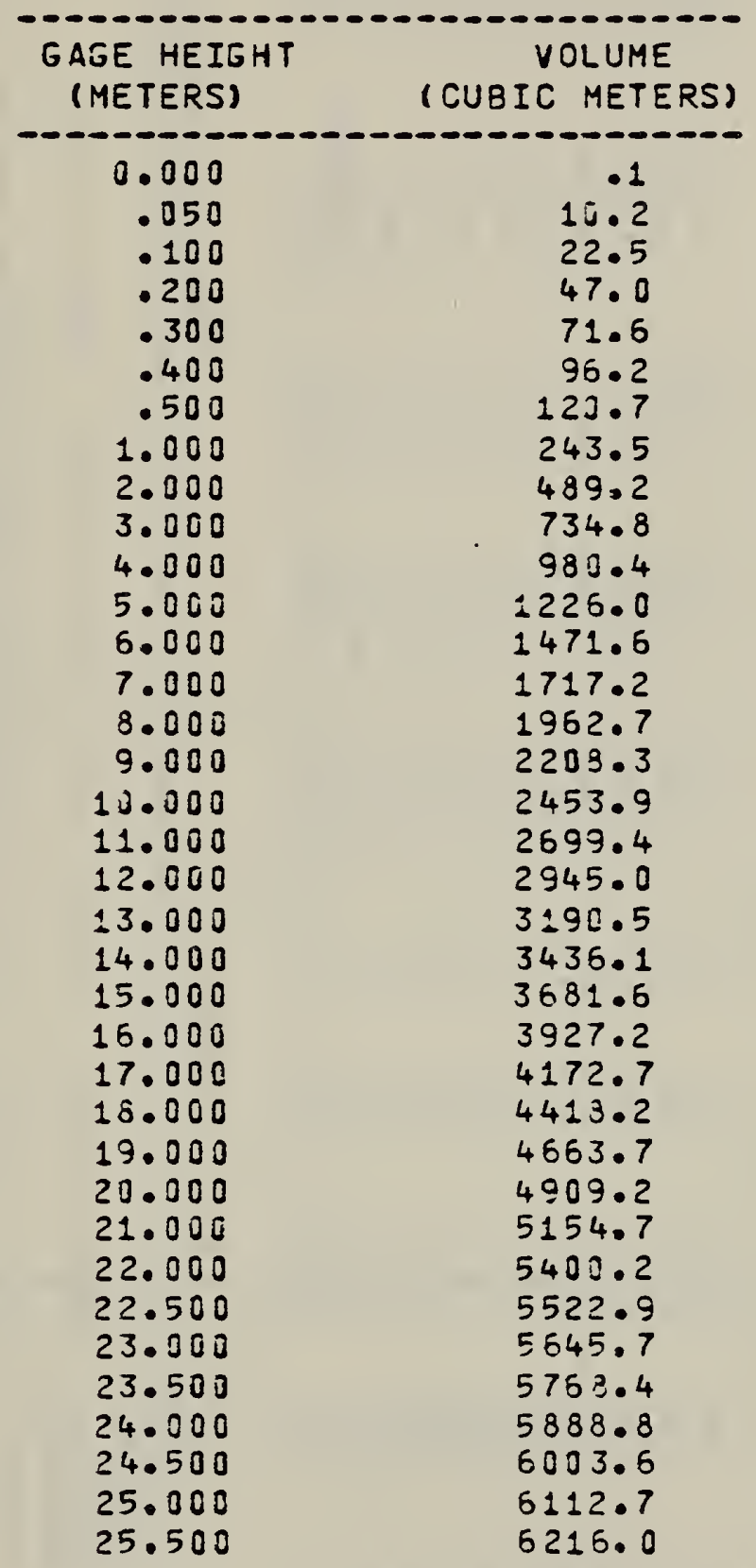




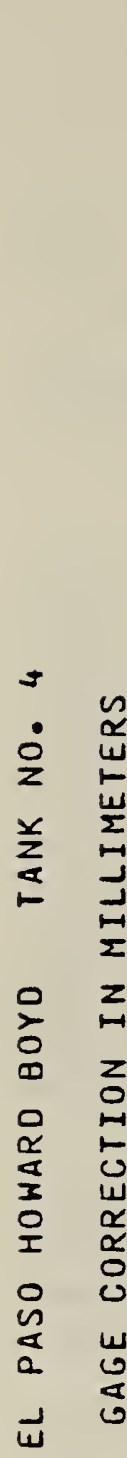

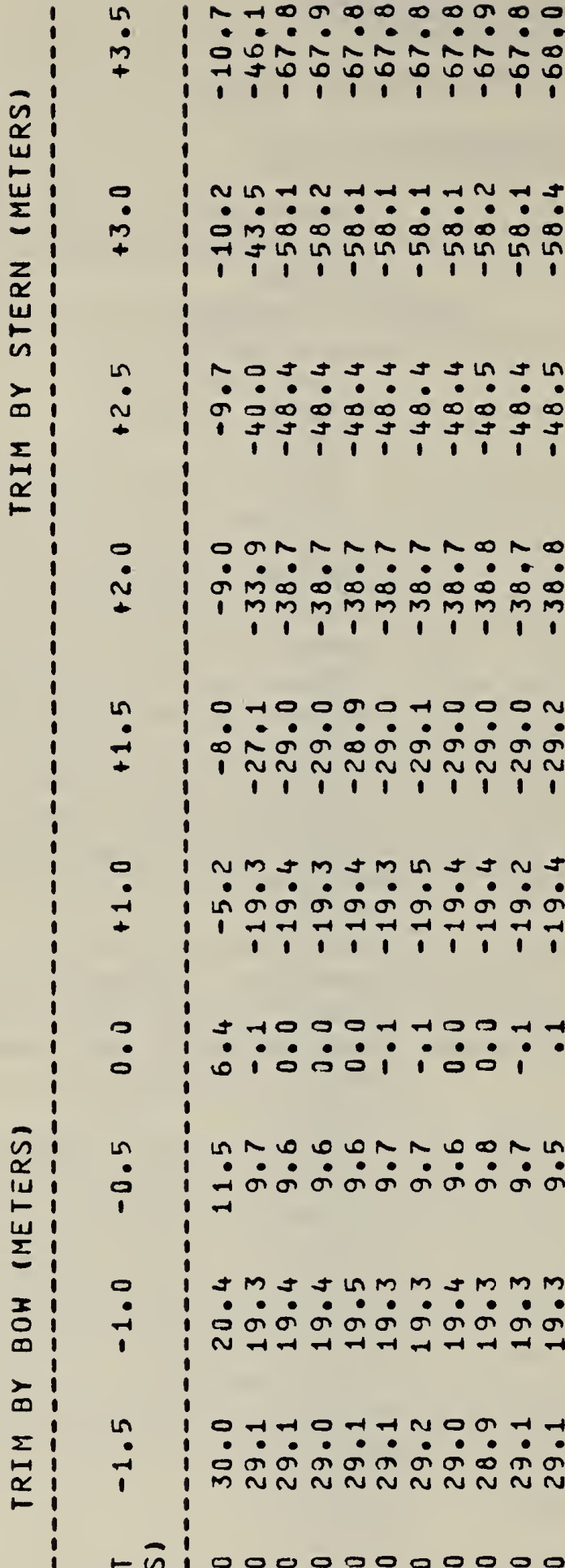

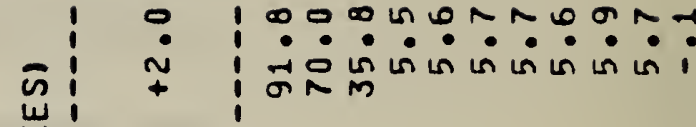

w

$\alpha$

w

n: $: N N$ :

- : $:$ :

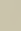

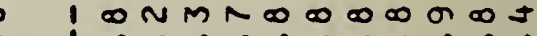
$\dot{i} \dot{i} \dot{\sim} \dot{\sim} \dot{\sim} \dot{\sim} \dot{\sim} \dot{\sim}$ in

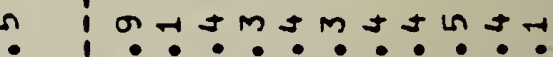
- ! N

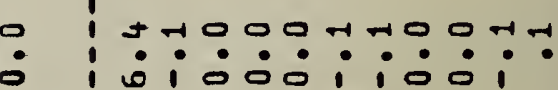

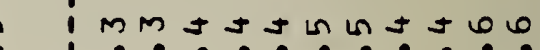

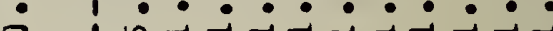

: 1 मीन

I $\alpha$, in 0000000000 जण !

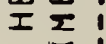
H $N$ N N

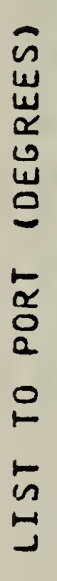

- inranomonolo

- $1 \cdot \bullet \cdot \bullet \cdot \bullet \cdot$ $00+\sim N M m \sim m+$ $m=1 ! 1 ! 1 \% 1$

In 1 od $\therefore \quad$ i $1 \quad 1$ L 1 1 11111111

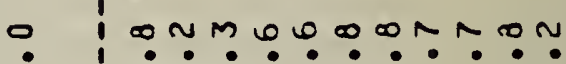

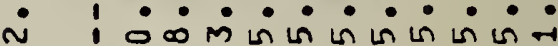
1 1 in N $111111,1,1$

$\bar{n}:$

도 $\alpha 0000000000$ ज心

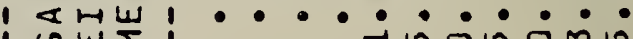
ज出! 


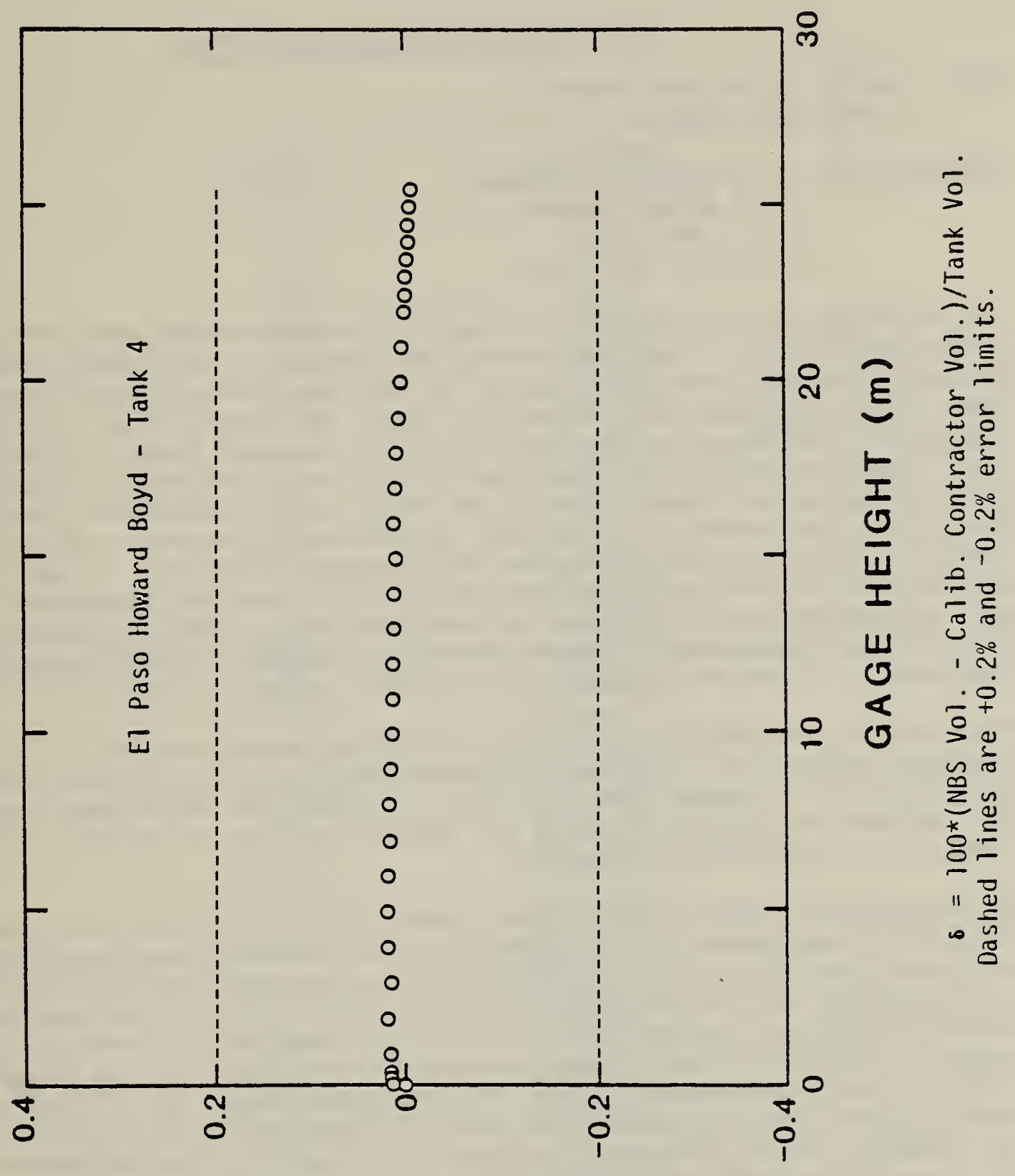

(\%) \& NOIL $\forall I \wedge \exists O$ 


\section{REPORT OF CALIBRATION}

For: Tank \# 5 on the LNG Tanker

E1 Paso Howard Boyd

Requested by: El Paso Marine Company

2919 Allen Parkway

P. 0. Box 1592

Houston, TX 77001

The following tables have been calculated from dimensional measurements on tank number 5 of the liquefied natural gas tanker El Paso Howard Boyd while berthed at Newport News Shipbuilding and Drydock Company, Newport News, VA. These tables represent the volume of a liquid enclosed in the tank as a function of the height of the liquid surface, measured along a straight line, fixed with respect to the tank. This line is defined as being located at the longitudinal center line of the tank's capacitance gage. Secondary tables are also presented which allow correction of the main tables for specific angles of ship orientation with respect to gravity, as referred to the six sets of draft marks on the ship's hull. Both the measurement method and the computational algorithms are outlined in the paper "Multiple Redundancy in the Measurement of Large Structures," Annals of the International Institution of Production Engineering Research (CIRP), Volume 27/1, 1978.

The tank was measured empty while at an average temperature of $22.2^{\circ} \mathrm{C}$. The tabulated volumes and the error estimates apply to the tank under these conditions. The volumes have also been corrected for the volume occupied by the corregations (deadwood) which was measured in the laboratory using a hydrostatic displacement technique.

The measurement method used includes geometrically redundant cross checks which allow assessment of the random error in the measurement process, For this tank, the total volume, excluding the vapor domes, was $27637.4 \mathrm{~m}^{3}$ with an uncertainty of $13.8 \mathrm{~m}^{3}$ ( $0.05 \%$ of total volume) at the three standard deviation limit of random error. Including an analysis of probable systematics by adding the absolute magnitude of the error sources, we estimate that the total uncertainty, at the $99 \%$ confidence level, is $+0.10 \%$ of the total volume. No estimates of the errors in the individual table entries are included, since without an estimate of the height error introduced by the liquid level gage such estimates would of necessity be incomplete.

For the Director,

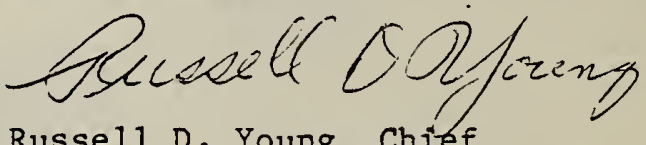

Russe11 D. Young, Chitef

Mechanical Processes Division

Center for Mechanical Engineering and Process Technology 
EL PASO HOHARD BOYD

MAIN VOLUME VS. HEIGHT TABLE

TANK NO. 5

\begin{tabular}{cc} 
GAGE HEIGHT & VOLUME \\
(METERS) & (CUBIC METERS) \\
\hline 0.000 & 4.0 \\
.050 & 48.3 \\
.100 & 95.1 \\
.200 & 189.2 \\
.300 & 284.0 \\
.400 & 379.5 \\
.500 & 475.6 \\
1.000 & 966.4 \\
2.000 & 1998.8 \\
3.000 & 3698.9 \\
4.000 & 4256.8 \\
5.000 & 5478.6 \\
6.000 & 6691.3 \\
7.000 & 7904.0 \\
8.000 & 9116.7 \\
9.000 & 10329.4 \\
10.000 & 11542.1 \\
11.000 & 12754.8 \\
12.000 & 13967.5 \\
13.000 & 15180.2 \\
14.000 & 15392.9 \\
15.000 & 17605.6 \\
16.000 & 18818.3 \\
17.000 & 20018.8 \\
18.000 & 21157.1 \\
19.000 & 22227.8 \\
20.000 & 23230.8 \\
21.000 & 24166.3 \\
22.000 & 25034.2 \\
22.500 & 25442.8 \\
23.000 & 25834.4 \\
23.500 & 26209.2 \\
24.000 & 26567.1 \\
24.500 & 26938.1 \\
25.000 & 27232.2 \\
25.500 & 27539.4 \\
& \\
\hline 1000 & \\
\hline 0 &
\end{tabular}




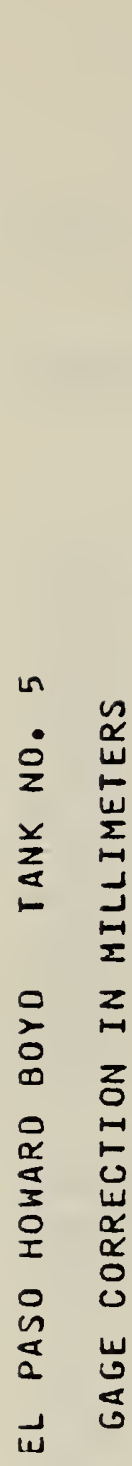

L I I I ON

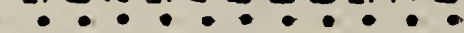
$N \omega \sim \sim M M M M M$

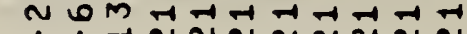
1 1 - 1 N $N$ N $N$ N

- $\quad$ anNN $\dot{*} \cdot \dot{0} \dot{0} \dot{0} \dot{0} \dot{0} \dot{m}$

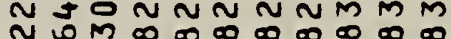
1 1 तो

in $\ln \sigma \sigma \infty \infty \pi \rightarrow-\ln \infty$ i $: \dot{\sim} \dot{\sim} \dot{a} \dot{\sim} \dot{\sim} \dot{\sim} \dot{\sim} \dot{\sim}$ N 0 N in in in in in un in in 1 1 ना नान

$\Sigma$

$\sigma \pm \infty \ln \sim \sim \sim \sigma \sigma 0$ $\cdot \bullet \cdot \cdot \cdot \cdot \cdot \cdot \cdot \cdot$ $00 \sigma-1+1-1-1-1+10$ $10 \pi-4+\pi-1$ 1 1 1 1 1 1 1 1

L $10 J m N A M M M M M J$ : 위 1111,111111

- 1 - ! $\quad \dot{0} \dot{0} \dot{0} \dot{0} \dot{0} \dot{0} \dot{0}$

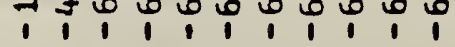

$0 \quad 100000000000$

- $\quad \dot{1} \dot{0} \dot{0} \dot{0} \dot{0} \dot{0} \dot{0} \dot{0}$ Ln un Ln un un un $a t a$ in : $\dot{0} \dot{0} \dot{0} \dot{0} \dot{0} \dot{0} \dot{0} \dot{0}$

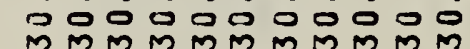
1 aróara on 0 on ட் $\dot{0} \dot{0} \dot{0} \dot{0} \dot{0} \dot{0} \dot{0}$ 

$\infty$

$\Sigma$

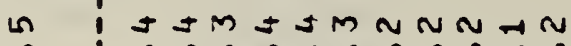

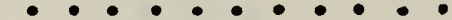

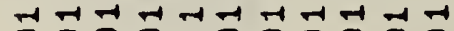

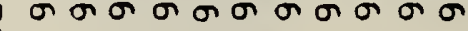

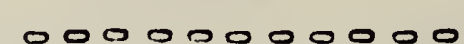
in $x$, in 0000000000 जज, a n w

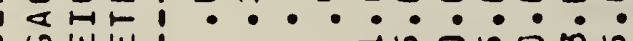
I $\pm \Sigma i$

$\rightarrow+N N N$ 


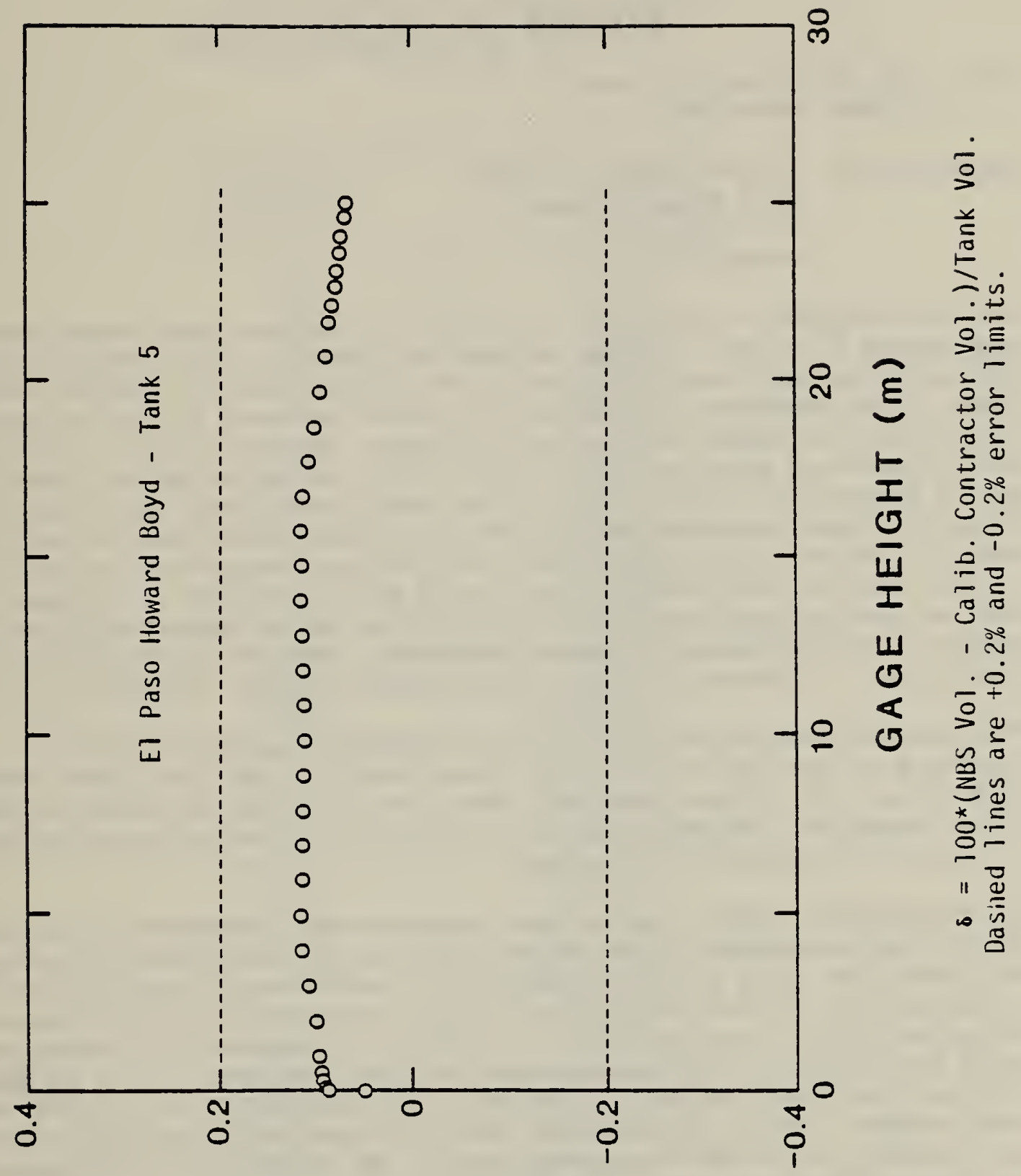

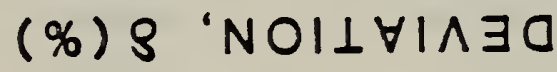




\section{REPORT OF CALIBRATION}

For: Tank 非 6 on the LNG Tanker

El Paso Howard Boyd

Requested by: E1 Paso Marine Company

2919 Allen Parkway

P. O. Box 1592

Houston, TX 77001

The following tables have been calculated from dimensional measurements on tank number 6 of the liquefied natural gas tanker El Paso Howard Boyd while berthed at Newport News Shipbuilding and Drydock Company, Newport News, VA. These tables represent the volume of a liquid enclosed in the tank as a function of the height of the liquid surface, measured along a straight line, fixed with respect to the tank. This line is defined as being located at the longitudinal center line of the tank's capacitance gage. Secondary tables are also presented which allow correction of the main tables for specific angles of ship orientation with respect to gravity, as referred to the six sets of draft marks on the ship's hull. Both the measurement method and the computational algorithms are outlined in the paper "Multiple Redundancy in the Measurement of Large Structures," Annals of the International Institution of Production Engineering Research (CIRP), Volume 27/1, 1978.

The tank was measured empty while at an average temperature of $20.6^{\circ} \mathrm{C}$. The tabulated volumes and the error estimates apply to the tank under these conditions. The volumes have also been corrected for the volume occupied by the corregations (deadwood) which was measured in the laboratory using a hydrostatic displacement technique.

The measurement method used includes geometrically redundant cross checks which allow assessment of the random error in the measurement process; For this tank, the total volume, excluding the vapor domes, was $27631.2 \mathrm{~m}^{3}$ with an uncertainty of $13.8 \mathrm{~m}^{3}(0.05 \%$ of total volume) at the three standard deviation limit of random error. Including an analysis of probable systematics by adding the absolute magnitude of the error sources, we estimate that the total uncertainty, at the $99 \%$ confidence level, is $+0.10 \%$ of the total volume. No estimates of the errors in the individual table entries are included, since without an estimate of the height error introduced by the liquid level gage such estimates would of necessity be incomplete.

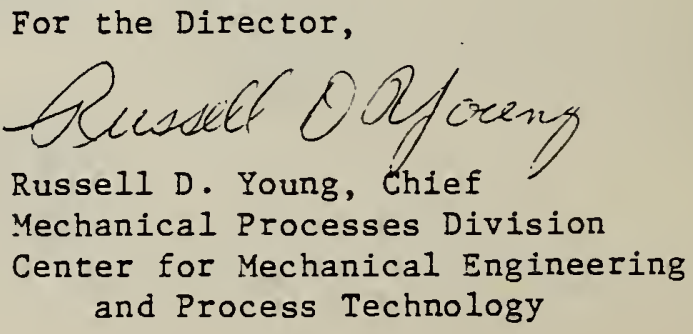


EL PASO HOWARD BOYD

MAIN VOLUME VS. HEIGHT tABLE

TANK NO. 6

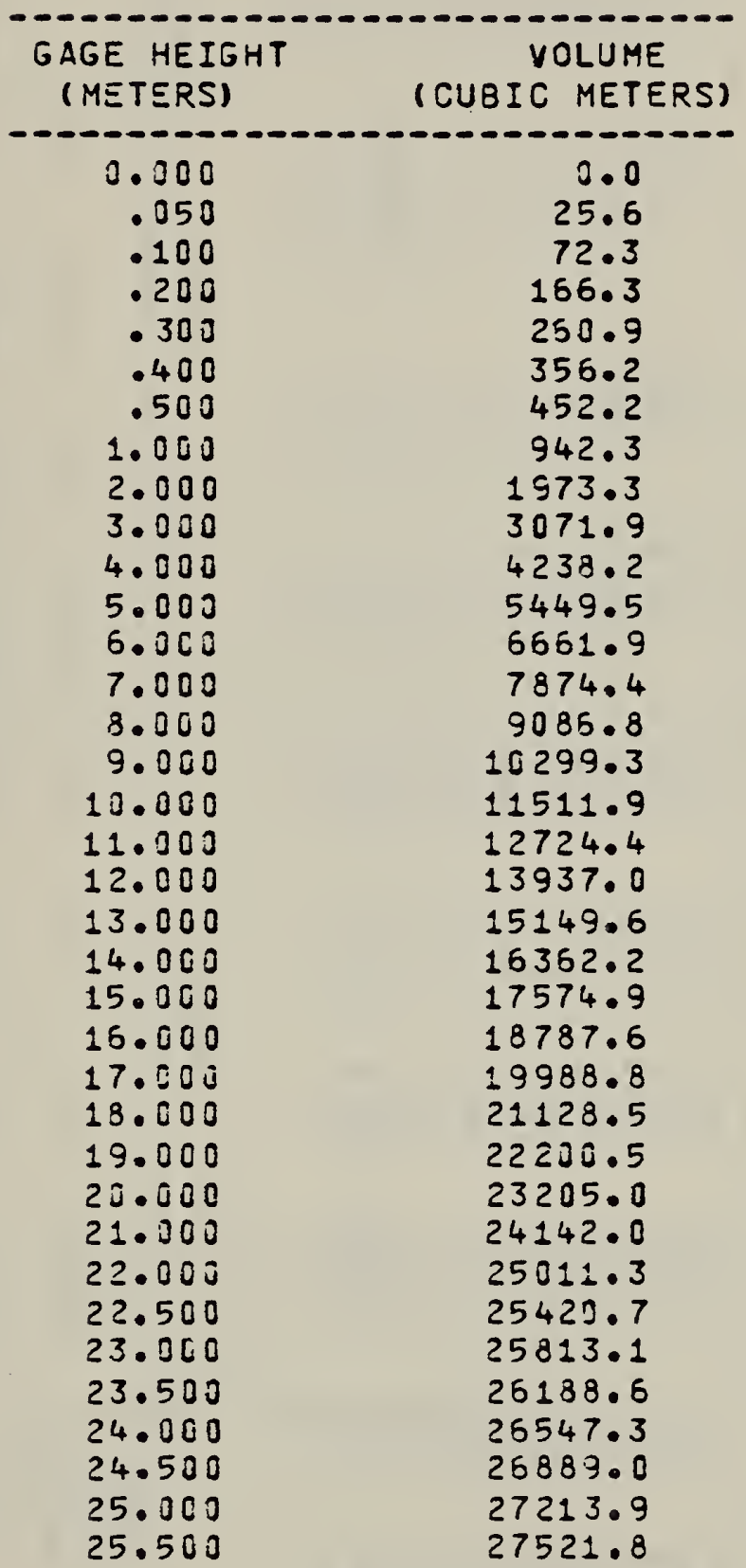




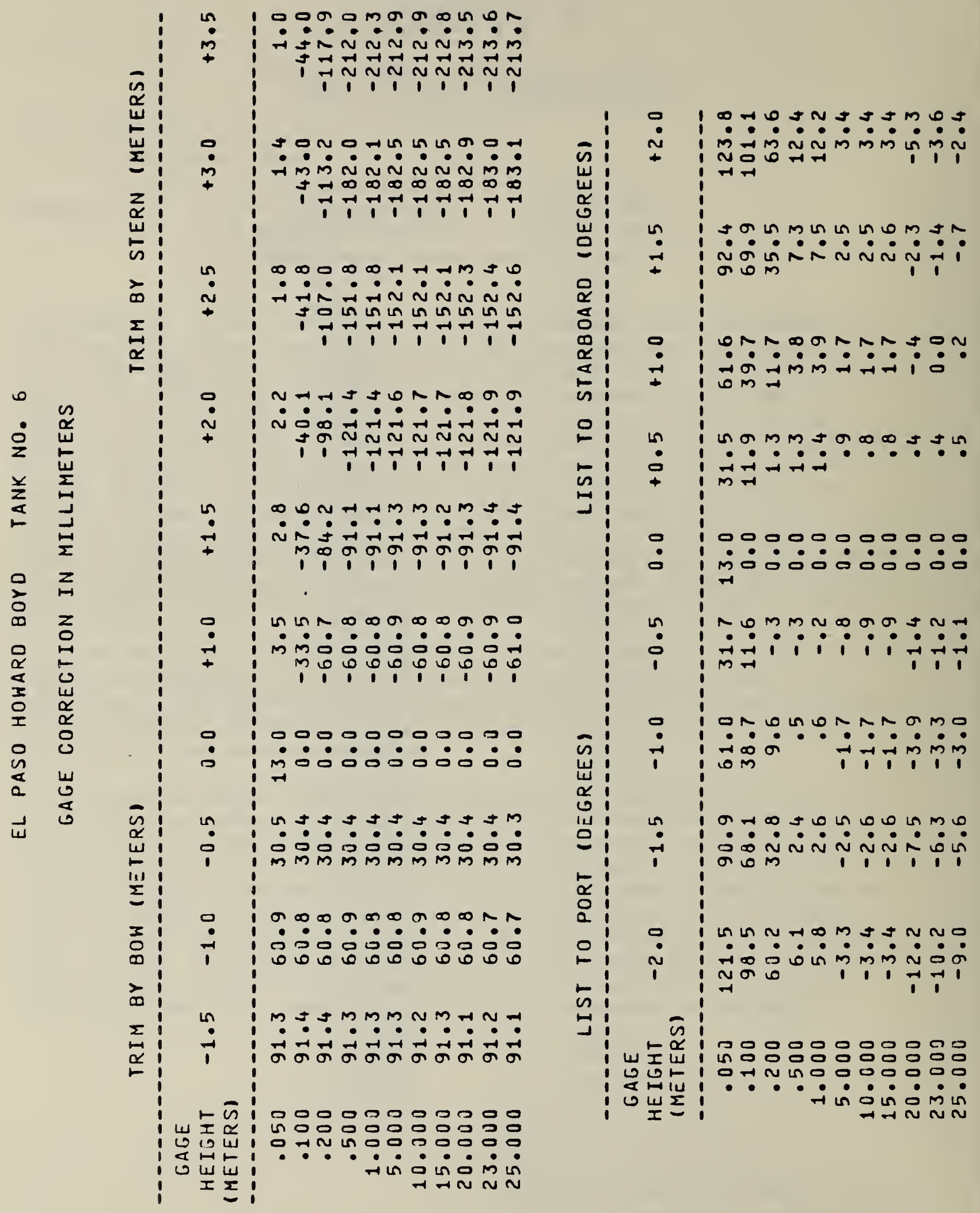




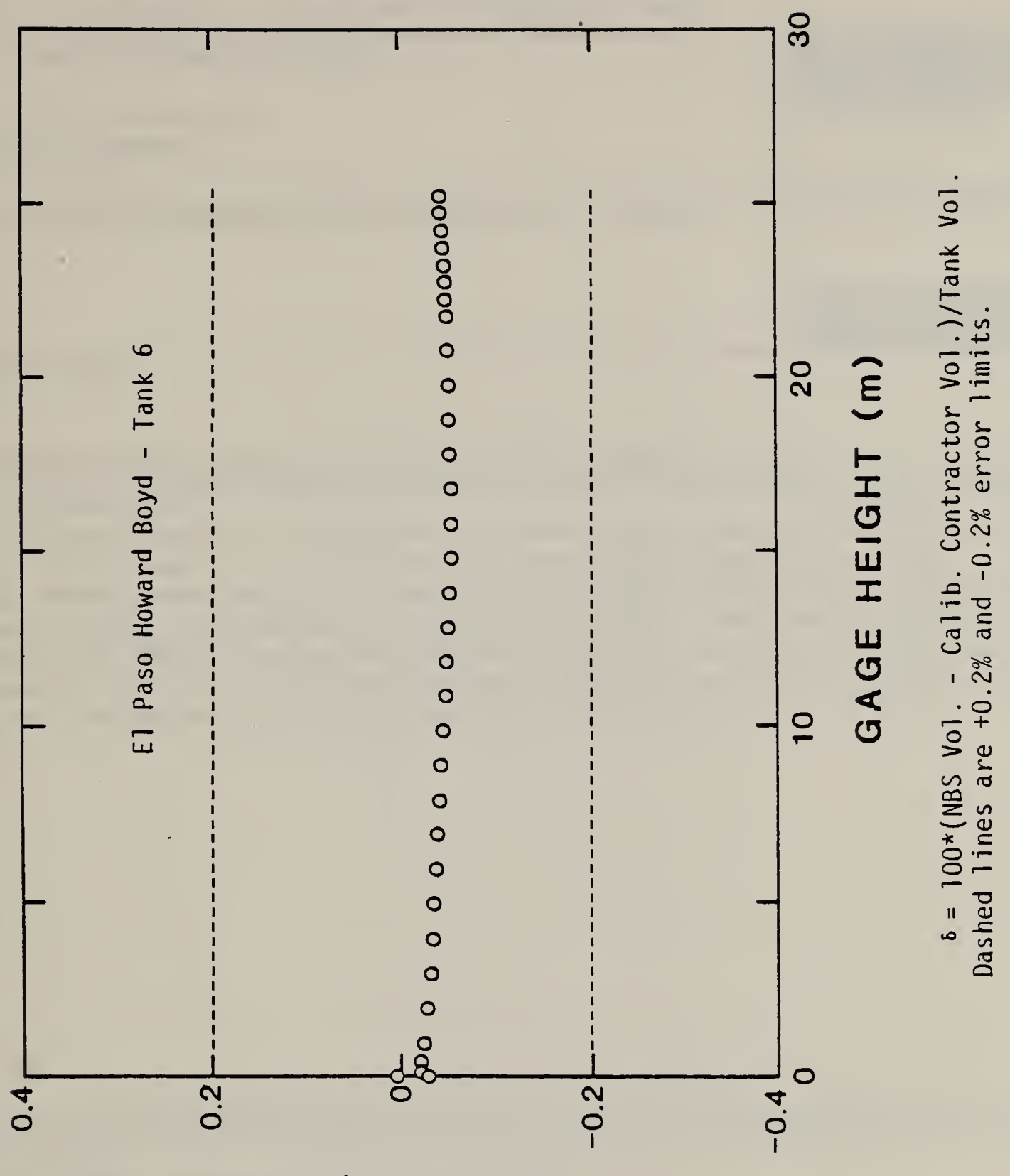

(\%) \& NOIL $\forall I \wedge \exists 0$ 

NBS-114A (REV. 9-78)

\begin{tabular}{|c|c|c|c|}
\hline $\begin{array}{l}\text { U.S. DEPT. OF COMM. } \\
\text { BIBLIOGRAPHIC DATA } \\
\text { SHEET }\end{array}$ & $\begin{array}{l}\text { 1. PUBLICATION OR REPORT NO. } \\
\text { NBSIR } 80-2141\end{array}$ & 2.GovtL Accession No & 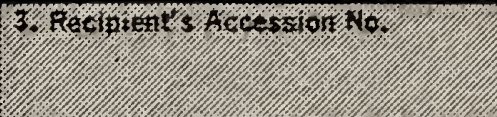 \\
\hline \multirow{2}{*}{\multicolumn{3}{|c|}{$\begin{array}{l}\text { 4. TITLE AND SUBTITLE } \\
\text { Estimated Accuracy of Calibration of Some Membrane } \\
\text { Type LNG Transport Tanks. }\end{array}$}} & 5. Publication Date \\
\hline & & & 6. Performing Organization Code \\
\hline \multicolumn{3}{|c|}{$\begin{array}{l}\text { 7. AUTHOR(S) W. C. Haight, R. J. Hocken, B. Borchardt, C. L. } \\
\text { Carrol1, R. G. Hartsock, C. P. Reeve, F. Scire, R. Veale }\end{array}$} & 8. Performing Organ. Report No. \\
\hline \multirow{2}{*}{\multicolumn{3}{|c|}{$\begin{array}{l}\text { NATIONAL BUREAU OF } \\
\text { DEPARTMENT OF COMI } \\
\text { WASHINGTON, DC } 20231\end{array}$}} & 10. Prolect/Task/Wonk Unit No \\
\hline & & & 11. Contract/Grant No. \\
\hline \multirow{2}{*}{\multicolumn{3}{|c|}{ 12. SPONSORING ORGANIZATION NAME AND COMPLETE ADDRESS (Streot, City, State, zIP) }} & 13. Type of Report \& Period Covered \\
\hline & & & 14. Spansoring Agency Code \\
\hline
\end{tabular}

15. SUPPLEMENTARY NOTES

Document describes a computer program; SF-185, FIPS Software Summary, is attached.

16. ABSTRACT (A 200-word or less factual summary of most sigrificant information. If document includes a significant bibliography or literaturo survey, mention it here.)

The. National Bureau of Standards has completed a study on the calibration uncertainty of ship cargo tanks used to transport Liquid Natural Gas (LNG). The data from measurements made on 18 such tanks is presented, along with a comparison to measurement determined from an independent technique. Calibration reports for each tank measured by NBS are presented, including tables that relate tank volume to liquid level in the tank. The measurement technique used was accurate to $\pm 0.05 \%$ of total volume and agreed with the independent measurement data to t0. $2 \%$.

17. KEY WORDS (six to twelve entries; alphabetical order; capitalize only the first letter of the first key word unless a proper name; separated by semicolons)

Laser; LNG; tanks; ships; volume; dimensions.

18. AVAILABILITY Unimited

For Official Distribution. Do INot Release to NTIS

Order From Sup. of Doc., U.S. Government Printing Office, Wasinington, DC 20402, SD Stock No. SN003-003-

$\square$ Order From National Technical Information Service (NTIS), Springfield, VA. 22161

\begin{tabular}{|l|c|}
\hline $\begin{array}{l}\text { 19. SECURITY CLASS } \\
\text { (THIS REPORT) }\end{array}$ & $\begin{array}{c}\text { 21. NO. OF } \\
\text { PRINTED PAGES } \\
\text { UNCLASSIFIED }\end{array}$ \\
\hline $\begin{array}{l}\text { 20. SECURITY CLASS } \\
\text { (THIS PAGE) }\end{array}$ & $\begin{array}{c}\text { 22. PrICe } \\
\$ \$ 9.50\end{array}$ \\
UNCLASSIFIED & \\
\hline
\end{tabular}



. 
